Ministry of Economv and Finance

Department of the Treasurv

Analisi e Programmazione

Economico Finanziaria

Working Papers

$N^{\circ} 6$ - December 2016

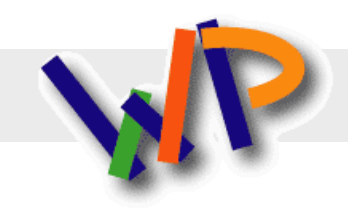

ISSN 1972-411X

\title{
Job Creation Tax Credits, Fiscal Foresight, and Job Growth: Evidence from U.S. States
}

Robert S. Chirinko, Daniel J. Wilson

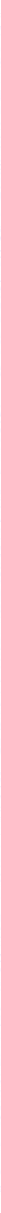




\section{Working Papers}

The working paper series promotes the dissemination of economic research produced in the Department of the Treasury (DT) of the Italian Ministry of Economy and Finance (MEF) or presented by external economists on the occasion of seminars organized by MEF on topics of institutional interest to the DT, with the aim of stimulating comments and suggestions.

The views expressed in the working papers are those of the authors and do not necessarily reflect those of the MEF and the DT.

\section{(C) Copyright:}

2016, Robert S. Chirinko, Daniel J. Wilson

The document can be downloaded from the Website www.dt.tesoro.it and freely used, providing that its source and author(s) are quoted. 


\section{CONTENTS}

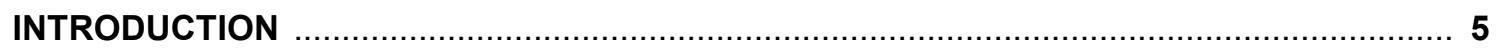

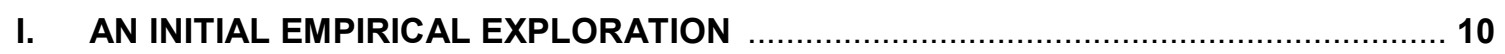

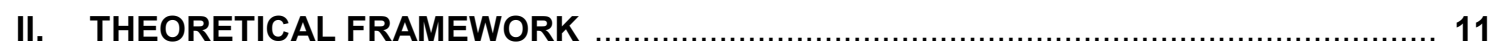

III. EMPIRICAL PRELIMINARIES AND SPECIFICATION ISSUES .............................. 25

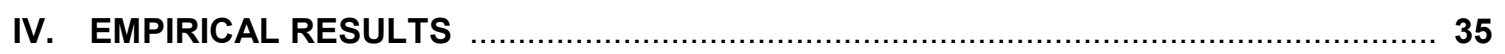

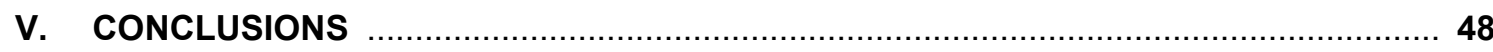

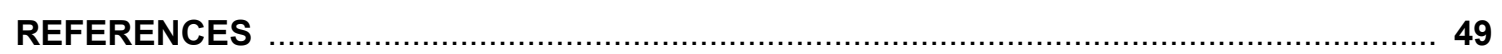

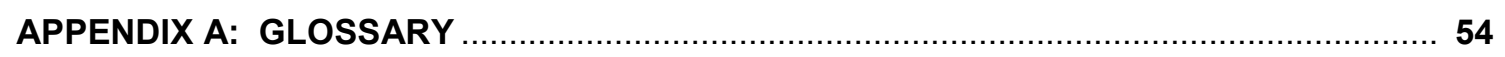

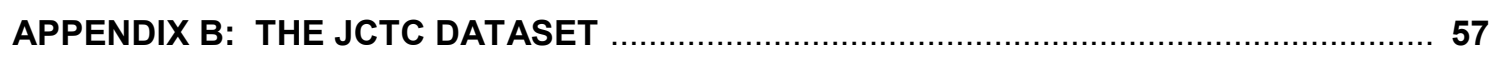

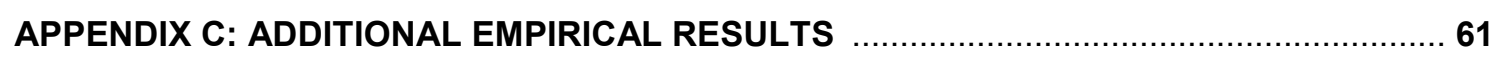

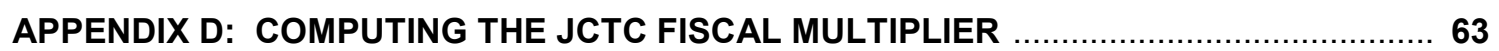

FIGURES

TABLES 


\title{
Job Creation Tax Credits, Fiscal Foresight, and Job Growth: Evidence from U.S. States
}

Robert S. Chirinko and Daniel J. Wilson*

\begin{abstract}
This paper studies fiscal foresight -- alterations of current behavior by forwardlooking agents in anticipation of future policy changes - using variation in state job creation tax credits (JCTCs).

Nearly half of the U.S. states enacted JCTCs between 1990 and 2007, and their unique experiences provide a rich source of information for assessing the quantitative importance of fiscal foresight. We investigate whether JCTCs affect employment growth before, at, and after the time they go into effect. A theoretical model identifies three key conditions necessary for fiscal foresight, captures the effects of the rolling base feature of JCTCs, and generates several empirical predictions.

We evaluate these predictions in a difference-in-difference regression framework applied to monthly panel data on employment, the JCTC effective and legislative dates, and various controls. Failing to account for the distorting effects of fiscal foresight can result in upwardly biased estimates of the impact of the JCTC fiscal policy by as much as $34 \%$. We also find that the cumulative effect of the JCTCs is positive, but it takes several years for the full effect to be realized. The cost per job created is approximately $\$ 18,000$, which is low relative to cost estimates of recent federal fiscal programs. This figure implies a fiscal multiplier on JCTC tax expenditures of about 1.66.
\end{abstract}

JEL Classification: E62 (fiscal policy), E24 (employment), H25 (business taxes), H71 (state and local taxation, subsidies, and revenue).

Keywords: Fiscal foresight, job creation tax credits, state business tax incentives, implementation lags, fiscal policy.

\footnotetext{
* Robert S. Chirinko, Department of Finance, 2333 University Hall, University of Illinois at Chicago, 601 South Morgan (MC 168), Chicago, Illinois 60607-7121. PH: 312355 1262. FX: 312413 7948. EM: Chirinko@uic.edu

Daniel J. Wilson, Federal Reserve Bank of San Francisco, Mail Stop 1130, 101 Market Street, San Francisco, CA 94105. PH: 415974 3423. FX: 415974 2168. EM: Daniel.Wilson@sf.frb.org
}

Acknowledgements: We would like to acknowledge the excellent research assistance provided by Katherine Kuang, Charles Notzon, Tom O'Conner, Kevin Vo, and the comments and suggestions from seminar/conference participants at the American Economic Association, CESifo, Econometric Society, Einaudi Institute of Economics and Finance, European Central Bank, Federal Reserve Bank of San Francisco, Federal Reserve System Committee on Regional Analysis, Goethe University, Institute for Advanced Studies (Vienna), International Institute for Public Finance, Italian Ministry of Economy and Finance, IZA, National Tax Association, North American Regional Science Association, Oxford University, Southern Economic Association, Universities of La Sapienza, Tor Vergata, and Urbino, University of Dublin, University of Illinois at Chicago, University of Lugano, and the Upjohn Foundation, especially our formal discussants, Tim Bartik, Elliott Dubin, Leo Feler, Bill Hoyt, Yolanda Kodrzycki, Tuomas Kosnen, and Sarah Zubairy. Comments from Olivier Blanchard and Adam Shapiro have also been appreciated. Financial support from the Federal Reserve Bank of San Francisco and the Upjohn Foundation is gratefully acknowledged. 


\section{INTRODUCTION}

There is a great deal of evidence that fiscal policy works well, almost everywhere, perhaps especially well when the interest rate is at its effective lower bound.

Stanley Fischer (2015)

Recent years have seen a resurgence in interest by policymakers and economists alike in the use of fiscal policy as a tool for promoting both short-run and long-run economic growth. The Economic Stimulus Act of 2008 and the American Recovery and Reinvestment Act of 2009 are indicative of this renewed interest, and they presage more frequent reliance on fiscal policy as a policy tool in the years ahead. As indicated by the above quotation, one of the key lessons learned over the past 20 years by Board of Governors Vice Chair Fischer is that "fiscal policy works well."

But how well? Assessing the quantitative impacts of fiscal policies is made difficult by "fiscal foresight," alterations of current behavior by forward-looking agents in anticipation of future policy changes. ${ }^{1}$ In particular, lags between when a fiscal policy is signed into law and when it goes into effect encourage fiscal foresight and create anticipation effects that bias inferences. The quantitative importance of anticipation effects is a key policy question and has been the subject of much previous research and debate. Several recent empirical studies of fiscal multipliers distinguish between anticipated and unanticipated changes in aggregate fiscal policy. Auerbach and Gale (2009), Leduc and Wilson (2013), Leeper, Richter, and Walker (2012), Mertens and Ravn (2010, 2012), and Ramey (2011), among others, report significant differences between anticipated and unanticipated shocks in terms of their co-movements with

\footnotetext{
${ }^{1}$ The quantitative importance of monetary policy depends on the related concept of "forward guidance," which has a similar analytic structure to fiscal foresight -- as an announcement today of future monetary policy impacts real behavior today. McKay, Nakamura, and Steinsson (2016) demonstrate that the effectiveness of forward guidance is decreased by a precautionary saving motive in a fully rational model and Gabaix (2016) shows that its effectiveness is increased in the presence of myopia. As shown in the theoretical model developed in Section II, the effectiveness of fiscal foresight in a fully rational model depends on production function and output market characteristics.
} 
macroeconomic activity, pointing to the importance of fiscal foresight. ${ }^{2}$ The evidence in Hsieh (2003, p. 397) provides a nuanced view with anticipated income changes affecting consumption "when the income changes are large, regular, and easy to predict" but not when the income changes are small and irregular. The simulations of Yang (2005) confirm the importance of fiscal foresight in a perfect foresight model. By contrast, the VAR analyses of Blanchard and Perotti (2002) and Perotti (2012) and the single-equation analysis of Poterba (1988) find no evidence of fiscal foresight in advance of fiscal shocks and pre-announced tax changes, respectively.

All of the above studies are based on aggregate data. ${ }^{3}$ Estimating anticipation effects with aggregate data faces some acute challenges. Observed movements in macroeconomic outcomes during periods between the passage of fiscal legislation and its implementation are due both to overall economic conditions and to any anticipation effects. Disentangling these two components in aggregate time series data requires substantial variation in the data and strong assumptions. In particular, concerns have been raised about differences in the information sets available to agents and econometricians, and the resulting problem of non-fundamentalism or non-invertability (Forni, Gambetti, and Sala (forthcoming), Leeper, Walker, and Yang (2008)).

We turn to the substantial variation in state-level panel data to shed light on the existence and quantitative importance of fiscal foresight for firms. We focus on a particular fiscal policy, job creation tax credits (JCTCs). Nearly half of U.S. states have enacted permanent, broad-based

\footnotetext{
${ }^{2}$ Coglianese, Davis, Kilian, and Stock (2015) document the importance of anticipatory spending on gasoline in advance of pre-announced increases in gasoline taxes. Similarly, D'Acunto, Hoang, and Weber (2016), using German survey data, find that the fraction of respondents reporting that "it's a good time to buy" durable goods increased sharply after the announcement in November 2005 of a forthcoming consumption tax hike to take effect in 2007.

${ }^{3}$ Despite its clear policy importance, the literature on fiscal foresight using panel or microeconomic data is surprisingly sparse. Herrera and Rangaraju (n.d.) is an exception. They assess fiscal foresight with municipal bond spreads and document the importance of anticipation effects in a FAVAR model but, unlike in the current study, they do not use cross-state or panel variation to quantify the impact of fiscal foresight. A related literature has looked at the consumer spending response of households to the receipt of pre-announced tax rebates (see Johnson, Parker, and Souleles (2006), Parker, Souleles, Johnson, and McClelland (2013), and Shapiro and Slemrod (2009)). These studies exploit quasi-random variation across households in the timing of rebate receipt to estimate their spending response to the rebate receipt. However, they are unable to estimate announcement/anticipation effects because the rebate legislation is the same for all households.
} 
JCTCs over the past twenty years. ${ }^{4}$ Figure 1 shows the policy diffusion process over time for these state JCTCs (based on the legislative enactment dates that we compiled for this paper). To the best of our knowledge, the first JCTC was enacted in 1979 by Maine, followed by one in Nebraska in 1987. Since then, these tax credits have proliferated, with an additional 19 states adopting permanent JCTCs during our sample period, the beginning of 1990 to the end of 2007. Figure 2 shows the geographical distribution of these credits. The plurality of JCTC states are in the eastern United States, but there are also many in the Midwest and South.

Four important aspects of state JCTCs give rise to a powerful empirical context for identifying the effects of fiscal foresight. First, we do not have to disentangle the effects of fiscal policy from monetary policy in our state panel dataset. Second, JCTCs are a very important tax incentive. According to one recent study (Upjohn 2016), when compared with four other frequently-used state and local economic incentives (property tax abatements, investment tax credits, $R \& D$ tax credits, and customized job training), JCTCs represent $45 \%$ of the total value of incentives. Property tax abatements are the next largest at $27 \%$.

Third, states adopting JCTCs differ in whether their credit goes into effect immediately or with a delay (and in the length of the delay). The variation in this dimension allows us to estimate the effects of fiscal foresight because such foresight is reduced, if not eliminated, when there is no implementation delay. Based on states' legislative records, we are able to measure the existence and length of each JCTC implementation delay period by identifying two key dates:

- the "signing" date on which the legislation is signed into law by the state's governor and

- the "qualifying" date on or after which net new hires by an in-state employer can qualify for the credit. ${ }^{5}$

\footnotetext{
${ }^{4}$ Here and throughout the paper we focus on JCTCs that are "broad" in the sense that they apply to employers in a wide range of industries, in all parts of the state and without substantial non-employmentbased requirements. Neumark and Grijalva (2013) document that many states additionally have narrow hiring credits targeted at particular industries (such as biotechnology, information technology, or motion pictures), particular areas of the state ("enterprise zones"), or particular actions (such as headquarters relocation, facilities expansion, or research and development). We also focus on JCTCs that are "permanent" in the sense that their legislation did not set an expiration date. This latter restriction rules out temporary JCTCs that are sometimes passed as short-run stimulus measures. These temporary JCTCs are likely to be endogenous with respect to current and expected employment growth. For similar reasons, we consider only JCTCs passed prior to the Great Recession, which began in December 2007.

${ }^{5}$ This timing convention is used frequently in the fiscal foresight literature (Mertens and Ravn, 2012, $\mathrm{p}$.

146). These and other terms are discussed in detail in Section III.A and Appendices A and B.
} 
The relation between signing and qualifying dates defines two JCTC regimes that may exhibit different employment responses. We present a partial equilibrium theoretical model to show how a firm's optimal labor demand varies over time in each of the two regimes. When the qualifying date occurs after the signing date, employers anticipate the forthcoming decline in the effective wage. Hence, they have an incentive to initially decrease employment during the implementation period (the period between the signing and qualifying dates) and then to compensate for this decrease by raising employment sharply at the qualifying date. We refer to this potential negative effect as an Anticipatory Dip, and the subsequent offsetting positive effect as a Compensating Rebound. Each is a specific result of fiscal foresight. States whose JCTCs have an implementation period are classified as delayed-JCTC states. Alternatively, the qualifying date may occur at or before the signing date. We classify these states as immediateJCTC states and expect that the response of employment at the qualifying date will be less than for delayed-JCTC states; this difference measures the Compensating Rebound.

The fourth and final important aspect of state JCTCs is that the economic outcome they are intended to stimulate, employment growth, is measured with substantial accuracy (by the BLS) and at a high frequency (monthly). This allows us to precisely estimate the dynamic response of state employment growth around JCTC adoptions for each of the two regimes. Specifically, for delayed-JCTC states, we estimate average employment growth before, at, and after the qualifying date, while for immediate-JCTC states, we estimate average employment growth at and after the qualifying date. We can thus estimate the presence and magnitudes of the Anticipatory Dip and Compensating Rebound.

Moreover, we are also able to evaluate the cumulative impact of JCTCs on local job growth (which we label CUM), which is important for both state and federal policymakers considering such policies. Federal JCTCs have been much debated in recent years in the U.S. and abroad. ${ }^{6}$ For instance, Bartik and Bishop (2009) argue that a "well-designed temporary federal job creation tax credit should be an integral part of the effort to boost job growth." In 2010, a limited JCTC was part of the Hiring Incentives to Restore Employment (HIRE) Act. A second JCTC was part of President Obama's 2011 proposed American Jobs Act that would have

\footnotetext{
${ }^{6}$ JCTC's have been enacted recently in Italy (Ministero Dell'Economia e Delle Finanze, 2015) and
} France (Cahuc, Carcillo and Le Barbanchon, 2016). 
offered a tax credit of $\$ 4,000$ for hiring long-term unemployed workers, but the legislation was not passed by Congress. JCTCs continue to be discussed well into the current economic expansion. For example, in his 2015 Martin Feldstein lecture, Alan Krueger (2015) discusses ongoing problems in labor markets and remarks that "...I would prefer more targeted measures...., such as a tax credit for employers who hire the long-term unemployed or direct employment."

Our paper provides quantitative evidence on the importance of Anticipatory Dips (ADs), Compensating Rebounds (CRs) and the cumulative impacts (CUMs) of JCTCs. The paper proceeds as follows. Section I presents two initial empirical explorations. We examine employment growth before and after the month in which firms qualify for the JCTC. We document that employment growth rises when firms become eligible for JCTCs and that, consistent with fiscal foresight, the increase is larger for delayed-JCTC-states. This informal evidence illustrates the potential role of policy implementation delays in generating ADs and CRs.

Section II constructs a partial equilibrium theoretical framework for understanding the effects of a JCTC on labor costs and analyzes the intertemporal decisions faced by a firm. Our analysis identifies three key conditions necessary for an AD and CR and generates several empirical predictions. Moreover, the theoretical framework provides guidance for correctly measuring the magnitude of the pecuniary incentive provided by JCTCs.

Section III describes the unique dataset that we have hand-collected on permanent, broadbased state JCTCs signed into law in the United States since 1990. Nineteen JCTCs are identified, six for delayed-JCTC states where the signing date is before the qualifying date, and the complementary class of 13 immediate-JCTC states. The latter serves as a control group critical for quantifying the CRs. Further details are provided in Appendix A (Glossary) and Appendix B (containing details about our JCTC dataset). Section III also discusses empirical preliminaries and specification issues. We examine the factors leading to JCTC adoption and conclude that reverse causation (employment growth leading to JCTC adoption) is unlikely to be a concern. The statistical properties of the monthly employment data are examined, and we find that the growth rate of employment is stationary. Based on these empirical results, we specify an estimating equation that delivers consistent estimates of the response of employment growth to 
JCTCs. Lastly, we use the inverse probability weighting (IPW) estimator, a matching type estimator that controls for possible selection effects that might bias our estimates.

Section IV presents our main empirical results, as well as several robustness checks and extensions. Our baseline estimates of the effects of delayed JCTCs and immediate JCTCs are obtained from difference-in-difference regression model using panel data for the 48 contiguous U.S. states. We document the importance of fiscal foresight, both in terms of an AD before and then a CR after the qualifying date for delayed-JCTC states. Employment growth responds sluggishly to JCTCs. We use our estimates and JCTC data to compute a cost per job created and the associated fiscal multiplier.

Section V concludes.

\section{AN INITIAL EMPIRICAL EXPLORATION}

Before proceeding to a detailed econometric analysis of JCTCs, we first present some initial non-parametric graphical evidence on the importance of fiscal foresight. Our simple event study exercise illustrates the potential role of policy implementation delays in affecting the dynamics of economic activity around the time of policy enactments.

We compare employment growth averaged over $\mathrm{N}$ months before and after a JCTC event. A JCTC event is defined as the first month in which both new employment can qualify for the credit and the credit legislation has been enacted into law. The event window is defined by $\mathrm{N}$, which is either 1, 6, 12, or 36 months. The scatterplots in Figure 3 show employment growth before (on the horizontal axis) and after (on the vertical axis) these events for all 19 JCTC states in our sample sorted into two regimes. Delayed-JCTC states - where the credit becomes effective one or more months after it is enacted into law - are colored orange/grey; immediateJCTC states - where the credit becomes effective immediately upon enactment - are colored black. The solid line in each scatterplot is a 45 degree line. If there is an increase in state employment growth at and after the event date, the data point for that state will lie above the 45 degree line.

Figure 3 documents that employment growth tends to be higher after a JCTC becomes effective. This pattern appears to weaken somewhat as the event window is lengthened from 1 month to 36 months. The scatterplots also show that the response to the JCTC is larger for 
delayed-JCTC states than immediate-JCTC states, suggesting the empirical importance of CRs and possibly ADs.

The simple event study uses no controls. A more complete analysis will pool the data and use all of the variation in a difference-in-difference regression framework. Before we begin this more complete empirical analysis, we develop and study a theoretical model in the next section.

\section{THEORETICAL FRAMEWORK}

This section presents a dynamic model of the firm that provides guidance about the patterns of policy-response coefficients we should expect from a forward-looking firm facing a permanent JCTC. We begin by defining the firm's cash flows and the constraints that it faces. The first-order conditions (FOCs) characterizing optimal behavior are examined. These determine the steady-state values for three real variables - labor, output, and sales, as well as the transition behavior in the face of a policy stimulus. The adoption of a JCTC is then analyzed in three perfect foresight models of increasing generality in terms of the responses of the real variables away from the steady-state. We focus on the delayed-JCTC regime (which contains an implementation period between signing and qualifying months), highlight several empirical implications, measure the magnitude of the pecuniary incentive provided by JCTCs, and identify the three key conditions necessary for the emergence of Anticipatory Dips (ADs) and Compensating Rebounds (CRs).

In brief, a negatively-sloped demand curve, decreasing returns, and an inventory technology are needed to provide the firm the motivation and means to shift sales and employment intertemporally and generate ADs and CRs. The inventory technology should be interpreted broadly as representative of any margin that allows firms to decouple current employment from meeting current product demand. For example, for firms that carry little inventory, the AD could take the form of temporarily reduced employment for non-production tasks that meet administrative needs or augment other forms of organization capital. The CR would then take the form of replenishing employment geared at those tasks.

\section{II.A. Optimization Problem}

Cash flow in period $t$ is composed of four elements. First, revenues $\left(\operatorname{REV}_{t}\right)$ accrue to the firm from sales $\left(S_{t}\right)$ in a market where the firm may have market power $\left(P_{t}=P\left[S_{t}\right], P^{\prime}\left[S_{t}\right] \leq 0\right)$. 
The demand curve is linear with slope $(-\beta / 2)$ and a constant term equal to $(1+\beta)$. The linearity assumption is made for convenience; the parametric restriction as a simple device for assuring that, in the steady-state (SS), the firm faces an elastic demand curve for any value of $\beta$,

$$
\begin{aligned}
\operatorname{REV}\left[\mathrm{S}_{\mathrm{t}}\right] & \equiv \mathrm{P}_{\mathrm{t}} * \mathrm{~S}_{\mathrm{t}}=\alpha * \mathrm{~S}_{\mathrm{t}}-(\beta / 2) * \mathrm{~S}_{\mathrm{t}}^{2}, \\
\alpha & \equiv 1+\beta \\
& \left|\frac{\mathrm{d} \mathrm{S}_{\mathrm{t}}}{\mathrm{dP}_{\mathrm{t}}} \frac{\mathrm{P}_{\mathrm{t}}}{\mathrm{S}_{\mathrm{t}}}\right|_{S \mathrm{SS}}=(1+2 / \beta)>1 \quad 0<\beta<\infty,
\end{aligned}
$$

where we assume in equation (1c) that the steady-state value of $S_{t}$ equals one (an assumption verified in sub-section II.C).

Second, labor is the only factor of production, and production cost $\left(\mathrm{COST}_{t}\right)$ is the product of an exogenous wage $(w)$ and labor input $\left(\mathrm{L}_{\mathrm{t}}\right)$,

$$
\operatorname{CosT}\left[\mathrm{L}_{\mathrm{t}}\right] \equiv \mathrm{W}^{*} \mathrm{~L}_{\mathrm{t}} .
$$

Third, the firm smooths production intertemporally by adjusting the end-of-the-period inventory stock $\left(\mathrm{I}_{\mathrm{t}}\right)$. The firm has an exogenous target inventory-to-sales ratio $(\zeta)$. Deviations from this target result in the following quadratic cost,

$$
\mathrm{f}\left[\mathrm{I}_{\mathrm{t}-1}, \mathrm{~S}_{\mathrm{t}}\right] \equiv(\mu / 2) *\left(\mathrm{I}_{\mathrm{t}-1}-\zeta^{*} \mathrm{~S}_{\mathrm{t}}\right)^{2} \quad \mu \geq 0 .
$$

Such a cost is standard in the inventory literature (cf., Ramey and West, 1999, equation 3.1) and represents inventory holding and stockout costs. If $\mathrm{f}[$.$] is linear, \zeta=0$, and $(\mu / 2)$ equals the cost of borrowed funds, then equation (3) would represent the carrying cost of inventory.

Fourth, the firm receives a job creation tax credit equal to the product of the legislated tax credit rate $\left(\tau_{t}\right)$, the wage rate, and the level of credit-qualifying employment. For the state credits in our sample, credit-qualifying employment is current employment, $\mathrm{L}_{\mathrm{t}}$, minus employment in the previous period, $\mathrm{L}_{\mathrm{t}-1}$ (or averaged over several previous periods such as the past 12 months). Because the previous period is not a fixed interval at a point in time but rather a window that moves forward in time with employment, this type of credit is known as a "rolling base" credit. The rolling base feature of these credits has important implications on the incentives from, and the cost of, tax credit programs. These implications are examined in sub- 
section II.E below. Here we assume a rolling base and the tax credit received by the firm is defined as follows,

$$
\begin{gathered}
\mathrm{g}\left[\mathrm{L}_{\mathrm{t}}, \mathrm{L}_{\mathrm{t}-1}: \tau_{\mathrm{t}}\right] \equiv \tau_{\mathrm{t}} * \mathrm{w} *\left(\mathrm{~L}_{\mathrm{t}}-\mathrm{BASE}_{\mathrm{t}}\right), \\
\mathrm{BASE}_{\mathrm{t}} \equiv \mathrm{L}_{\mathrm{t}-1} .
\end{gathered}
$$

The tax credit rate is noted explicitly in equation (4a) as a conditioning variable given its central role in the subsequent analysis. An implicit assumption in the theoretical model is that the firm has positive taxable profits and/or that the credit is fully refundable (i.e., the firm does not need taxable profits to receive the credit). In our dataset, a little over half of JCTC states have nonrefundable credits, but those states have carryback and carryforward provisions that should confer nearly all of the JCTC's effective value to recipient firms.

In maximizing cash flow qua profits over the planning period, the firm faces production function, inventory accumulation, and isoperimetric constraints. The production function depends only on labor, ${ }^{7}$

$$
\mathrm{Q}_{\mathrm{t}}=\mathrm{L}_{\mathrm{t}}^{(1 / \delta)} \text {, }
$$

where $\delta>1$ so that returns to labor are decreasing. The latter property is required for satisfying the second-order conditions (cf. fn. 10) and the uniqueness of the steady-state (cf. fn. 11). The end-of-period inventory stock is accumulated according to the following recursive equation,

$$
I_{t}=Q_{t}-S_{t}+I_{t-1} \text {. }
$$

Equation (6) will be appended to the optimization problem with a time-varying shadow price, $\theta_{\mathrm{t}}$. The final constraint concerns the inventory stock at the end of the planning period. The firm begins the planning period with an inventory stock, $\mathrm{I}_{0}$. If left unconstrained, the firm will end the planning period at time $\mathrm{T}$ with the inventory stock completely depleted, and some of its profit will be illusory. To avoid this extreme inventory drawdown that would distort profits and employment decisions, we require that $\mathrm{I}_{\mathrm{T}}=\mathrm{I}_{0}$, which, after repeated substitution with equation (6), is equivalent to the following isoperimetric constraint,

\footnotetext{
${ }^{7}$ This formulation of the production function is consistent with a constant returns-to-scale production function with labor and a fixed factor as arguments, where the latter is normalized to one and fixed during the length of the period over which we evaluate the impact of the JCTC.
} 


$$
\mathrm{I}_{\mathrm{T}}-\mathrm{I}_{0}=0=\sum_{\mathrm{t}=1}^{\mathrm{T}}\left(\mathrm{Q}_{\mathrm{t}}-\mathrm{S}_{\mathrm{t}}\right) .
$$

Note that this is a weaker constraint than the special case of assuming the firm starts with zero inventory because, in this special case, the firm will optimally deplete the inventory stock completely by period $\mathrm{T}$ and $\mathrm{I}_{\mathrm{T}}=\mathrm{I}_{0}=0$. The constraint in equation (7) will be appended to the optimization problem with a time-invariant shadow price, $\phi$. This constant shadow price of output plays a critical role in the intertemporal allocation of labor, output, and sales for a firm facing a delayed JCTC and in the emergence of ADs and CRs.

Combining the four relations defining cash flow $\left(\mathrm{CF}_{t}\right)$, discounting $\mathrm{CF}_{\mathrm{t}}$ by a constant discount factor $\left(\mathrm{R}^{\mathrm{t}}\right.$ depending on a constant discount rate $\rho$ ), assuming that cash flows accrue at the end of the period, substituting $L_{t}$ for $Q_{t}$ with equation (5), and appending the two constraints, we write the dynamic optimization problem as follows,

$$
\begin{gathered}
\Pi_{0}=\underset{\left\{\mathrm{L}_{\mathrm{t}}, \mathrm{S}_{\mathrm{t}}, \mathrm{I}_{\mathrm{t}}\right\}}{\operatorname{Max}} \sum_{\mathrm{t}=1}^{\mathrm{T}} \mathrm{R}^{\mathrm{t}}\left\{\mathrm{CF}\left[\mathrm{L}_{\mathrm{t}}, \mathrm{S}_{\mathrm{t}}, \mathrm{I}_{\mathrm{t}-1}, \mathrm{~L}_{\mathrm{t}-1}: \tau_{\mathrm{t}}\right]+\theta_{\mathrm{t}}\left(\mathrm{I}_{\mathrm{t}}-\mathrm{L}_{\mathrm{t}}^{(1 / \delta)}+\mathrm{S}_{\mathrm{t}}-\mathrm{I}_{\mathrm{t}-1}\right)+\phi \sum_{\mathrm{t}=1}^{\mathrm{T}}\left(\mathrm{L}_{\mathrm{t}}^{(1 / \delta)}-\mathrm{S}_{\mathrm{t}}\right)\right\} \\
\mathrm{R}^{\mathrm{t}} \equiv(1+\rho)^{-\mathrm{t}} \quad \rho>0 \\
\quad \mathrm{CF}\left[\mathrm{L}_{\mathrm{t}}, \mathrm{S}_{\mathrm{t}}, \mathrm{I}_{\mathrm{t}-1}, \mathrm{~L}_{\mathrm{t}-1}: \tau_{\mathrm{t}}\right] \equiv\left(\operatorname{REV}\left[\mathrm{S}_{\mathrm{t}}\right]-\operatorname{COST}\left[\mathrm{L}_{\mathrm{t}}\right]-\mathrm{f}\left[\mathrm{I}_{\mathrm{t}-1}, \mathrm{~S}_{\mathrm{t}}\right]+\mathrm{g}\left[\mathrm{L}_{\mathrm{t}}, \mathrm{L}_{\mathrm{t}-1}: \tau_{\mathrm{t}}\right]\right)
\end{gathered}
$$

\section{II.B. First Order Conditions}

The firm maximizes discounted cash flows by appropriate choices of labor, sales, and the inventory stock. Given the inventory accumulation constraint, the latter variable is predetermined by the choices of labor and sales, and it could be eliminated from equation (8) with equation (6). We include $I_{t}$ explicitly in equation (8) to facilitate the interpretation of the first-order conditions. We begin with the perturbation of equation (8) with respect to $I_{t}$,

$$
\begin{gathered}
\mathrm{I}_{\mathrm{t}}:-\mathrm{R} * \mu\left(\mathrm{I}_{\mathrm{t}}-\zeta * \mathrm{~S}_{\mathrm{t}+1}\right)+\theta_{\mathrm{t}}-\mathrm{R} * \theta_{\mathrm{t}+1}=0, \\
\rightarrow \\
\theta_{\mathrm{t}}=\sum_{\mathrm{s}=0}^{\mathrm{T}} \mathrm{R}^{\mathrm{t}-\mathrm{s}-1} \mu\left(\mathrm{I}_{\mathrm{t}+\mathrm{s}}-\zeta * \mathrm{~S}_{\mathrm{t}+\mathrm{s}+1}\right) .
\end{gathered}
$$


Equation (9a) is a first-order difference equation in $\theta_{\mathrm{t}}{ }^{8}$ It can be solved by recursive substitution for $\theta_{\mathrm{t}+\mathrm{s}}$ and by imposing the terminal condition that that $\theta_{\mathrm{T}}$ equals zero (discussed below). This solution is presented in equation $(9 b)$ and defines $\theta_{t}$ as the shadow price of adding a unit of inventory in period $t$ and keeping that unit in inventory until period $\mathrm{T}$. If in period $t$, the inventory stock exceeds its target level $\left(\left(\mathrm{I}_{\mathrm{t}+\mathrm{s}}-\zeta^{*} \mathrm{~S}_{\mathrm{t}+\mathrm{s}+1}>0\right), \forall \mathrm{s}=0, \mathrm{~T}\right)$, an addition to inventory aggravates the imbalance, is costly to the firm, and $\theta_{t}>0 .{ }^{9}$ These incremental costs are increasing in $\mu$ and are discounted by $\mathrm{R}$. If in period $\mathrm{t}$, the inventory stock is below its target level, then the additional unit is beneficial to the firm, the incremental cost is negative, and $\theta_{\mathrm{t}}<0$. In the steady-state, the inventory stock equals its target level, the inventory imbalance is zero, and $\theta_{\mathrm{t}}=0$.

The key decisions made by the firm concern labor and sales. The first-order condition for labor is as follows,

$$
\begin{aligned}
& \mathrm{L}_{\mathrm{t}}: \mathrm{w} *\left(1-\tau_{\mathrm{t}}+\tau_{\mathrm{t}+1} * \mathrm{R}\right)+\theta_{\mathrm{t}} *\left(\mathrm{~L}_{\mathrm{t}}^{((1-\delta) / \delta)} / \delta\right)=\phi *\left(\mathrm{~L}_{\mathrm{t}}^{((1-\delta) / \delta)} / \delta\right), \\
& \rightarrow \\
& \begin{aligned}
\operatorname{MPL}\left[\mathrm{L}_{\mathrm{t}}\right]=\mathrm{w}_{\mathrm{t}}^{\mathrm{EFF}} /\left(\phi-\theta_{\mathrm{t}}\right) \quad & \mathrm{w}_{\mathrm{t}}^{\mathrm{EFF}} \equiv \mathrm{w}^{*}\left(1-\tau_{\mathrm{t}}+\tau_{\mathrm{t}+1} * \mathrm{R}\right) \\
& \operatorname{MPL}\left[\mathrm{L}_{\mathrm{t}}\right] \equiv(1 / \delta) * \mathrm{~L}_{\mathrm{t}}^{((1-\delta) / \delta)}
\end{aligned}, \\
& \rightarrow \\
& \mathrm{L}_{\mathrm{t}}=\left(\frac{\phi-\theta_{\mathrm{t}}}{\delta * \mathrm{w}_{\mathrm{t}}^{\mathrm{EFF}}}\right)^{(\delta /(\delta-1))} \\
& \mathrm{Q}_{\mathrm{t}}=\left(\frac{\phi-\theta_{\mathrm{t}}}{\delta * \mathrm{~W}_{\mathrm{t}}^{\mathrm{EFF}}}\right)^{(1 /(\delta-1))} \text {. }
\end{aligned}
$$

\footnotetext{
${ }^{8}$ If the cash flow term defined in equation $(8 \mathrm{c})$ had also included an inventory carrying cost $\left(\mathrm{c}^{*} \mathrm{I}_{\mathrm{t}-1}\right)$, this additional cost term would have merely redefined $\theta_{t}$. Inventory carrying costs would enter equation (9a) as $-\mathrm{R}^{*} \mathrm{c}$ and, in this case, equation $(9 \mathrm{~b})$ would contain an additive constant multiplied by the discount factor.

${ }^{9}$ We assume that the inventory imbalance is reduced monotonically to zero. Given the quadratic specification, inventory imbalances of either sign are penalized, and it would be unnecessarily costly for the firm to overshoot the steady-state value.
} 
The two terms on the left side of equation (10a) define the total cost from hiring an incremental worker (and hence producing an incremental unit of output). The first term reflects labor costs represented by the effective wage rate, $\mathrm{w}_{\mathrm{t}}^{\mathrm{EFF}}$, which is equal to the sum of the cost of hiring labor $(\mathrm{w})$ less the tax credit $\left(-\mathrm{w} * \tau_{\mathrm{t}}\right)$ received in period $\mathrm{t}$ and, owing to the rolling base feature of the tax credit (discussed in more detail in sub-section II.E), plus the tax credit that will not be received in period $\mathrm{t}+1\left(\mathrm{w} * \tau_{\mathrm{t}+1} * \mathrm{R}\right)$. Taken together, these latter two terms form the effective tax credit rate that differs markedly from the legislated tax credit rate, $\tau$. The second term is the cost of adding to an inventory imbalance. If $\theta_{t}$ is positive due to a positive inventory imbalance, incremental output from a new hire increases the imbalance and is costly to the firm. These incremental costs are equal to the benefit from an additional hire, represented by the term on the right side of equation (10a). This term is the constant shadow price of output, $\phi$, multiplied by the marginal product of labor.

These relations are rearranged into a more concise expression in equation (10b), which shows that labor is optimally chosen such that its marginal product equals labor's effective wage rate "deflated" by the true price of output, which is its shadow price net of any cost due to an inventory imbalance. Equation (10c) is a rearrangement of equation (10b) and relates $\mathrm{L}_{t}$ to the production function parameter, shadow prices, and the effective wage rate. Equation (10d) is the corresponding expression for $Q_{t}$. Note that the object $\left(\phi-\theta_{t}\right)$ appearing in the numerators is always positive given the wage rate term in equation (10a).

The second key choice by the firm concerns sales determined by the following firstorder condition,

$$
\begin{aligned}
\mathrm{S}_{\mathrm{t}}: & \left(\alpha-\beta * \mathrm{~S}_{\mathrm{t}}\right)+\mu * \zeta\left(\mathrm{I}_{\mathrm{t}-1}-\zeta * \mathrm{~S}_{\mathrm{t}}\right)+\theta_{\mathrm{t}}=\phi, \\
& \rightarrow \\
& \mathrm{S}_{\mathrm{t}}=\frac{\alpha+\mu * \zeta * \mathrm{I}_{\mathrm{t}-1}+\theta_{\mathrm{t}}-\phi}{\beta+\mu * \zeta^{2}} .
\end{aligned}
$$

Equation (11a) is a perturbation of equation (8) that impacts cash flow in three ways. The first term in equation (11a) is the marginal revenue, which decreases in the level of sales because of the downward-sloping demand curve. The second term reflects the cash flow from a change in the target and depends on the sign of the inventory imbalance. An increase in sales (and hence 
the target level of inventory) reduces a positive imbalance and adds to cash flow. The impact is negative when the inventory imbalance is negative. Note that this effect disappears if the target level is zero $(\zeta=0)$. The third term is the shadow price of inventory imbalances. The shadow price's impact on an incremental sale is opposite to its impact on labor because $Q_{t}$ (dependent on $\mathrm{L}_{\mathrm{t}}$ ) and $\mathrm{S}_{\mathrm{t}}$ have opposite but numerically identical effects on the inventory stock. If this cost is positive due to a positive inventory imbalance, an incremental sale reduces the imbalance and increases cash flow. These three terms define the total cash flow from an incremental sale and, under profit-maximization, equal the constant shadow price of output, $\phi$. Equation (11b) is a rearrangement of equation (11a) that relates $S_{t}$ to demand curve parameters, the predetermined inventory stock, and shadow prices.

Lastly, perturbations of the shadow prices yield the per-period inventory accumulation constraint and the planning-period isoperimetric constraint, respectively,

$$
\begin{array}{ll}
\theta_{t}: & \mathrm{I}_{\mathrm{t}}=\mathrm{L}_{\mathrm{t}}^{(1 / \delta)}-\mathrm{S}_{\mathrm{t}}+\mathrm{I}_{\mathrm{t}-1}, \\
\phi: & \sum_{\mathrm{t}=1}^{\mathrm{T}}\left(\mathrm{L}_{\mathrm{t}}^{(1 / \delta)}-\mathrm{S}_{\mathrm{t}}\right)=0,
\end{array}
$$

\section{II.C. Steady-State}

These first-order conditions form the basis of our analysis of the steady-state and transition associated with a delayed JCTC. In this sub-section, we analyze a steady-state defined by two characteristics: the inventory stock equaling its target value $\left(\mathrm{I}_{\mathrm{SS}}=\zeta * \mathrm{~S}_{\mathrm{SS}}\right)$ and sales equaling output $\left(\mathrm{S}_{\mathrm{SS}}=\mathrm{Q}_{\mathrm{SS}}\right)$. The first characteristic implies that $\theta_{\mathrm{SS}}=0$ and that sales and output given by equations (10d) and (11b), respectively, can be written as follows, ${ }^{10}$

$$
\begin{aligned}
& \mathrm{Q}_{\mathrm{SS}}=\left(\frac{\phi_{\mathrm{SS}}}{\delta * \mathrm{w}_{\mathrm{SS}}^{\mathrm{EFF}}}\right)^{(1 /(\delta-1))}, \\
& \mathrm{S}_{\mathrm{SS}}=\frac{\alpha-\phi_{\mathrm{SS}}}{\beta} .
\end{aligned}
$$

\footnotetext{
${ }^{10}$ In the steady-state, the second-order conditions can be verified. The matrix of second derivatives for $\mathrm{L}$ and $S$ is as follows, $\left[\begin{array}{lr}((1-\delta) / \delta) * L^{(1-2 \delta) / \delta)} & 0 \\ 0 & -\beta\end{array}\right]$, which is negative definite for $\delta>1$ and $\beta>0$. Note
} that the first-order condition for $I_{t}$ vanishes in the steady-state. 
In order to analyze how variables respond to the introduction of a JCTC, we consider an initial steady state in which there is no JCTC, and hence $\mathrm{w}_{\mathrm{SS}}^{\mathrm{EFF}}=\mathrm{w}$. In order to form baseline values, we adopt the normalization that $\mathrm{w}=(1 / \delta)<1$. The second characteristic and the normalization implies the following solution for the shadow price of output,

$$
\begin{aligned}
\mathrm{Q}_{\mathrm{SS}}=\mathrm{S}_{\mathrm{SS}} & \rightarrow \mathrm{h}\left[\phi_{\mathrm{SS}}\right]=0 \rightarrow \phi_{\mathrm{SS}}=1, \\
& \mathrm{~h}\left[\phi_{\mathrm{SS}}\right] \equiv \beta\left(\phi_{\mathrm{SS}}\right)^{(1 /(\delta-1))}+\phi_{\mathrm{SS}}-\alpha .
\end{aligned}
$$

The unique solution to equation (16) is $\phi_{\mathrm{SS}}=1 .{ }^{11}$ With this value for the shadow price of output, $\mathrm{S}_{\mathrm{SS}}=\mathrm{Q}_{\mathrm{SS}}=\mathrm{L}_{\mathrm{SS}}=1$. The critical result here is that the optimal choice of labor in the initial steady state is 1 . Therefore, the effects of introducing a JCTC can be easily computed as a deviation from unity.

\section{II.D. Responses To A JCTC: No Rolling Base; No Inventory Costs}

We now examine the firm's responses to the introduction of a JCTC. In order to highlight three different channels of influence, we will examine in this sub-section a special case of the model in which the JCTC does not have a rolling base and the inventory technology is costless. Sub-section II.E reintroduces the rolling base. Sub-section II.F contains a general model with the rolling base and costly inventory.

In anticipation of the empirical analysis, we divide the timeline for a firm in a delayedJCTC state into three intervals,

BEFORE: The months between the signing date and the qualifying date.

AT: $\quad$ The month containing the qualifying date.

AFTER: The months after the qualifying date. ${ }^{12}$

The AT and AFTER intervals capture the immediate and lagged responses, respectively, to the same JCTC stimulus. We draw a distinction between them to isolate the CR and CUM effects.

\footnotetext{
${ }^{11} \mathrm{~A}$ value of $\phi_{\mathrm{SS}}=1$ is a solution to equation (16). Since $\mathrm{h}[0] \leq 0, \lim _{\phi_{\mathrm{SS}} \rightarrow \infty} \mathrm{h}\left[\phi_{\mathrm{SS}}\right] \rightarrow+\infty$, and $\mathrm{h}^{\prime}\left[\phi_{\mathrm{SS}}\right]>0 \forall \phi_{\mathrm{SS}}>0$, we can verify that $\phi_{\mathrm{SS}}=1$ is the unique solution to $\mathrm{h}[\phi]$ provided $\delta>1, \alpha=1+\beta$, and $\beta \geq 0$.

${ }^{12}$ By definition, the BEFORE interval is empty (zero length) for immediate-JCTC states.
} 
We assume that the firm begins in the steady-state with no JCTC. At the beginning of the planning period, policymakers adopt a permanent JCTC with a "qualifying date" (the date at which time employment above the credit base qualifies for the credit) in the future. ${ }^{13}$ This situation describes delayed-JCTC states and leads to some very interesting dynamic behavior that we study in terms of its effect on employment in the BEFORE and then in the AT and AFTER intervals. There are two restrictive assumptions adopted in this sub-section. The rolling base is eliminated so that $\mathrm{BASE}_{\mathrm{t}} \equiv 0$ or a constant in equation (4b). We maintain that there is an inventory stock that allows production to be smoothed across periods, but inventory costs are absent $(\mu=0)$. The first-order conditions for labor and sales for this restricted model are as follows,

$$
\begin{array}{lll}
\mathrm{L}_{\mathrm{t}}=\left(\frac{\phi}{\delta * \mathrm{w}_{\mathrm{t}}^{\mathrm{EFF}}}\right)^{(\delta /(\delta-1))} & \mathrm{t} \in\{\mathrm{BEFORE}\}, \\
\mathrm{L}_{\mathrm{t}}=\left(\frac{\phi}{\delta^{*} \mathrm{w}_{\mathrm{t}}^{\mathrm{EFF}}}\right)^{(\delta /(\delta-1))} & \mathrm{w}_{\mathrm{t}}^{\mathrm{EFF}} \equiv \mathrm{w} *\left(1-\tau_{\mathrm{t}}\right) & \mathrm{t} \in\{\text { AT, AFTER }\}, \\
\mathrm{S}_{\mathrm{t}}=\frac{\alpha-\phi}{\beta} & \mathrm{t} \in\{\text { BEFORE,AT,AFTER }\} .
\end{array}
$$

The introduction of the JCTC lowers $\mathrm{w}_{\mathrm{t}}^{\mathrm{EFF}}$ in the AT and AFTER intervals. Thus, $\mathrm{L}_{\mathrm{t}}$ rises at the time of the qualifying date and stays permanently higher. These initial hiring and production plans lead to an imbalance with $S_{t}$, which, for the moment, remains fixed. A change in the shadow price of output restores the balance over the planning period. Per equations (17), the decline in $\phi$ (below its initial steady state value of 1 ) has three effects. First, it raises $\mathrm{S}_{\mathrm{t}}$ uniformly in all three intervals. Second, it lowers $L_{t}$ and $Q_{t}$ in the BEFORE interval relative to the initial steady-state. Third, it also lowers $L_{t}$ and $Q_{t}$ in the AT and AFTER intervals. However, this decrease (due to the decline in $\phi$ ) is more than offset by the stimulus from the

\footnotetext{
${ }^{13}$ Here and in the empirical work we assume that there is no uncertainty regarding the date at which firms begin to qualify for the tax credit. In our dataset, there are no instances of a delayed-JCTC state failing to honor the qualifying date once the JCTC has been signed into law.
} 
lower effective wage rate. ${ }^{14}$ The adjustment process continues until the increased level of sales matches the increased level of output over the planning period.

The above analysis generates an $\mathrm{AD}$ due to fiscal foresight. ${ }^{15}$ Even though the effective wage rate in the BEFORE interval does not change, employment in that interval falls relative to its prior steady-state value. This change represents a shift in production from high-cost to lowcost periods as the firm, foreseeing the future drop in the effective wage rate, adopts an intertemporal production plan that minimizes average production costs and satisfies an endogenous sales constraint.

The AD directly leads to the CR. The level of sales following from the implementation of the JCTC is determined by the new steady-state value of the shadow price of output $(\phi)$. This value will be the same whether or not an AD exists. Hence, the levels of employment and output during the AT and AFTER intervals must be larger when an AD occurs in the BEFORE interval in order to compensate for the lost output. This extra output is the CR, the "compensating rebound."

A downward-sloping demand curve, an inventory technology, and decreasing returns to labor are necessary elements for the AD and CR. The absence of either of the first two conditions would lead to a sequence of static optimization problems. If the firm faces a perfectly elastic demand curve, then all of period t's production could be sold without the penalty from declining marginal revenues. In this case, the dynamic elements in the optimization problem

${ }^{14}$ This net effect depends on the properties of the term $\phi_{\mathrm{SS}} /\left(\delta^{*} \mathrm{w}_{\mathrm{SS}}^{\mathrm{EFF}}\right)$ appearing in equation (14); specifically, the elasticity of $\phi$ with respect to $\mathrm{w}_{\mathrm{SS}}^{\mathrm{EFF}}\left(\varepsilon_{\phi, w_{\mathrm{SS}}^{\mathrm{EFF}}}\right)$ must be less than one. To evaluate this condition, rewrite the steady-state relation $\mathrm{h}\left[\phi_{\mathrm{SS}}\right]$ in terms of $\mathrm{w}_{\mathrm{SS}}^{\mathrm{EFF}}$ (which does not generally appear in $\mathrm{h}\left[\phi_{\mathrm{SS}}\right]$ because of the normalization, $\left.\mathrm{w}=(1 / \delta)<1\right)$, $\mathrm{h}\left[\phi_{\mathrm{SS}}\right]=\kappa\left[\phi_{\mathrm{SS}}\left[\mathrm{w}_{\mathrm{SS}}^{\mathrm{EFF}}\right], \mathrm{w}_{\mathrm{SS}}^{\mathrm{EFF}}\right] \equiv \beta\left(\phi_{\mathrm{SS}}\left[\mathrm{w}_{\mathrm{SS}}^{\mathrm{EFF}}\right] /\left(\delta^{*} \mathrm{w}_{\mathrm{SS}}^{\mathrm{EFF}}\right)\right)^{(1 /(\gamma-1))}+\phi_{\mathrm{SS}}\left[\mathrm{w}_{\mathrm{SS}}^{\mathrm{EFF}}\right]-\alpha \equiv \chi\left[\mathrm{w}_{\mathrm{SS}}^{\mathrm{EFF}}\right]$. In any steadystate, $\mathrm{Q}_{\mathrm{SS}}=\mathrm{S}_{\mathrm{SS}}$ and hence $\chi^{\prime}\left[\mathrm{w}_{\mathrm{SS}}^{\mathrm{EFF}}\right]=0$ through an adjustment in $\phi$ to the change in $\mathrm{w}_{\mathrm{SS}}^{\mathrm{EFF}}$. Differentiating $\chi\left[\mathrm{w}_{\mathrm{SS}}^{\mathrm{EFF}}\right]$ with respect to $\mathrm{w}_{\mathrm{SS}}^{\mathrm{EFF}}$, setting the derivative equal to zero, and evaluating this derivative at the original steady-state, we obtain $\varepsilon_{\phi_{\mathrm{SS}}, \mathrm{w}_{\mathrm{SS}}^{\mathrm{EFF}}}=(\beta /(\beta+\delta-1))<1$ provided $\delta>1$.

${ }^{15}$ Our Anticipatory Dip differs from the well-known Ashenfelter Dip (Ashenfelter, 1978; Heckman and Smith, 1999). While both Dips involve transitory declines of employment and earnings, respectively, prior to the implementation of a policy, the channels differ. The Ashenfelter Dip is a selection phenomenon driven by low opportunity costs; Anticipatory Dips are driven by intertemporal tradeoffs. 
disappear, and period t production is based only on the period $t$ wage rate. Thus, output and employment do not change in the BEFORE interval, and an $\mathrm{AD}$ does not exist. If an inventory technology is absent, then $Q_{t}$ must equal $S_{t}$ in each period, and the firm no longer has a separate sales decision. ${ }^{16}$ In this case, the inability to change inventory prevents the firm from taking advantage of the differential production costs due to the delayed implementation of the JCTC program. Again, the dynamic optimization problem becomes a sequence of static problems, and there are no interrelations among anticipated future wage rates and current employment decisions.

Decreasing returns to labor are also necessary for the $\mathrm{AD}$ and $\mathrm{CR}$. With increasing or constant returns and a future pre-tax wage rate substantially lower than the current level, all production would tend to "bunch" in that future period independent of a JCTC. The extent of "bunching" would depend on the inventory stock and desired level of sales.

In sum, a negatively-sloped demand curve and decreasing returns provide the motivation to smooth sales and employment across periods. ${ }^{17}$ An inventory technology provides the means to shift production across periods. All three elements are needed to provide the firm the motivation and means to shift sales and employment intertemporally and generate ADs and CRs. II.E. Responses To A JCTC: No Inventory Costs

We now relax one of the two restrictions in the above model and analyze the effects of the rolling base on the response to the delayed JCTC. The qualitative effects on employment are identical to those documented in sub-section II.D, though the quantitative effects differ. With a rolling base, the effective wage (equation (10b)) is impacted differently in the BEFORE interval and then in the AT and AFTER intervals,

\footnotetext{
${ }^{16}$ If an inventory technology is not available to the firm, the inventory accumulation constraint $\left(I_{t}=Q_{t}-S_{t}+I_{t-1}\right)$ would be removed from the optimization problem (equation (8a)) and $S_{t}$ would be replaced by $Q_{t}$ for all $t$.

${ }^{17}$ Decreasing returns and a negatively-sloped demand curve are also necessary for the satisfaction of the second-order conditions (cf. fn. 10).
} 


$$
\begin{array}{ll}
\frac{\partial \mathrm{w}_{\mathrm{t}}^{\mathrm{EFF}}}{\partial \tau_{\mathrm{t}}}=\mathrm{w}^{*} \mathrm{R}=\mathrm{w} *(1 /(1+\rho))>0 & \mathrm{t} \in\{\text { BEFORE }\}, \\
\frac{\partial \mathrm{w}_{\mathrm{t}}^{\mathrm{EFF}}}{\partial \tau_{\mathrm{t}}}=-\mathrm{w} *(1-\mathrm{R})=-\mathrm{w} *(\rho /(1+\rho))<0 & \mathrm{t} \in\{\text { AT, AFTER }\} .
\end{array}
$$

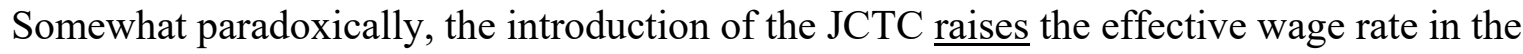
BEFORE interval. With a delayed JCTC, the firm is not eligible to receive the tax credit in the BEFORE interval, and hence obtains no benefits. However, any hiring in the BEFORE interval raises the employment base above which subsequent employment must rise in order to qualify for the credit. Hence, employment in the BEFORE interval lowers the value of the credit in future periods. ${ }^{18}$ Being forward-looking, the firm internalizes this cost when choosing employment in the BEFORE interval. This negative effect on profitability is measured in equation (18a) by the discounted wage rate.

In the AT and AFTER intervals, the JCTC lowers effective wages. However, the quantitative impact is dramatically reduced by the rolling base feature of the tax credit. The $\rho /(1+\rho)$ term in equation $(18 b)$ reflects that, with a rolling base, eligible incremental employment receives a tax credit today but at the expense of eliminating the tax credit on incremental employment tomorrow. This latter cost is discounted and, hence the overall stimulus from the tax credit increases with the discount rate. Since the discount rate is generally a small number, the rolling base feature drives a large wedge between the legislated and effective tax credits and affects the specification of the JCTC in the econometric equation. Assuming an expected long-run nominal return on equity of $10 \%$ and an expected long-run inflation rate of $3 \%, \rho$ is $7 \%$, and $(\rho /(1+\rho)) \approx 0.065$. Hence, after the qualifying date, the effective tax credit rate is only $6.5 \%$ of the legislated credit rate. In the extreme with no discounting $(\rho=0)$, the credit provides no stimulus at all.

${ }^{18}$ Altshuler (1988) identified a similar perverse effect with respect to the R\&D tax credit. 


\section{II.F. Responses To A JCTC: The General Model}

This sub-section analyzes the general model in which the JCTC is delayed and has a rolling-base and, unique to this sub-section, inventory imbalances are costly. ${ }^{19}$ We introduce the latter effect by allowing $\mu>0$. The first-order conditions for the general model are modified by including terms containing the cost of inventory imbalances ( $\mu$ interacted with the inventory/sales target, $\zeta)$ and the shadow price of adding to inventory imbalances $\left(\theta_{t}\right)$,

$$
\begin{array}{ll}
\mathrm{L}_{\mathrm{t}}=\left(\frac{\phi-\theta_{\mathrm{t}}}{\delta * \mathrm{w}_{\mathrm{t}}^{\mathrm{EFF}}}\right)^{(\delta /(\delta-1))} \quad \mathrm{w}_{\mathrm{t}}^{\mathrm{EFF}} \equiv \mathrm{w} *\left(1+\tau_{\mathrm{t}+1} * \mathrm{R}\right) & \mathrm{t} \in\{\text { BEFORE }\}, \\
\mathrm{L}_{\mathrm{t}}=\left(\frac{\phi-\theta_{\mathrm{t}}}{\delta * \mathrm{w}_{\mathrm{t}}^{\mathrm{EF}}}\right)^{(\delta /(\delta-1))} \quad \mathrm{w}_{\mathrm{t}}^{\mathrm{EFF}} \equiv \mathrm{w} *\left(1-\tau_{\mathrm{t}}+\tau_{\mathrm{t}+1} * \mathrm{R}\right) & \mathrm{t} \in\{\text { AT, AFTER }\}, \\
\mathrm{S}_{\mathrm{t}}=\frac{\alpha+\mu * \zeta * \mathrm{I}_{\mathrm{t}-1}+\theta_{\mathrm{t}}-\phi_{\mathrm{SS}}}{\beta+\mu * \zeta^{2}} & \mathrm{t} \in\{\text { BEFORE, AT, AFTER }\} .
\end{array}
$$

The introduction of costly inventory imbalances modifies the quantitative but not the qualitative effects of the JCTC analyzed above. With $S_{t}$ and $\phi$ held at their initial steady-state levels, employment initially decreases in the BEFORE interval and increases in the AT and AFTER intervals. The BEFORE response in employment results in an inventory drawdown, $\theta_{t}<0$ (per equation (9b)), and incremental employment in all periods becomes more valuable by reducing the inventory imbalance. Consequently, an unambiguous implication of the general model is that inventory costs lead to a smaller fall in employment in the BEFORE interval.

The relative change in employment in the AT and AFTER intervals is subject to two contrasting effects and the net effect of the introduction of inventory costs is ambiguous. Since the inventory drawdown in the BEFORE period is lower, there is a reduced need to replenish inventory and relative employment falls. However, in the AT and AFTER intervals, there is an added incentive to hire labor and produce output to eliminate the costly inventory imbalance, and relative employment rises.

\footnotetext{
${ }^{19}$ Abel (1982) and Auerbach (1989) also use dynamic optimizing models to study anticipated tax changes. Their models give explicit consideration to adjustment costs but do not contain decision margins for inventories and sales. The present model identifies the three key conditions impinging on inventories, sales, and production necessary for the emergence of Anticipatory Dips and Compensating Rebounds.
} 
Inventory, its shadow price, and sales respond differently in subsequent periods relative to the model in sub-section II.E. In the face of a negative inventory imbalance, an incremental sale aggravates the imbalance and becomes less valuable in a model with costly inventory. The inventory imbalance is largest in the BEFORE interval and falls over time. The decrease in the imbalance results in an increase in $\theta_{\mathrm{t}}$ that stimulates sales. Rather than being constant over the planning period, sales in the general model rises over time. As in all models considered here, $\phi$ adjusts so that the inventory imbalance is eliminated by the end of the planning period at which time $\theta_{\mathrm{T}}=0$.

Figure 4 summarizes the theoretical predictions for the path of employment over the planning period and the interesting dynamics associated with a delayed JCTC. With a delayedJCTC, employment falls after the credit is enacted (at date $t^{\mathrm{S}}$ ) as forward-looking firms delay hiring and draw down inventories to meet current demand. This decline is amplified when the value of the tax credit is computed with a rolling base. The combined effect is illustrated by line segment $\mathrm{AB}$. When the JCTC goes into effect (at qualifying date $\mathrm{t}^{\mathrm{Q}}$ ), employment rises sharply for several reasons: rebuilding the work force (line segment BC), responding to the lower effective wage rate (line segment $\mathrm{CD}$ ), and replenishing inventory (line segment DE). Note that only the response indicated by line segment $\mathrm{CD}$ represents the "true" short-run stimulative effect of a JCTC. Gradually, employment falls as inventories return toward their steady-state levels, but it remains above the original employment level because of lower labor costs (line segment $\mathrm{AF}$, which is the same length as line segment $\mathrm{CF}$ ).

In sum, Figure 4 represents the Anticipatory Dip by line segment $\mathrm{AB}$ and the Compensating Rebound by line segments $\mathrm{BC}$ and DE.

\section{II.G. Immediate-JCTC vs. Delayed-JCTC Regimes}

The above analysis has focused on a firm facing a delayed-JCTC, which has been adopted by six states between 1990 and 2007. For a JCTC that goes into effect immediately, as is the case in 13 states, the pattern of employment in the AT and AFTER intervals is qualitatively similar to those displayed in Figure 4. An important difference is that fiscal foresight and the associated ADs and CRs do not exist. For immediate-JCTC states, where firms qualify for the JCTC at $t^{\mathrm{Q}}$, the employment increase in the AT interval will be smaller than it is for firms in the delayed-JCTC states because there is no need to compensate for deferred hiring and inventory 
drawdowns; that is, the $\mathrm{CR}$ is absent. Thus, analyzing employment responses in immediateJCTC states provides a clean read on the true effectiveness of JCTCs (line segment CD), whereas employment responses in delayed-JCTC states with implementation lags are likely to overstate the effectiveness of tax credits (by the sum of the line segments $\mathrm{BC}$ and $\mathrm{DE}$ ). These predictions are summarized in Table 1 and lead to three hypotheses about employment growth that we test:

1. Anticipatory Dips (ADs): the negative response in the BEFORE interval for delayedJCTC states;

2. Compensating Rebounds (CRs): the positive responses in the AT intervals for both delayed-JCTC and immediate-JCTC states, with the former being larger than the latter;

3. Cumulative Effects (CUMs): the positive responses over the BEFORE, AT, and AFTER intervals, taken as a whole, for both delayed-JCTC and immediate-JCTC states.

\section{EMPIRICAL PRELIMINARIES AND SPECIFICATION ISSUES}

\section{III.A Employment and JCTC Data}

Our empirical work focuses on the relation between JCTCs and employment. The latter is measured by monthly, seasonally adjusted, private non-farm employment data for the period January 1990 to December $2010 .^{20}$ The earlier date is the first month in which these data are published by the Bureau of Labor Statistics. The latter date is chosen because it provides at least three years of employment data after the final JCTC in our sample; in our econometric model, we allow for an adjustment period (the AFTER interval) of up to 36 months. Our analysis excludes JCTCs that went into effect after December 2007, the official NBER start date of the Great Recession. This date was chosen in order to avoid any influence of the Great Recession on the adoption of this fiscal policy. Similarly, we exclude JCTCs passed during the Great Recession or the weak subsequent recovery to avoid potential endogeneity concerns. ${ }^{21}$

\footnotetext{
${ }^{20}$ The employment data come from the BLS's Current Employment Statistics series. For details on the BLS, see http://www.bls.gov/bls/empsitquickguide.htm\#payroll.

${ }^{21}$ Wilson (2012) documents the large cross-state differences in the federal stimulus provided by the 2009 American Recovery and Reinvestment Act and finds that the stimulus spending had a substantial impact on state employment. See, also, Neumark and Grijalva (2013) for a study of the impact of JCTCs during the Great Recession.
} 
The JCTCs are credits that employers in the state can apply against their business income tax liability - both corporate or non-corporate -- upon hiring the worker. ${ }^{22}$ We conducted an initial state-by-state search for JCTCs from various sources to identify an exhaustive list of permanent, broad-based JCTCs adopted and put into effect prior to December 2007

We restrict our focus to JCTCs that are "permanent," in the sense that their legislation did not set an expiration date, in order to rule out temporary JCTCs that are sometimes passed as short-run stimulus measures (i.e., countercyclical fiscal policies). These temporary JCTCs theoretically have different dynamic effects than do permanent JCTCs, and they are more likely to be endogenous with respect to current and expected employment growth.

For each JCTC, we hand-collected information on the signing date, the qualifying date, the pecuniary value of the tax credit, and other relevant characteristics. For the period 1990 to 2007, we identified 19 JCTC adoptions. Details about the identification, valuation, and design of JCTCs are provided in Appendix B.

Table 2 presents summary statistics for the employment level (in thousands), employment growth rate (in percentage points), and pecuniary value of the JCTC sorted by the JCTC status of states. As shown by the median values in panel A, column 2, the size (measured by employment) of the median delayed-JCTC state is somewhat larger (20\%) than for the median no-JCTC state, while the median immediate-JCTC state is much larger (65\%). In panel B, the median employment growth rates for delayed-JCTC and immediate-JCTC states are about equal $(0.112 \%$ and $0.106 \%$, respectively) but below the median growth rate for no-JCTC states of $0.149 \%$. Panel C documents that JCTCs tend to be more generous in the immediate-JCTC states. These latter two relations suggest that an evaluation of possible bias arising from the endogeneity of JCTC adoption with respect to employment growth is warranted. Consequently, before analyzing the impact of JCTCs on employment growth in Section IV, we first study the JCTC adoption decision and determine the statistical properties of the employment data. These results inform the specification of our empirical model in sub-section D.

\footnotetext{
${ }^{22}$ Business income taxes are generally corporate income taxes (assessed on "C-corporations") and individual income taxes, such as those assessed on S-corporations, limited liability partnerships, and other pass-through entities for which business income is passed through to owners as individual income. Texas has a franchise tax accessed on both types of business enterprises.
} 


\section{III.B. Understanding JCTC Adoption}

Apart from developing a better general understanding of JCTCs, analyzing the adoption decision is useful for assessing and possibly correcting for any endogeneity of JCTC adoption with respect to recent employment growth. It is worth noting that, for several of the JCTCs in our sample, the enacting legislation includes an explicit statement of objectives. In each case, the legislation emphasizes longer-term economic development objectives and/or state competitiveness and not short-term stimulus. Here are a few examples taken from enacted legislation:

* The Arkansas General Assembly recognizes that job creation and capital investment in Arkansas is dependent upon being competitive with other states for business locations and expansions.

* The objective of the job creation tax credit is to increase the number and quality of new jobs in [Maryland] by encouraging: A. Significant expansions of existing private sector enterprises; B. Establishment of new private sector enterprises; C. Creation of family supporting jobs; and D. Revitalization of neighborhoods and commercial areas.

* It is the intent of the Louisiana Legislature that: (1) The state of Louisiana provide appropriate incentives to support establishments of basic industries that hold the promise of significant development of the economy of the state of Louisiana. (2) The amount of such incentives provided in connection with a particular establishment shall...[B]e directly related to the jobs created as a result of the establishment locating in the state of Louisiana.... ${ }^{23}$

Of course, it is still possible that shocks affecting a state's recent employment growth will influence the timing and likelihood of that state adopting a JCTC. In particular, weak employment growth might make it more likely that JCTC legislation will be enacted and, with serial correlation in employment growth, OLS estimates of the effectiveness of the JCTC may be biased downward. To assess the potential importance of such endogeneity, we estimate the following logit equation ( $\Phi\{$.$\} ) containing lagged employment growth and controls,$

$\operatorname{PROB}\left\{\mathrm{D}_{\mathrm{i}, \mathrm{t}}^{\text {Signing }}=1\right\}=\Phi\left\{\right.$ LGROWTH $_{\mathrm{i}, \mathrm{t}}$, REPUBLICAN $_{\mathrm{i}, \mathrm{t}}$, COMPETITION $\left._{\mathrm{i}, \mathrm{t}}, \mathrm{CITR}_{\mathrm{i}, \mathrm{t}}, \mathrm{u}_{\mathrm{i}, \mathrm{t}}\right\}$,

${ }^{23}$ Oklahoma's JCTC legislation also includes this exact same language (apart from replacing "Louisiana" with "Oklahoma"). 
where $\mathrm{D}_{i, \mathrm{t}}^{\text {Signing }}$ is an indicator variable for the signing date in state $\mathrm{i}$ at time $t, \mathrm{PROB}[$.$] is the$ probability that $\mathrm{D}_{\mathrm{i}, \mathrm{t}}^{\text {Signing }}=1, \mathrm{LGROWTH}_{\mathrm{i}, \mathrm{t}}$ is employment growth defined below in eight different ways, REPUBLICAN ${ }_{\mathrm{i}, \mathrm{t}}$ is an indicator variable measuring the strength of Republican influence in state government, COMPETITION $\mathrm{i}_{\mathrm{t}, \mathrm{t}}$ is the fraction of bordering states with JCTCs, CITR $_{i, t}$ is the corporate income tax rate, and $u_{i, t}$ is an error term containing a white-noise component and a state fixed effect. Since there may be a number of factors determining JCTC adoption not included in equation (20), we also control for a time-invariant element of statespecific factors as a robustness check. With state fixed effects, consistent estimation is possible with a logit model but not a probit model (Cameron and Trivedi, 2005, Section 23.4).

Logit estimates of equation (20) are presented in Table 3. Since assessing the role of employment growth is the primary purpose of this exercise, we measure employment growth $\left(\right.$ LGROWTH $\left._{i, t}\right)$ eight different ways: employment growth in state i over four disjoint intervals defined from $\mathrm{t}-3$ to $\mathrm{t}, \mathrm{t}-6$ to $\mathrm{t}-3, \mathrm{t}-12$ to $\mathrm{t}-6$, and $\mathrm{t}-24$ to $\mathrm{t}-12$, and each of these growth rates relative to the average employment growth rate in the states bordering state $i$. Prior employment growth is not closely correlated with the JCTC adoption decision. Tests of the joint significance of employment growth rates (the penultimate bottom row of Table 3) have p-values that are very far from conventional significance levels. (Similar results are obtained when the employment growth rates are entered ad seriatim.) There is a marked difference in the coefficient estimates between column 1 (where state fixed effects are omitted) and the other four columns (where they are included and states without a JCTC are dropped because their dependent variable has no within-state variation). Importantly, there is no evidence in any of the five models indicating that employment growth influences JCTC adoptions in our sample.

For models including state fixed effects (columns 2 to 5), JCTC adoptions are influenced positively and significantly by competition from tax policies of bordering states. By contrast, there is no discernible relation between political party or own-state corporate income tax rates and JCTC adoption.

In sum, the results in Table 3 suggest that JCTCs are adopted as longer-term tax policy measures in response to a general desire to cut business taxes, promote economic development, and improve the state's competitiveness. They do not appear to be short-term, countercyclical 
policies responding to anemic employment. Most importantly for the validity of our estimates, there is no evidence for reverse causation from lagged employment growth to JCTC adoption. Nonetheless, as an additional safeguard against the adverse impact of endogeneity, we utilize these logit estimates for inverse probably weighting in our main empirical models, as explained in Section III.F.

\section{III.C. Properties of the Monthly Employment Data}

The statistical properties of the monthly employment data are important for proper specification of the econometric equation relating employment to JCTCs. We access stationarity with informal and formal tests. We first estimate models with log employment and the firstdifference of log employment as the dependent variable and the same set of independent variables: current, lagged (12 months), and led (12 months) dummies for the effective date of the JCTC and various lags of the dependent variable (LDV).

For the log levels equation, the LDV coefficient (when only one LDV is included) is close to one. For additional lags of the LDV, the sum of LDV coefficients is greater than one. Thus, the log levels equation would not appear to be a suitable specification for employment.

By contrast, for the log difference equation, the LDV coefficient (when only one LDV is included) is close to zero. Additional lags of the LDV yield coefficient sums that become positive and statistically significant, but the near constancy of the $\mathrm{R}^{2} \mathrm{~s}$ suggests that there is little additional explanatory power provided by extra lags. These results strongly suggest that employment is best modeled as a simple growth rate.

This initial conclusion is confirmed by a formal unit root test (Pesaran, 2007) that extends the standard augmented Dickey-Fuller test to allow for cross-sectional dependence. This test indicates that the log employment series has a unit root and confirms that employment should be modeled as a simple growth rate.

Taken together, the results presented in Section III.B and IIII.C indicate that an estimating equation with employment growth as the dependent variable and a measure of JCTCs as an independent variable will deliver consistent parameter estimates.

\section{III.D. Allowing For Imperfect Fiscal Foresight}

The model and empirical implications developed in Section II were based on the notion of "perfect fiscal foresight" where there is no uncertainty concerning the date at which the JCTC will become effective. After the signing date, the firm is certain when it can qualify for tax 
credits (no state has ever rescinded a credit before the qualifying date). Before the signing date, there is no anticipation of a JCTC adoption, and hence also no uncertainty. Such a formulation, while convenient analytically, could lead to a misspecified empirical model. Legislation is not created in a vacuum or as a "helicopter drop." Discussions about JCTCs may occur prior to the signing date, and they introduce the possibility of anticipation even prior to the signing date. We label the impact of this uncertain anticipation on firm behavior as "imperfect fiscal foresight" and expand the empirical model to include a PRE-SIGNING interval. ${ }^{24}$

To investigate the extent to which potential future JCTC legislation is "on the radar" of businesses and the public prior to the month in which the legislation is eventually signed, we conduct an extensive search for JCTC-related news articles in the states that eventually adopted a JCTC. Specifically, for each JCTC state, we used the Nexis search engine and Nexis' vast database of newspaper articles to identify articles that satisfy all of the following criteria: (1) classified by Nexis as being about that state, (2) published within six months of the signing month of that state's JCTC, (3) includes the word "governor" or "legislature" or "assembly", and (4) the list of subjects identified by Nexis for the article contains both "job creation" and "tax incentives." We then reviewed the search results and eliminated any articles that clearly were not about JCTC legislation. For each JCTC state, we counted the number of JCTC-related articles in each month from six months prior to signing to six months after signing. For each of these "event time" months, we then averaged over the 19 states. The results are shown in Figure 6. As expected, JCTCs are discussed most during the signing month, though there also are many articles in the subsequent month as well (note that, if the JCTC legislation is signed toward the

\footnotetext{
${ }^{24}$ More formally, one can think of agents in the current period $t$ having an expected value of the statutory tax credit rate $(\tau)$ that impacts the effective wage rate for any arbitrary future date $\mathrm{T}$. In a world with no pre-signing anticipation, $\mathrm{E}_{\mathrm{t}}\left[\tau_{\mathrm{T}}\right]=0$ for $\mathrm{t}<\mathrm{t}^{\mathrm{S}}$ and $\mathrm{E}_{\mathrm{t}}\left[\tau_{\mathrm{T}}\right]=\tau_{\mathrm{T}}$ for $\mathrm{t} \geq \mathrm{t}^{\mathrm{S}}$. That is, upon signing $\left(\mathrm{t} \geq \mathrm{t}^{\mathrm{S}}\right)$ there is perfect foresight (no uncertainty) about the value of the credit in any future period. In a world with presigning anticipation, $\mathrm{E}_{\mathrm{t}}\left[\tau_{\mathrm{T}}\right]=0$ for $\mathrm{t}<\mathrm{T}-\mathrm{J}^{\text {PRE-SIGN }} ; 0<\mathrm{E}_{\mathrm{t}}\left[\tau_{\mathrm{T}}\right]=\mathrm{p}_{\mathrm{t}}{ }^{*} \tau_{\mathrm{T}}<\tau_{\mathrm{T}}$ for $\mathrm{t}^{\mathrm{S}}-\mathrm{J}^{\text {PRE-SIGN }}<\mathrm{t}<\mathrm{t}^{\mathrm{S}}$; and $\mathrm{E}_{\mathrm{t}}\left[\tau_{\mathrm{T}}\right]=\tau_{\mathrm{T}}$ for $\mathrm{t} \geq \mathrm{t}^{\mathrm{S}}$, where $0<\mathrm{p}_{\mathrm{t}}<1$ is the probability of JCTC signing and $\mathrm{J}^{\text {PRE-SIGN }}$ is the number of months prior to JCTC signing in which agents begin placing a non-zero probability on that event. We would expect $p_{t}$ to be constant or increase with time during the PRE-SIGNING interval. Prior to the PRE-SIGNING interval, there is no perceived uncertainty and an expectation that the credit rate will remain at zero. During the PRE-SIGNING interval, agents believe there is a possibility of a non-zero credit rate at any future date and hence $0<\mathrm{E}_{\mathrm{t}}\left[\tau_{\mathrm{T}}\right]<\tau_{\mathrm{T}}$. Upon signing, all uncertainty is resolved and we return to perfect foresight where $\mathrm{E}_{\mathrm{t}}\left[\tau_{\mathrm{T}}\right]=\tau_{\mathrm{T}}$.
} 
latter part of a month, relevant news articles that occur only a few days later are counted in the subsequent month). Interestingly and consistent with imperfect fiscal foresight, JCTCs receive much attention several months before being signed into law. The peak is four months prior to the signing date. Six months prior to signing, attention is scarce. These data suggest that the PRE-SIGNING interval may be a maximum of six months. However, the extent to which firms actually alter behavior during this interval is an empirical matter and, as we shall see, is shorter than six months. ${ }^{25}$

\section{III.E. Specification Of The Estimating Equation}

With these conclusions in mind, we derive a regression specification relating employment growth to JCTCs and other likely determinants of employment growth,

$$
\begin{aligned}
& \Delta \mathrm{L}_{\mathrm{i}, \mathrm{t}} / \mathrm{L}_{\mathrm{i}, \mathrm{t}-1}
\end{aligned}
$$

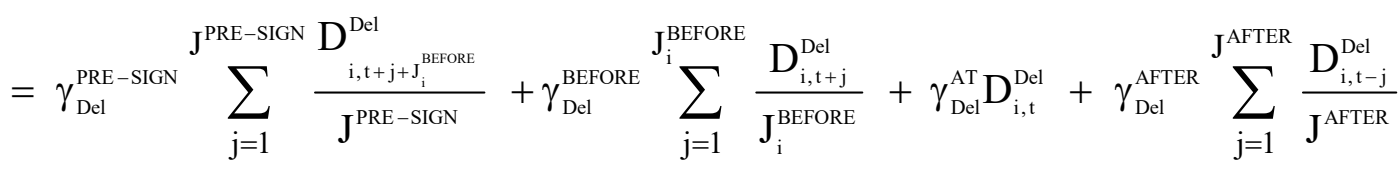

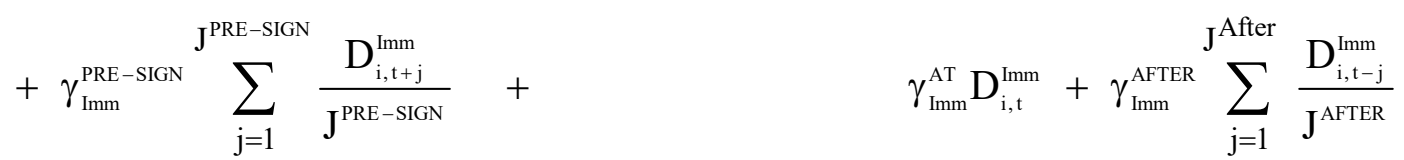

$$
\begin{aligned}
& +\kappa X_{i, t}+u_{i, t} \text {, }
\end{aligned}
$$

$\mathrm{D}_{\mathrm{i}, \mathrm{t}}^{\mathrm{Del}}$ is an indicator variable that equals one in the qualifying month for a delayed-JCTC state and equals zero otherwise. $D_{i, t}^{\operatorname{Imm}}$ is an indicator variable that equals one in the latter of the signing month and qualifying month for an immediate-JCTC state and equals zero otherwise. The parameter $\mathrm{J}^{\mathrm{PRE}-\mathrm{SIGN}}$ is the length of the PRE-SIGNING interval for state $i$; the baseline value is two months, though we vary this length from one to six months in Table 6 . The parameter $\mathrm{J}_{\mathrm{i}}^{\mathrm{BEFORE}}$ is the length of the BEFORE interval for state $i$ determined by each state's JCTC legislative history and the resulting "distance" between the signing and qualifying dates; the $i$ subscript indicates that the distance will vary by state. The AT interval is only one month

\footnotetext{
${ }^{25}$ It should also be emphasized that the existence of JCTC-related articles up to six months prior to the signing of legislation does not necessarily imply that the probability, as of six months prior, of JCTC legislation being enacted is much above zero. These articles only suggest that a future JCTC is being considered, not that it is necessarily probable. As noted earlier, the extent to which employers alter employment decisions in advance of a JCTC signing depends on their assessment of the probability of that signing eventually occurring.
} 
long. The parameter $\mathrm{J}^{\mathrm{AFTER}}$ is the length of the AFTER interval assumed to be the same for all states; the baseline value is 36 months, though we also set this length at 12 and 24 months in Table $4 .{ }^{26}$ The fiscal stimulus occurs only in the AT interval. The coefficient on the indicator variable for the AFTER interval captures lagged effects of the AT interval stimulus. Note that our theoretical framework predicts that, in the long run (steady-state), the level of employment induced by the JCTC is higher but bounded (see equation (14) raised to the power $\delta$ ). Hence, we assume that these lagged effects vanish after a certain horizon - i.e., the end of the AFTER interval. The purpose of dividing by the interval lengths is so that the $\gamma \mathrm{s}$ will reflect average monthly growth rate effects and can be compared across intervals of different lengths. The vector-valued variable $X_{i, t}$ represents control variables, $u_{i, t}$ is an error term that contains three components (discussed below), and $\kappa$ and the $\gamma \mathrm{s}$ are parameters to be estimated.

As highlighted by the theoretical model, there exists multiple intervals (PRE-SIGNING, BEFORE, AT, AFTER) in which employment is expected to respond differently to the JCTC. The object of our analysis is to generate consistent estimates of the $\gamma$ s for each interval and across the delayed-JCTC and immediate-JCTC regimes. Equation (21) is not a first-order condition from a structural model, and the $\gamma \mathrm{s}$ should not be interpreted as structural parameters. ${ }^{27}$ Rather, the $\gamma \mathrm{s}$ are average treatment effects measuring the impact on employment growth of the JCTC, by regime, on a monthly basis over an interval. Specifically, $\gamma_{\mathrm{Del}}^{\mathrm{PRE}-\mathrm{SIGN}}$ $\left(\gamma_{\mathrm{Imm}}^{\text {PRE-SIGN }}\right)$ is the average effect of a JCTC in a delayed-JCTC (immediate-JCTC) state during the PRE-SIGNING interval; $\gamma_{\mathrm{Del}}^{\mathrm{BEORE}}$ is the average effect of a JCTC in a delayed-JCTC state during the BEFORE interval; $\gamma_{\mathrm{Del}}^{\mathrm{AT}}\left(\gamma_{\mathrm{Imm}}^{\mathrm{AT}}\right)$ is the average effect of a JCTC in a delayed-JCTC (immediateJCTC) state during the AT interval; and $\gamma_{\text {Del }}^{\text {AFTER }}\left(\gamma_{\mathrm{Imm}}^{\mathrm{AFTER}}\right)$ is the average effect of a JCTC in a delayed-JCTC (immediate-JCTC) state during the AFTER interval.

\footnotetext{
${ }^{26}$ In the one case (Virginia) where the state repealed the JCTC, the AFTER interval is truncated if the number of months between the initial qualifying date and the withdraw date is less than the specified length of the AFTER interval (i.e., 12, 24. or 36 months).

${ }^{27}$ Recall from equations (17) and the surrounding text that the response of employment to the JCTC depends directly on the JCTC and indirectly on the JCTC-induced movement in $\phi$.
} 
The vector $\mathrm{X}_{\mathrm{i}, \mathrm{t}}$ in equation (21) represents four control variables included in the baseline model. One way to control for overall demand conditions in the state and avoid endogeneity problems is to include a measure of the state's exposure to particularly fast-growing or slowgrowing industries. For example, even in absence of any employment-inducing fiscal policies, a state with a large IT industry during the late 1990s was likely to experience rapid employment growth during that period. We control for industry-driven employment changes by first predicting a state's year-over-year employment growth rate with a weighted-average across industries of the national (excluding own-state) employment growth rates (year-over-year), where the weights are the state's employment shares in each industry. Multiplying this predicted annual growth rate by the level of own-state employment in period t-12 yields a predicted level of employment in period t. This "predicted" employment variable, $\mathrm{L}_{\mathrm{i}, \mathrm{t}}^{\mathrm{P}}$, was introduced by Bartik (1991) and is frequently referred to as the "Bartik shift-share variable." If the state is small relative to the nation, then this variable will not be correlated with the error term. Our empirical model is stated in terms of monthly growth rates, we therefore add the monthly growth rate of this predicted employment variable, $\Delta \mathrm{L}_{\mathrm{i}, \mathrm{t}}^{\mathrm{P}} / \mathrm{L}_{\mathrm{i}, \mathrm{t}-1}^{\mathrm{P}}$, to our baseline specification.

The three other control variables were included previously in the logit model. Section III.B documented that the adoption of a JCTC is positively influenced by JCTCs in effect in bordering states. Since one of the underlying channels of influence may be the effect of bordering state JCTCs on state $i$ 's employment, we include COMPETITION $_{i, t}$ as an additional control variable. The variable CITR $_{\mathrm{i}, \mathrm{t}}$ is also statistically significant in the logit model. Lastly, we include REPUBLICAN ${ }_{i, t}$ as a fourth control variable for completeness.

We model the error term in equation (21) with a conventional two-way error components structure,

$$
\mathrm{u}_{\mathrm{i}, \mathrm{t}}=\alpha_{\mathrm{i}}+\beta_{\mathrm{t}}+\varepsilon_{\mathrm{i}, \mathrm{t}}
$$

where $\alpha_{i}$ is a state-specific effect (for the employment growth rate), $\beta_{t}$ is a time fixed effect, and $\varepsilon_{\mathrm{i}, \mathrm{t}}$ is a white noise error term.

Substituting equations (22) into equation (21) and inserting the four control variables, we obtain the following estimating equation, 


$$
\begin{aligned}
& \Delta \mathrm{L}_{\mathrm{i}, \mathrm{t}} / \mathrm{L}_{\mathrm{i}, \mathrm{t}-1}
\end{aligned}
$$

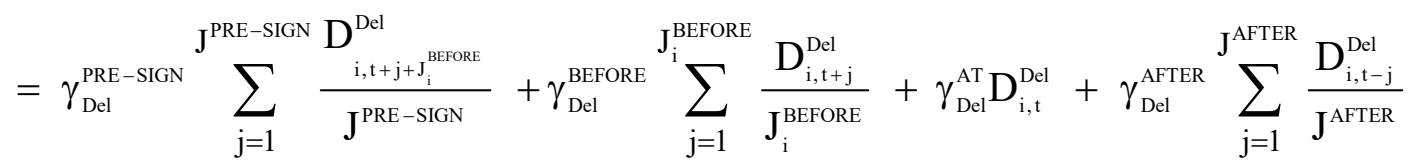

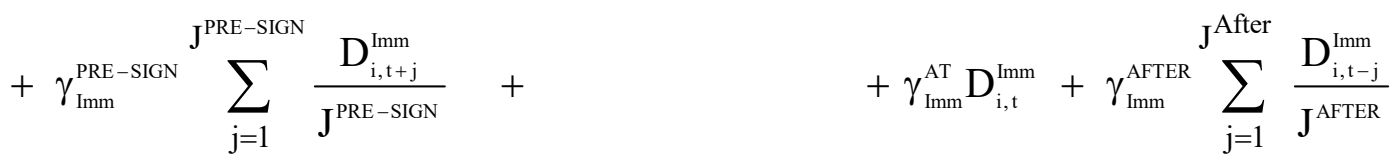

$$
\begin{aligned}
& +\kappa_{1}\left(\Delta \mathrm{L}_{\mathrm{i}, \mathrm{t}}^{\mathrm{P}} / \mathrm{L}_{\mathrm{i}, \mathrm{t}-1}^{\mathrm{P}}\right)+\kappa_{2} \text { COMPETITION }_{\mathrm{i}, \mathrm{t}}+\kappa_{3} \text { TAXRATE }_{\mathrm{i}, \mathrm{t}}+\kappa_{4} \text { REPUBLICAN }_{\mathrm{i}, \mathrm{t}} \\
& +\alpha_{i}+\beta_{t}+\varepsilon_{i, t}
\end{aligned}
$$

where the no-JCTC states serve as the control group.

Equation (23) uses simple indicator variables to represent the effects of the JCTCs and is our baseline model. However, an indicator variable cannot account for variation across states and intervals in the value of the tax credit. As indicated by the theoretical model, there are subtle relations between the JCTC and its ultimate incentive effects that may vary by state and by interval within a state. As an extension to the baseline empirical model, we also estimate a specification which attempts to capture this variation in pecuniary incentives. Specifically, we compute the logarithmic time differences of the effective wage rates entering the first-order conditions in equations (19) for the BEFORE and AT intervals. Per the discussion in sub-section III.D, the pecuniary incentives in the PRE-SIGNING interval are equated to those for the BEFORE interval. For the AFTER interval, the pecuniary incentives are zero (i.e., the JCTC adopted in the AT interval provides no additional stimulus in the AFTER interval). Nonetheless, we allow for lagged effects of the initial stimulus by including $\mathrm{J}^{\mathrm{AFTER}}$ lags of the stimulus in the baseline estimating equation (similar to the inclusion of $\mathrm{J}^{\mathrm{AFTER}}$ lags of $\mathrm{D}_{\mathrm{i}, \mathrm{t}-\mathrm{j}}^{\mathrm{Del}}$ and $\mathrm{D}_{\mathrm{i}, \mathrm{t}-\mathrm{j}}^{\mathrm{Im} m}$ in the indicator variable specification (equation 23)). We further assume that variations in JCTCs have no effect on the gross-of-JCTC wage rate and that the non-JCTC induced changes in the wage rate are captured by time and state fixed effects.

\section{III.F. Inverse Probability Weighting (IPW)}

While our logit estimates suggest that selectivity with respect to employment growth is not a problem that will adversely affect our estimates, endogeneity may occur for other reasons, especially arising from omitted variables. In order to further guard against the possible distorting effects, we obtain coefficient estimates using an Inverse Probability Weighting (IPW) estimator. 
The IPW is a type of matching estimator and is implemented in a two-step procedure (Hirano, Imbens, and Ridder, 2003). First, we use the logit model to estimate probabilities of "treatment" (i.e., the adoption of a JCTC) and non-treatment. We then estimate our main empirical model (equation (23)) using weighted least squares. The weight for each treated observation is the estimated inverse probability of treatment for that observation (given its values for the variables that go into the logit model). The weight for each non-treated observation is the estimated inverse probability of non-treatment (i.e., the inverse of one minus the probability of treatment) for that observation. Thus, the IPW is putting more weight on treated observations that are unlikely to have been treated and more weight on untreated observations likely to have been treated. This weighting moves the adjusted data closer to a randomized experiment (where all observations are equally likely to be treated).

The IPW works well when there is a close correspondence between the domains of the densities of the probability of a JCTC signing for those states that have adopted and those that have not adopted. The kernel densities of the probability of a JCTC signing presented in Figure 5 suggest that this criterion is met with the current application of the IPW. Moreover, as we shall see below, IPW and OLS (i.e., equal-weighted IPW) estimates are quite similar, suggesting informally that selectivity and omitted variables biases are of minimal concern in our data.

\section{EMPIRICAL RESULTS}

This section presents estimates of the impact of JCTCs on employment growth that allow us to assess the three key empirical relations summarized in Table 1:

1. The AD (Anticipatory Dip): $\gamma_{\text {Del }}^{\mathrm{PRE}-\mathrm{SIGN}} * \mathrm{~J}_{\mathrm{Del}}^{\mathrm{PRE}-\mathrm{SIGN}}+\gamma_{\mathrm{Del}}^{\mathrm{BEFORE}} * \mathrm{~J}_{\mathrm{Del}}^{\mathrm{BEFORE}}<0$,

2. The CR (Compensating Rebound): $\gamma_{\mathrm{Del}}^{\mathrm{AT}}>\gamma_{\mathrm{Imm}}^{\mathrm{AT}}$,

3. The CUM (Cumulative Effects): $\mathrm{CUM}_{\text {Del }}>0 ; \mathrm{CUM}_{\mathrm{Imm}}>0$.

Our baseline estimates are with the JCTC measured by an indicator variable and are presented in sub-section A. For the $\mathrm{AD}$, the $\mathrm{J}_{\mathrm{Del}}^{\mathrm{PRE}-\mathrm{SIGN}}$ and $\mathrm{J}_{\mathrm{Del}}^{\mathrm{BEFORE}}$ scalars are needed to compute the total effect over the intervals from the average monthly effects represented by the $\gamma \mathrm{s}$. The robustness of these results is examined in the additional empirical results presented in subsections $\mathrm{B}$ and $\mathrm{C}$. 


\section{IV.A. Baseline Estimates}

Table 4 contains our baseline estimates of the $\gamma$ coefficients for the four intervals for the delayed regime and the three intervals for the immediate regime, as well as their cumulative sums. The coefficient estimates are based on equation (23). The $\gamma$ for a given interval represents the conditional average employment growth per month (in percentage points) within the. The Cumulative Effect (CUM) sums the product of each $\gamma$ and the number of months in its interval for either the delayed or immediate regime. For the baseline model, the length of the PRE-SIGNING interval is two months. The length of the BEFORE interval varies by state, so we use its average length, 4.25 months, for this calculation. The length of the AT interval is one month. The length of the AFTER interval varies across the three sets of results for 12, 24, and 36 months (the latter will be our baseline value). The standard errors are robust to heteroskedasticity and to clustering of residuals by state. State clustering allows for general serial correlation of residuals, as recommended in Bertrand, Duflo and Mullainathan (2004).

We begin with the results in the first two columns for an AFTER interval of 12 months. For the delayed regime, the coefficients in the PRE-SIGNING and BEFORE intervals are -0.072 and -0.039 , respectively, and statistically significantly different from zero individually and jointly (summed and weighted by $J_{\text {Del }}^{\mathrm{PRE}-S I G N}$ and $\mathrm{J}_{\text {Del }}^{\mathrm{BEFORE}}$ ). These coefficients indicate that employment growth in delayed-JCTC states before the qualifying date of the tax credit is 0.320 $(=-0.072 * 2-0.039 * 4.5)$ percentage points lower than it would have been without the credit adoption. This represents a $285 \%$ reduction relative to the median monthly employment growth in delayed-JCTC states of 0.112 (see Table 2). An AD is clearly identified for the delayed regime.

The CR is evaluated by comparing employment growth in the AT interval across regimes. The coefficients for the delayed and immediate regimes are 0.141 and 0.043 , respectively; only the former coefficient is statistically different from zero. For the regression in columns 1 and 2, when the AFTER interval is 12 months, this difference is 0.098 , which is economically large and statistically significant (with a p-value of 0.099).

By contrast, the third empirical relation noted at the beginning of this section is not fully supported. While the CUM for immediate-JCTC states is positive and statistically significant, the CUM for delayed-JCTC states is negative and not statistically different from zero. 
A possible explanation of the CUM results is that some firms adjust slowly to the tax incentive and 12 months is too short a period to capture the ultimate responses to the JCTCs. These laggard firms, relative to those responding in the AT interval, may be more bureaucratic or face a small pool of available workers. Given the rolling base feature of JCTCs, the firm has only a modest incentive to take the credit as soon as possible. The financial incentive to hire today and take the credit vs. delaying the new hire until tomorrow is the one-period discount factor, approximately $6.5 \%$ of the legislated tax credit. This small gain has to be balanced against adjustment frictions and disruptions from accelerated hiring. This adjustment may be even slower for firms in delayed-JCTC states, whose employment and production decisions have been disrupted by the AD. Consequently, new employment may occur very gradually for some firms, and it may take several years for the full effects of the JCTC to be reflected in employment growth.

This conjecture is examined in the remaining entries in Table 4, which extends the length of the AFTER interval from 12 to 24 and 36 months in two separate regressions. Since the intervals are largely orthogonal to each other, these extensions have no noticeable effect on other coefficients, and the $\mathrm{AD}$ and $\mathrm{CR}$ are similar in these specifications. The AD estimates are stable across models with an approximate value of 0.30. In all three models, the AD is highly statistically significant, with a p-value below 0.001 . The $\mathrm{CR}$ is also stable across models, with a point estimate around 0.10 and a p-values below 0.10 . The $\gamma$ coefficients for the AFTER interval become precisely estimated when the interval length is 36 months and, interestingly, CUMs for the delayed and immediate regimes are nearly identical, though only the CUM for immediate-JCTC states is precisely estimated. For an AFTER interval of 36 months, the results are largely consistent with the three empirical implications listed at the beginning of this section.

The quantitative importance of ADs for JCTCs documented in Table 4 suggests that ignoring fiscal foresight can lead to incorrect inferences regarding both short-run and longer-run policy impacts when the policy is anticipated. First, it is clear that the sharp boost in employment growth that occurs in delayed-JCTC states in the month in which the credits go into effect is not an accurate assessment of the short-run effectiveness of the credit. Rather, it mostly reflects the Compensating Rebound in employment growth following on the Anticipatory Dip. The true short-run impact of these credits is better revealed by the small and statistically 
insignificant AT interval effect for immediate-JCTC states. Another way to see this point is to consider what inference researchers might draw if they evaluated the impact of JCTCs using the standard event study approach, ignoring fiscal foresight. In that case, they would not distinguish between delayed-JCTC and immediate-JCTC states and they would not account for any potential drop in employment growth prior to the AT interval. In other words, they would simply regress employment growth on the JCTC indicator in the AT interval (along with controls and state and month fixed effects). We find that such a regression yields an AT effect of 0.074 (with a p-value of 0.026$), 65 \%$ larger than the size of the AT interval effect for immediate-JCTC states from Table 4. Again, this estimate would give a misleading impression of the effectiveness of JCTCs because part of this effect is due to fiscal foresight, specifically the CR for the delayed-JCTC states.

Second, ignoring fiscal foresight can also lead to incorrect inferences regarding the longer-run impact of JCTCs. Consider the estimated cumulative effect of JCTCs on employment in Table 4 when AFTER equals 36 months. We see that the cumulative effect for delayed-JCTC states would be raised by $34 \%$ (to 1.104 from 0.821 ) if we ignored the decrease during the PRESIGNING and BEFORE intervals. ${ }^{28}$

\section{IV.B. An Alternative Measure Of The JCTC}

Measuring the JCTC with an indicator variable has the advantage that it is likely to have much less measurement error than a variable that reflects the complexities of the legislated tax code (e.g., refundability, transferability, tax credit caps) that cannot be reflected in a single figure. In such a situation, using a coarse categorical variable may lead to less biased econometric estimates. Nonetheless, the baseline results could be misleading for two reasons. If the effective JCTC is relatively higher for delayed-JCTC states, the larger increase we observe at the AT intervals may be due to the larger effective JCTCs, not the CR effect that seems to be documented in Table 4 . The summary statistics suggest that this is not a concern, as the median credit value, as a percent of the state's average manufacturing wage, for delayed-JCTC states is $3.4 \%$, while that for immediate-JCTC states is 5.0\% (see Table 2, Panel C).

\footnotetext{
${ }^{28}$ This figure is computed as follows: $1.104=(0.821-\mathrm{AD})$, where $\mathrm{AD}=-0.283(=-0.067 * 2.00-0.033$ *4.5 months), where 2.00 is the length of the PRE-SIGNING interval and 4.25 months the average length (for delayed-JCTC states) of the BEFORE interval.
} 
Our theoretical model suggests that a second source of bias may occur because the incentives induced by JCTCs vary by regime and interval and hence the responses of employment growth might differ across regimes and intervals. To account for these possibly distorting effects, we replace the JCTC indicator variables in equation (23) with the pecuniary values of JCTCs as suggested by our theoretical model (equations (19)). For delayed-JCTC states, the model implies that the regressors for employment growth are $-\tau_{i} /(1+\rho)$ for the BEFORE interval and $\tau_{i}$ for the AT and AFTER intervals $\left(\gamma_{\text {Del }}^{\text {PRE-SIGN }}\right.$ and $\gamma_{\text {Del }}^{\text {BEFORE }}$ is multiplied by -1 in Table 5). ${ }^{29}$ For immediate-JCTC states, the regressor is $\tau_{\mathrm{i}} *(\rho /(1+\rho))$ for the AT and AFTER intervals. ${ }^{30}$ We assume $\rho$ is a real discount rate of $7 \%$. Note that the legislated credit rates, $\tau_{i}$, and hence the incentive effects, vary by state.

The results with these pecuniary measures of the JCTCs are presented in Table 5, though the absence of some required information on the value of tax credits reduces the number of JCTC states used in this empirical analysis by $26 \%$. For an AFTER interval of 36 months, the pattern of results is very similar to those with the indicator variable reported in Table 4: an AD and CR are evident, and the CUMs are positive. The prominent difference in the results is that most of the coefficients are now less precisely estimated. As noted above, we attribute this imprecision to the measurement error in the pecuniary JCTC variable. The results in Table 5 document that our baseline results are qualitatively robust to conditioning on the value of the JCTC.

\section{IV.C. Additional Empirical Results}

This sub-section presents seven additional empirical results that provide robustness checks and identify estimation biases.

First, recall that our baseline sample includes JCTCs through 2007 and employment data through 2010 in order to allow for at least 36 months of post-credit employment dynamics. A potential concern is that including employment during the Great Recession in our sample could

\footnotetext{
${ }^{29}$ The PRE-SIGNING interval was not part of the theoretical model, and the appropriate regressor for the delayed-JCTC states is $-\tau_{\mathrm{i}} /(1+\rho)$ multiplied by -1 .

${ }^{30}$ For the purposes of exposition, we present here the first-order Taylor approximations of the logarithmic differences rather than the full (messier) expressions of the logarithmic differences. We compute the regressors using the full expressions.
} 
be problematic because of the dramatic labor market contractions during the Great Recession, which began in December 2007. To evaluate this potential bias, we re-run the baseline models in Table 4 using employment data only through December 2007 (and hence including only the 17 JCTCs adopted as of December 2004 to allow for 36 months of employment dynamics). The results are shown in Appendix C, Table 1 and are similar to the baseline results in Table 4. For delayed-JCTC states, in the specification with an AFTER interval of 36 months, the coefficients for the PRE-SIGNING, BEFORE, and AT intervals for the delayed regime are very close to the comparable coefficients in Table 4. The coefficient for the AFTER interval is lower and less precisely estimated, and hence so is CUM. For immediate-JCTC states, the PRE-SIGNING coefficient is a bit smaller, the AT coefficient larger, and the AFTER coefficient and CUM effect largely unchanged, though both of the latter coefficients are less precisely estimated. In sum, apart from the precision of the estimates (recall the reduction in the number of JCTC "events"), the results are largely robust to excluding the effects of the Great Recession.

Second, timing is very important in our study. We have been able to identify the precise months for the JCTC signing and qualifying months and have used this information to guide our empirical work. However, as discussed in sub-section III.D, firms may anticipate the signing of JCTC legislation and reduce employment accordingly. ${ }^{31}$ The results of our analysis of news articles reported in Figure 6 indicated that JCTCs are in the news up to five months before the tax credit is signed into law. It is thus useful to examine the sensitivity of our empirical results to variations in the length of the PRE-SIGNING interval of one, two, four, or six months. For delayed-JCTC states, statistically significant coefficients for the PRE-SIGNING interval are obtained for an interval length of one and two months. Recall that the reported coefficients are averages for the interval, and hence the overall impact for the two-month interval is nearly twice as large as that for the one-month interval. Based on these results, we select a PRE-SIGNING interval of two months for our baseline model. For immediate-JCTC states, there is no evidence of a pre-signing effect.

Third, our assessments are also not sensitive to the control variables. Estimates without control variables are presented in Table 7, columns 3 and 4 (the first two columns in Table 7

\footnotetext{
${ }^{31}$ Kueng (2015) documents such an anticipation signing effect for municipal bondholders and federal personal income tax rates.
} 
report our baseline results). While three of the four control variables listed in equation (23) are statistically significant, excluding all four control variables has little effect on the estimated coefficients in the PRE-SIGNING, BEFORE, and AT intervals. The only change is that the AFTER coefficient for delayed-JCTC states falls by $26 \%$ relative to the baseline model.

Fourth, tax legislation is sometimes passed as a package involving changes in several tax instruments (Wildasin, 2007). Our baseline specification includes the corporate income tax rate as a control, and we explore the robustness of our results by adding the state fixed investment tax credit rate and the state research and development tax credit rate to the baseline specification. The results of repeating the regressions underlying Table 4 while including these two additional controls are shown in Appendix C, Table 2. As above, the baseline results are very insensitive to the inclusion of these two additional control variables.

Fifth, by contrast, the results are sensitive to the exclusion of state and time fixed effects. Table 7 presents the baseline model without state fixed effects (columns 5 and 6) or without time fixed effects (columns 7 and 8); in both cases, the control variables are also excluded. Removing state fixed effects leads to bifurcated results. The estimated $\gamma \mathrm{s}$ for the PRE-SIGNING, BEFORE, and AT intervals are fairly stable and continue to confirm the presence of an AD and CR. However the AFTER coefficients drop sharply, and the CUMs turn negative. Excluding the state effects would likely lead to a misspecified model. Examining the role of incentives (as a \% of value added), Upjohn (2016) reports that state dummies (entered in isolation with no interaction effects) capture $80 \%$ of the total explained variation (in a model with state, industry and time fixed effects) and $53 \%$ of the overall variation in incentives. Removing time fixed effects impacts most of the coefficients. In sum, including state and time fixed effects are important for consistently and precisely estimating the cumulative effects of JCTCs.

Sixth, a perennial concern in policy event studies is selectivity. In the present case, it is possible that deficient employment growth might lead to the passage of JCTC legislation. This concern has been addressed and largely discounted by the logit models presented in Section III.B and Table 3. Moreover, the Inverse Probability Weighting (IPW) estimator discussed in Section III.E adjusts for selectivity or, more generally, various sources of endogeneity that may bias estimates. An informal test for the importance of endogeneity compares the IPW and OLS estimates, the latter possibly influenced by endogeneity. The OLS estimates prove to be quite 
similar to those presented previously in Table 4 with the exception of the AFTERDel coefficient and the related CUMDel. For an AFTER interval of 36 months, we have PRE-SIGNINGDel = $-0.071[p=0.068]$, PRE-SIGNING ${ }_{I m m}=0.050$ [0.178], BEFORE $=-0.040$ [0.057], $\mathrm{AT}_{\text {Del }}=$ 0.119 [0.023], $\mathrm{AT}_{\mathrm{Imm}}=0.059$ [0.073], AFTER ${ }_{\text {Del }}=0.018$ [0.143], $\mathrm{AFTER}_{\mathrm{Imm}}=0.021$ [0.076], $\mathrm{CUM}_{\text {Del }}=0.453$ [0.334], and $\mathrm{CUM}_{\mathrm{Imm}}=0.900$ [0.056]. Our conclusions about the $\mathrm{AD}$ and $\mathrm{CR}$ seem unaffected by selectivity or other sources of endogeneity.

Seventh and finally, the tax competition literature suggests that JCTC-induced increases in employment growth might create interstate spillovers, which could be negative or positive. In particular, a JCTC in one state could draw jobs away from other states or, alternatively, the stimulus to economic activity in the JCTC state could "leak" out to other states via induced upstream demand. Understanding spillovers is of particular importance if our results based on state tax credits are to inform the policy debates surrounding a potential federal JCTC. If positive (negative) spillovers exist, then our estimates are a lower (upper) bound on the likely effect of a federal tax credit because interstate mobility of labor and intermediate inputs is much greater than international mobility.

To examine spillovers, we analyze the effect of JCTCs on employment growth in neighboring states. If the employment growth associated with a JCTC is largely coming at the expense of neighboring states, then we would expect the JCTC for state $i$ to have a negative impact on employment growth in neighboring states. Conversely, if there is leakage of induced upstream demand to neighboring states, we would expect a given state's JCTC to have a positive impact on employment growth in those states. We test these propositions by forming for state $i$ its spatial lag of employment growth. The spatial lag is simply an equal-weighted average of employment growth in neighboring states. We then run the following model, which has the same specification as our baseline model (equation (23)) except that the dependent variable is the spatial lag of employment growth instead of own-state employment growth, 


$$
\begin{aligned}
& \mathrm{S}\left\{\Delta \mathrm{L}_{\mathrm{i}, \mathrm{t}} / \mathrm{L}_{\mathrm{i}, \mathrm{t}-1}\right\} \\
& =\chi_{\text {Del }}^{\text {PRE-SIGN }} \sum_{j=1}^{J^{\text {PRE-SIGN }}} \frac{D_{i, t+j+J_{i}^{\text {BEFoRE }}}^{\text {Del }}}{J^{\text {PRE-SIGN }}}+\chi_{\text {Del }}^{\text {BEFORE }} \sum_{j=1}^{J_{i}^{\text {BEFORE }}} \frac{D_{i, t+j}^{\text {Del }}}{J_{i}^{\text {BEFORE }}}+\chi_{\text {Del }}^{\text {AT }} D_{i, t}^{\text {Del }}+\chi_{\text {Del }}^{\text {AFTER }} \sum_{j=1}^{J^{\text {AFTER }}} \frac{D_{i, t-j}^{\text {Del }}}{J^{\text {AFTER }}} \\
& +\chi_{\text {Imm }}^{\text {PRE-SIGN }} \sum_{j=1}^{J^{\text {PRE-SIGN }}} \frac{D_{i, t+j}^{\text {Imm }}}{J^{\text {PRE-SIGN }}}+\quad+\chi_{\text {Imm }}^{\text {AT }} D_{i, t}^{\text {Imm }}+\chi_{\text {Imm }}^{\text {AFTER }} \sum_{j=1}^{J^{\text {After }}} \frac{D_{i, t-j}^{\text {Imm }}}{J^{\text {AFTER }}} \\
& +\kappa_{1}\left(\Delta \mathrm{L}_{\mathrm{i}, \mathrm{t}}^{\mathrm{P}} / \mathrm{L}_{\mathrm{i}, \mathrm{t}-1}^{\mathrm{P}}\right)+\kappa_{2} \text { COMPETITION }_{\mathrm{i}, \mathrm{t}}+\kappa_{3} \text { TAXRATE }_{\mathrm{i}, \mathrm{t}}+\kappa_{4} \text { REPUBLICAN }_{\mathrm{i}, \mathrm{t}} \\
& +\alpha_{i}+\beta_{t}+v_{i, t} \text {, }
\end{aligned}
$$

where $\mathrm{S}\{$.$\} is a spatial lag operator that weights only the neighboring states. { }^{32}$ The $\chi \mathrm{s}$ are estimated coefficients that capture interstate effects.

The results are shown in Table 8 with three different definitions of neighboring states all bordering states equally weighted (columns 1 and 2), all other 47 states supplier-trade weighted (columns 3 and 4), and the five closest states inverse-distance weighted (columns 5 and 6. All estimates are based on PRE-SIGNING and AFTER intervals of two and 36 months, respectively. With the exception of the PRE-SIGNING interval for immediate states, all of the coefficients are imprecisely estimated. We thus find no evidence that spillovers are quantitatively important.

\section{IV.D. Cost per job created And the JCTC Fiscal Multiplier}

Are JCTCs effective state policy tools? How does the job creation they induce compare to that achieved by other government policies? As a final exercise, we address these questions by presenting a back-of-the-envelope calculation of the cost per job created (or retained) for the average JCTC-adopting state and the associated JCTC fiscal multiplier.

The cost of a given state's JCTC program over the event window from signing date less the two months for the pre-signing interval $\left(\mathrm{t}_{\mathrm{i}}^{\mathrm{S}}-2\right)$ to 36 months after the qualifying date is as follows,

\footnotetext{
${ }^{32}$ An alternative specification might regress own-state employment growth on a spatial lag of neighboring-states JCTCs. We chose equation (24) because the lengths of BEFORE intervals vary by state and thus it is not straightforward to calculate a spatial lag of the BEFORE indicator variables.
} 


$$
\mathrm{C}_{\mathrm{i}}=\left(\mathrm{g}_{\mathrm{i}}^{\mathrm{CF}}+\mathrm{CUM}_{\mathrm{i}}\right) * \mathrm{~L}_{\mathrm{i}, \mathrm{s}} * \mathrm{w}_{\mathrm{i}} * \tau_{\mathrm{i}},
$$

where $\mathrm{L}_{\mathrm{t}_{1}^{\mathrm{s}}}$ is the level of employment in state $i$ as of its JCTC signing date, $w_{i}$ is its average annual wage, $\tau_{\mathrm{i}}$ is the legislated credit rate (as a percentage of the wage), CUMi is the cumulative growth rate of employment over the event window due to the tax credit, and $\mathrm{g}_{\mathrm{i}}^{\mathrm{CF}}$ is the (counterfactual) growth rate of employment that would have occurred in the absence of the tax credit. Thus, $\mathrm{g}_{\mathrm{i}}^{\mathrm{CF}} * \mathrm{~L}_{\mathrm{i}, \mathrm{t}_{\mathrm{i}}^{\mathrm{s}}}$ is the inframarginal amount of net job creation subsidized via the tax credit even though it would have occurred anyway, and $\mathrm{g}_{\mathrm{i}}^{\mathrm{CF}} * \mathrm{~L}_{\mathrm{i}, \mathrm{t}_{\mathrm{i}}^{\mathrm{S}}} * \mathrm{w}_{\mathrm{i}} * \tau_{\mathrm{i}}$ is the total amount of inframarginal subsidy.

The number of jobs created in a given state by its JCTC is given by the following equation,

$$
\mathrm{JC}_{\mathrm{i}}=\mathrm{CUM}_{\mathrm{i}} * \mathrm{~L}_{\mathrm{i}, \mathrm{t}_{\mathrm{i}}^{\mathrm{s}}} \text {. }
$$

(We are assuming that, if firms react to the incentive, they do so within 36 months after the qualifying date.) Therefore, the cost per job created $\left(\mathrm{CPJC}_{\mathrm{i}}\right)$ in state $i$ is:

$$
\mathrm{CPJC}_{\mathrm{i}}=\frac{\left(\mathrm{g}_{\mathrm{i}}^{\mathrm{CF}}+\mathrm{CUM}_{\mathrm{i}}\right) * \mathrm{~L}_{\mathrm{i}, \mathrm{i}}^{\mathrm{S}} * \mathrm{w}_{\mathrm{i}} * \tau_{\mathrm{i}}}{\mathrm{CUM}_{\mathrm{i}} * \mathrm{~L}_{\mathrm{i}, \mathrm{i}_{\mathrm{i}}^{\mathrm{S}}}}=\underbrace{\frac{\mathrm{CUM}_{\mathrm{i}}}{\mathrm{CUF}_{\mathrm{i}} * \mathrm{w}_{\mathrm{i}} *} \tau_{\mathrm{i}}}_{\substack{\text { Inframarginal } \\ \text { Subsidy }}}+\underbrace{\mathrm{w}_{\mathrm{i}} * \tau_{\mathrm{i}}}_{\substack{\text { Marginal } \\ \text { Subsidy }}} .
$$

The first term of the final equation is the inframarginal subsidy, the cost of the tax credit that went to subsidizing job creation that would have occurred anyway. The second term is the marginal subsidy, the cost that went to subsidizing the job creation that was due to the tax credit.

We calculate the CPJC along with the inframarginal and marginal components, for the average delayed-JCTC state and for the average immediate-JCTC state. For the average delayed-JCTC state, we calculate $\mathrm{g}^{\mathrm{CF}}$ by converting the average monthly employment growth rate over delayed-JCTC states, excluding months in the event window, to a growth rate over 43.5 months, the average length of the event window for delayed-JCTC states. ${ }^{33}$ Similarly, for the

\footnotetext{
${ }^{33}$ The computation for delayed-JCTC states is as follows: $43.5=36.0+1.0+4.5+2.0$, the number of average months in the AFTER, AT, BEFORE, and PRE-SIGNING intervals, respectively. The computation for immediate-JCTC states is similar but excludes the length of the BEFORE interval of 4.5.
} 
average immediate-JCTC state, we calculate $\mathrm{g}^{\mathrm{CF}}$ by converting the average monthly employment growth rate over those states, excluding months in the event window, to a 39 month growth rate, the length of the event window for immediate-JCTC states. These counterfactual growth rates are $3.96 \%$ and $3.10 \%$ for delayed-JCTC and immediate-JCTC states, respectively. We calculate the average nominal credit value $\left(\mathrm{w}^{*} \tau\right)$, by regime, from the data on average annual wages in manufacturing $(\$ 52,774$ for delayed-JCTC states and $\$ 36,629$ for immediateJCTC states) and the data described in Table 2 on mean legislated credit rates. The CUM, by regime, comes from Table 4 (with AFTER $=36$ months) and is approximately 0.0083 for both regimes.

The results of these calculations are shown in Table 9. For the average delayed-JCTC state, the CPJC is $\$ 14,511$. The marginal subsidy portion of this cost is simply the average nominal credit per job, $\$ 2,491$. The remaining $\$ 12,020$, or $83 \%$, is a subsidy to inframarginal job creation. For the average immediate-JCTC state, the CPJC is $\$ 19,479$, of which $21 \%$ is due to the marginal subsidy and $79 \%$ is a subsidy to inframarginal job creation. The average cost per job created across all states is a little under $\$ 18,000$, with about $80 \%$ of this cost being an inframarginal subsidy.

Several other studies have quantified the effects of employment-related tax credits. ${ }^{34}$ Kesselman, Williamson, and Berndt (1977) estimate a translog cost function on U.S. manufacturing data. Their estimates imply a cost per job created of $\$ 13,239$, about $25 \%$ lower than the figure based on our estimates in Table 9. ${ }^{35}$ Faulk (2002) examines an incremental job tax credit in Georgia. With cross-section data, she estimates separate employment equations for

\footnotetext{
${ }^{34}$ See Neumark (2013) and Neumark and Troske (2012) for surveys of this literature's policy recommendations.

${ }^{35}$ We compare the effective wage elasticities from the two studies. The Kesselmen, Williamson, and Berndt elasticity is based on the data in their Table 2, panel 4: column 1 (or column 2) for the wage change and column 7 for the employment change. (The resulting $0.130 \%$ elasticity is an average of the four entries in this table.) The Chirinko and Wilson elasticity is our estimated percent change in employment $(\mathrm{CUM}=0.0083)$ divided by the average percent change in the effective wage rate due to JCTCs. The latter is the weighted-average mean JCTC dollar amount divided by the weighted-average mean wage, averaging across the two JCTC regimes (6/19 weight on Delayed-JCTC states and 13/19 weight on Immediate-JCTC states). The Kesselmen et al. elasticity of 0.130 is $48 \%$ larger than our elasticity of 0.088 . We insert $\mathrm{CUM}^{\mathrm{Kesselmen}}=0.0083 * 1.48=0.012$ into equation (27) to get the $\$ 13,239$ cost per job created estimate implied by Kesselman et al.
} 
eligible firms that are participating or non-participating in the Georgia program and a probit selection equation to determine participation. For those eligible firms participating in the program, employment rose by between 23 to 28 percent. The cost was between $\$ 2,280$ and $\$ 2,680$ per job created.

More recently, Bartik and Bishop (2009) undertake a detailed simulation exercise of a temporary federal JCTC valued at 15\% of the wage cost of new employment in 2010 and $10 \%$ in 2011. They conclude that the cost per job created would be $\$ 4,656$ in 2010 and $\$ 6,301$ in 2011. These estimates include important macroeconomic feedback effects. With these excluded, their estimates can be compared to those in Table 9, and their estimated cost per job created is approximately $\$ 37,000$. Cahuc, Carcillo, and Le Barbanchon (2016) evaluate a French hiring credit that was temporary, unexpected, and targeted to low income workers in very small firms. Based on their estimated structural model, they conclude that the gross cost per job created for this credit is about one fourth of the average annual wage, which would correspond to roughly $\$ 10,000$ in the U.S. They estimate a permanent credit in an environment of flexible wages would have a cost per job created 14 times larger.

The studies above focused specifically on job creation tax credits. Recent years have also seen broader fiscal policy efforts aimed at stimulating employment growth. In particular, the American Recovery and Reinvestment Act (ARRA) sought to stimulate employment growth through a combination of federal spending and tax cuts. A number of recent studies have estimated the cost per job created of the ARRA spending. Wilson (2012) examined the impact of ARRA spending on job creation at the state level using exogenous formula apportionment of ARRA funds as an instrument for total ARRA spending by state. He estimated the cost per job created (or saved) from the spending to be around $\$ 125,000$. This estimate falls roughly in the middle of other cross-state analyses of the cost per job created of ARRA spending, such as the $\$ 202,000$ obtained by Conley and Dupor (2013) and the $\$ 26,000$ obtained by Chodorow-Reich, Feiveson, Liscow, and Woolston (2012).

Thus, even the lowest estimates of the cost per job created from the broad fiscal stimulus of the ARRA are well above our estimate of the cost per job created associated with JCTCs. Moreover, our CPJC estimates are for permanent JCTCs. The evidence cited above indicates that the CPJC from temporary JCTCs is likely to be even lower. This suggests temporary 
incentives targeted specifically at job creation may be more cost-effective policies for stimulating employment than general government spending.

Our CPJC estimate can be mapped into a fiscal multiplier of interest to macroeconomists and macro-policymakers and comparable to fiscal multipliers on government consumption expenditures appearing in the literature. ${ }^{36}$ The fiscal multiplier, $\Delta \mathrm{Q} / \Delta \mathrm{G}$, is defined as the change in output due to a $\$ 1$ change in government expenditures. Here, $\Delta \mathrm{G}$ is the increase in tax expenditures associated with a JCTC. Two steps are required to complete the mapping,

$$
\frac{\Delta \mathrm{Q}}{\Delta \mathrm{G}}=\frac{\Delta \mathrm{L}}{\Delta \mathrm{G}} * \frac{\Delta \mathrm{Q}}{\Delta \mathrm{L}}
$$

$\Delta \mathrm{L} / \Delta \mathrm{G}$ would appear to be just the inverse of the CPJC. In this case, our CPJC estimate of $\$ 18,000$ implies that 56 new jobs would be created by one million dollars of JCTC tax expenditures. However, this employment increase is a mixture of substitution and income effects; only the latter effect increases output in our partial equilibrium exercise. Using a CES production function and the conditions characterizing optimal behavior, we isolate the income effect (see Appendix D for the derivation). For a newly-enacted JCTC, the percentage change in employment due to factor substitution equals the substitution elasticity among productive factors multiplied by the percentage change in the effective wage rate. The latter is the statutory value of the JCTC adjusted for the rolling base feature of the tax credit. For a substitution elasticity of 1.0 (i.e., a Cobb-Douglas production function), we find that the substitution effect is $74 \% .{ }^{37}$ Hence the income effect is $26 \%$., and the first object in equation (28) is computed as follows, $\Delta \mathrm{L} / \Delta \mathrm{G}=56 * 0.26 \approx 15$. Of the 56 jobs created by one million dollars of JCTC tax expenditures, 15 jobs are due to higher output while the remaining 41 jobs are due to substitution toward labor away from capital and other productive factors.

The second step, calculating $\Delta \mathrm{Q} / \Delta \mathrm{L}$, translates the 15 jobs coming initially from JCTCinduced higher output into the corresponding change in GDP. We adopt a relatively simple and direct procedure for estimating this correlation, regressing the change in quarterly real GDP on the change in quarterly private nonfarm payroll employment for the period 1990:Q1 to 2010:Q4 (similar to an Okun's Law estimation but using employment instead of unemployment and the

\footnotetext{
spending multiplier.

${ }^{37}$ If the substitution elasticity is 0.50 , the substitution effect would be $37 \%$.
}

${ }^{36}$ We thank Olivier Blanchard for raising the question about the relation between our CPJC and the 
absolute change in GDP instead of its percentage change). This regression implies that an increase (decrease) of one private nonfarm job is on average associated with an increase (decrease) of $\$ 111,000$ (2009 real chained dollars) in GDP. Thus, \$1 million of JCTC tax expenditures is estimated to generate $\$ 1.66$ million of output $(\$ 111,000 * 15)$ - an output multiplier of about 1.66. This multiplier is in the upper range of estimates found in the literature, a result that follows straightaway from our relatively low cost per job created estimates. Nonetheless, one should keep in mind that this multiplier is a rather rough estimate. It is sensitive to the assumed elasticity of substitution between capital and labor, and it abstracts from general equilibrium effects such as the JCTC raising the pre-credit wage and labor supply.

\section{CONCLUSIONS}

This paper uses the experience of 19 U.S. states to inform policy discussions about fiscal foresight and the effectiveness of job creation tax credits (JCTCs). The relevant legislative dates for all broad-based state JCTCs passed in the U.S. since 1990 are compiled. Important for our analysis of fiscal foresight, the JCTCs are of two types, ones that take effect with a delay and others that take effect immediately. We develop a theoretical model that captures the effects of the rolling base feature of JCTCs and shows that this feature is quantitatively very important. The theoretical model highlights three key conditions necessary for the existence of fiscal foresight and delivers a set of empirical predictions evaluated in an event study framework.

Our econometric estimates lead to several conclusions. Fiscal foresight matters. Based on our unique dataset, we document the quantitative importance of Anticipatory Dips (ADs) and Compensating Rebounds (CRs). This intertemporal behavior runs counter to policy objectives and makes it difficult to accurately evaluate the impacts of fiscal policy. The evidence based on JCTCs suggests that failing to account for the distorting effects of fiscal foresight can lead to a substantial overstatement of the impacts of fiscal policy. For instance, we find that ignoring fiscal foresight would overstate the estimated stimulus to employment growth by $33 \%$.

We also find that the cumulative effect (CUM) of JCTCs is positive, but the effect takes two to three years to be fully observed in the data. These long lags, coupled with evidence from our logit analysis, suggest that the permanent state JCTCs we study in this paper are not countercyclical tools adopted to address transitory weaknesses in employment. Rather, they 
appear to be economic development policies with a longer run focus. Our estimates imply a cost per job created by permanent state JCTCs of approximately $\$ 18,000$, which implies a JCTC fiscal multiplier of about 1.66. Given other studies in the literature, these JCTCs appear to be quite cost effective compared with less targeted fiscal initiatives aimed at stimulating employment such as the 2009 federal stimulus package, though less cost effective than explicitly temporary JCTCs.

Our data collection effort revealed the surprising fact that many broad-based state JCTCs have an implementation lag. The quantitatively important AD found in this study raises a question: why would policymakers adopt legislation that would temporarily lower employment? The CR documented in our empirical work indicates that there will be a big jump in employment in the qualifying month and thus suggests an answer, albeit a cynical one. With a delayed JCTC, politicians can point to the large boost to employment growth, which tends to occur in the first month the credit goes into effect, as evidence of the wisdom of their policies and their concern for the unemployed.

\section{REFERENCES}

Abadie, Alberto, Diamond, Alexis, and Hainmueller, Jens. "Synthetic Control Methods for Comparative Case Studies: Estimating the Effect of California's Tobacco Control Program.” Journal of the American Statistical Association, 105 (2010), 493-505.

Abel, Andrew B. "Dynamic Effects of Permanent and Temporary Tax Policies in a q Model of Investment." Journal of Monetary Economics, 9 (May 1982), 353-374.

Altshuler, Rosanne. "A Dynamic Analysis of the Research and Experimentation Credit." National Tax Journal, 41 (December 1988), 453-466.

Ashenfelter, Orley. "Estimating the Effect of Training Programs on Earnings." Review of Economics and Statistics, 60 (1978), 47-57.

Auerbach, Alan J. "Tax Reform and Adjustment Costs: The Impact on Investment and Market Value.” International Economic Review, 30 (November 1989), 939-962.

Auerbach, Alan J. and Gale, William. "Activist Fiscal Policy to Stabilize Economic Activity." in Financial Stability and Macroeconomic Policy, Federal Reserve Bank of Kansas City. (2009), 327-374. 
Bartik, Timothy J. Who Benefits from State and Local Economic Development Policies? 1991. Kalamazoo, Michigan, W.E. Upjohn Institute for Employment Research.

Bartik, Timothy J. Jobs for the Poor: Can Labor Demand Policies Help? 2001. New York, Russell Sage Foundation.

Bartik, Timothy J., and John H. Bishop. "The Job Creation Tax Credit." Oct. 20, 2009. EPI Briefing Paper \#248.

Bertrand, Marianne, Esther Duflo, and Sendhil Mullainathan. 2004. "How Much Should We Trust Differences-in-Differences Estimates?" Quarterly Journal of Economics, 119(1): 249-275.

Blanchard, Olivier, and Perotti, Roberto. "An Empirical Characterization of the Dynamic Effects of Changes in Government Spending and Taxes on Output." Quarterly Journal of Economics, 117 (2002), 1329-1368.

Cahuc, Pierre, Carcillo, Stephane, Le Barbanchon, Thomas. "The Effectiveness of Hiring Credits.” Unpublished manuscript, January 2016.

Cameron, A. Colin, and Trivedi, Pravin K., Microeconometrics: Methods and Applications (Cambridge: Cambridge University Press, 2005).

Chodorow-Reich, Gabriel, Laura Feiveson, Zachary Liscow, and William Gui Woolston (2012). "Does State Fiscal Relief During Recessions Increase Employment? Evidence from the American Recovery and Reinvestment Act," American Economic Journal: Economic Policy 4(3): pp. 118-145.

Coglianese, John, Davis, Lucas W., Kilian, Lutz, and Stock, James H. "Anticipation, Tax Avoidance, and the Price Elasticity of Gasoline Demand." NBER Working Paper No. 20980 (February 2015).

Conley, Timothy G., and Bill Dupor. "The American Recovery and Reinvestment Act: Solely a Government Jobs Program?” Journal of Monetary Economics, 60 (Jan. 2013), 535-549.

D'Acunto, Francesco, Daniel Hoang, and Michael Weber. "The Effect of Unconventional Fiscal Policy on Consumption Expenditure.” NBER Working Paper No. 22563 (August 2016).

Faulk, Dagney. "Do State Economic Development Incentives Create Jobs? An Analysis of State Employment Tax Credits.” National Tax Journal, 55 (June 2002), 263-280.

Fischer, Stanley. "What have we learned from the crises of the last 20 years?" Speech at the International Monetary Conference, Toronto (June 1, 2015).

Forni, Mario, Gambetti, Luca, and Sala, Luca. "No News in Business Cycles." Economic 
Journal (forthcoming).

Gabaix, Xavier. “A Behavioral New Keynesian Model.” Harvard University (October 2016).

Heckman, James J., and Smith, Jeffrey A. "The Pre-Programme Earnings Dip and the Determinants of Participation in a Social Programme. Implications for Simple Programme Evaluation Strategies.” Economic Journal, 109 (July 1999), 313-348.

Herrera, Ana Maria, and Rangaraju, Sandeep Kumar. "The QuantitativeEffects of Tax Foresight: Not All States Are Equal.” University of Kentucky (n.d.).

Hirano, Keisuke, Guido W. Imbens, and Geert Ridder. Efficient Estimation of Average Treatment Effects Using the Estimated Propensity Score. Econometrica 71 (2003), 11611189.

Hsieh, Chang-Tai. "Do Consumers React to Anticipated Income Changes? Evidence from the Alaska Permanent Fund.” American Economic Review, 93 (March 2003), 397-405.

Johnson, David S., Jonathan A. Parker, and Nicholas S. Souleles. "Household Expenditure and the Income Tax Rebates of 2001." American Economic Review, 96 (December 2006), $1589-1610$.

Katz, Lawrence F. "Wage Subsidies for the Disadvantaged." in Generating Jobs: How to Increase Demand for Less-Skilled Workers, edited by Richard B. Freeman and Peter Gottschalk. 1998. New York: The Russell Sage Foundation, 21-53.

Kueng, Lorenz. "Tax News: The Response of Household Spending to Changes in Expected Taxes.” Northwestern University (2015).

Krueger, Alan B., "How Tight Is the Labor Market? The 2015 Martin Feldstein Lecture," NBER Reporter, 2015 (3).

Leduc, Sylvain, and Wilson, Daniel J. "Roads to Prosperity or Bridges to Nowhere? Theory and Evidence on the Impact of Public Infrastructure Investment." NBER Macroeconomics Annual 27 (2013), 89-142.

Leeper, Eric M., Richter, Alexander, W., and Walker, Todd B., "Quantitative Effects of Fiscal Foresight.” American Economic Journal: Economic Policy, 4 (May 2012), 115-144.

Leeper, Eric M., Walker, Todd B. and Yang, Shu-Chun Susan. "Fiscal Foresight: Analytics and Econometrics." NBER Working Paper No. 14028 (2008).

McKay, Alisdair, Nakamura, Emi, and Steinsson, Jón. "The Power of Forward Guidance Revisited.” American Economic Review, 106 (October 2016), 3133-3158. 
Mertens, Karel, and Ravn, Morten O. "Measuring the Impact of Fiscal Policy in the Face of Anticipation: a Structural VAR Approach.” The Economic Journal, 120 (May 2010), 393-413.

Mertens, Karel, and Ravn, Morten O. "Empirical Evidence on the Aggregate Effects of Anticipated and Unanticipated U.S. Tax Policy Shocks." American Economic Journal: Economic Policy, 4 (May 2012), 145-181.

Ministero Dell'Economia e Delle Finanze. Italy's Draft Budgetary Plan 2015. Rome (2015).

Neumark, David, "Spurring Job Creation in Response to Severe Recessions: Reconsidering Hiring Credits," Journal of Policy Analysis and Management 32 (2013), 142-171.

Neumark, David and Grijalva, Diego. "The Employment Effects of State Hiring Credits during and after the Great Recession.” NBER Working Paper No. 18928 (March 2013).

Neumark, David, and Kenneth Troske. "Point/Counterpoint: 'Addressing the Employment Situation in the Aftermath of the Great Recession'." Journal of Policy Analysis and Management, (2012) 160-68.

Parker, Jonathan A., Souleles, Nicholas S., Johnson, David S., McClelland, Robert. 2013. "Consumer Spending and the Economic Stimulus Payments of 2008." American Economic Review 103:6, 2530-2553.

Perotti, Roberto. "The Effects of Tax Shocks on Output: Not So Large, But Not Small Either." American Economic Journal: Economic Policy 4 (May 2012), 214-237.

Pesaran, M. H. (2007). "A Simple Panel Unit Root Test in the Presence of Cross Section Dependence." Journal of Applied Econometrics 22 (2007), 265-312.

Poterba, James M. "Are Consumers Forward Looking? Evidence from Fiscal Experiments." American Economic Review 78 (May 1988), 413-418.

Ramey, Valerie A. (2011). "Identifying Government Spending Shocks: It's all in the Timing," Quarterly Journal of Economics 126(1), 1-50.

Ramey, Valerie A., and West, Kenneth D., "Inventories." In Handbook of Macroeconomics, Volume.I. Edited by John Taylor and Michael Woodford. 1999. Elsevier Science, Amsterdam, 863-923.

Rogers, Cami. "State Guidelines: The Jobs Creation Tax Credit." Journal of State Taxation 16 (Winter 1998), 44-63.

Shapiro, Matthew D., and Slemrod, Joel. "Did the 2008 Tax Rebates Stimulate Spending?," American Economic Review 99 (May 2009), 374-79. 
Upjohn Foundation. Private communication (November 2016).

Wildasin, David E. "Comments: 'A Defense of the Commerce Clause's Role in Constraining State Business Tax Incentives' by Peter D. Enrich, 'A Market for Jobs Approach for Analyzing the Competition for Capital' by Ann Markusen, and 'State Investment Tax Incentives: What Are the Facts?' by Robert S. Chirinko and Daniel J. Wilson." National Tax Association, Proceedings of $99^{\text {th }}$ Annual Conference on Taxation (2007; CD-ROM): 45-49.

Wilson, Daniel J. "Fiscal Spending Jobs Multipliers: Evidence from the 2009 American Recovery and Reinvestment Act." American Economic Journal - Economic Policy, 4 (August 2012), 251-282.

Wilson, Daniel J. and Notzon, Charles. "Tax Credits for Job Creation and Retention: What Can We Learn from the States?" FRBSF Economic Letter, 2009-08 (February, 2009).

Yang, Shu-Chun Susan. "Quantifying Tax Effects under Perfect Foresight." Journal of Monetary Economics, 52 (2005), 1557-1568. 


\section{APPENDIX A: GLOSSARY}

$\mathrm{AD}=$ Anticipatory Dips. The phenomenon whereby economic agents know with a great deal of certainty that a JCTC will go into effect on a known date in the future. This situation only occurs during the period between the signing date and the qualifying date for tax credits with implementation periods; that is, delayed-JCTC states. See line segment AB in Figure 5. This phenomenon is one aspect of "fiscal foresight."

COMPETITION $_{\mathrm{i}, \mathrm{t}}$. Fraction of bordering states with JCTCs during the prior 12 months:

$=\sum_{\mathrm{j}=1}^{48} \omega_{\mathrm{j}, \mathrm{i}}^{\text {Bordering }} \operatorname{ACTIVE}_{\mathrm{j}, \mathrm{t}}^{\mathrm{JCTC}} / \mathrm{B}(\mathrm{i})$,

$\omega_{\mathrm{j}, \mathrm{i}}^{\text {Bordering }}=1$ if state $\mathrm{j}$ borders state $\mathrm{i}, \omega_{\mathrm{j}, \mathrm{i}}^{\text {Bordering }}=0$ otherwise;

$\operatorname{ACTIVE}_{\mathrm{j}, \mathrm{t}}^{\mathrm{JCTC}}=\operatorname{MAX}\left\{0, \mathrm{D}_{\mathrm{j}, \mathrm{t}-\mathrm{m}}^{\mathrm{SIGNING}}\right.$ for $\left.\mathrm{m}=1,12\right\}$,

$\mathrm{B}(\mathrm{i})$ is the number of states that border state $\mathrm{i}$.

$\mathrm{CPJC}_{\mathrm{i}}=$ Cost per job created in state $i$. The total subsidy to both inframarginal and marginal jobs divided by the number of jobs created by the JCTC. Cf. equation (27) and surrounding text.

$\mathrm{CR}=$ Compensating Rebound. The phenomenon whereby economic agents compensate for deferred hiring (due to the Anticipatory Dip) and replenish inventories. This situation only occurs for tax credits with implementation periods; that is, delayed-JCTC states. See line segments $\mathrm{BC}$ and $\mathrm{DE}$ in Figure 5. Note that Point $\mathrm{C}$ has the same value as Point $\mathrm{A}$. This phenomenon is one aspect of "fiscal foresight."

$\mathrm{D}_{\mathrm{i}, \mathrm{t}}^{\mathrm{Del}}$. An indicator variable that equals one in the qualifying month for a delayed-JCTC state and equals zero otherwise.

$\mathrm{D}_{\mathrm{i}, \mathrm{t}}^{\mathrm{Imm}}$. An indicator variable that equals one in the latter of the signing month and qualifying month for an immediate-JCTC state and equals zero otherwise.

$\mathrm{D}_{\mathrm{i}, \mathrm{t}}^{\text {Qualifying }}$. An indicator variable taking the value of 1 in the JCTC qualifying month $\left(\mathrm{t}=\mathrm{t}_{\mathrm{i}}^{\text {Qualifying }}\right) ; 0$ otherwise. This indicator variable will be 0 for all $\mathrm{t}$ for all states without a JCTC. During the sample period, Colorado passed two JCTCs; $\mathrm{D}_{\text {Colorado, } \mathrm{t}}^{\text {Qualifying }}=1$ only for the first adoption. 
$\mathrm{D}_{\mathrm{i}, \mathrm{t}}^{\text {Signing }}$. An indicator variable taking the value of 1 in the JCTC signing month $\left(\mathrm{t}=\mathrm{t}_{\mathrm{i}}^{\text {Signing }}\right), 0$ otherwise. This indicator variable will be 0 for all $\mathrm{t}$ for the 26 states without a JCTC. (Alaska, Hawaii, and the District of Columbia are excluded from our sample and hence this set of 26 states.) This variable is defined from January 1990 to December 2010. During this sample period, Colorado passed two JCTCs; $\mathrm{D}_{\text {Colorado, } \mathrm{t}}^{\text {Signing }}=1$ only for the first adoption. Prior to the sample period, only Maine and Nebraska had passed a JCTC, as indicated in Figure 1.

Fiscal Foresight. Alterations of current behavior by forward-looking agents in anticipation of future policy changes. Fiscal foresight results in an AD and CR. "Perfect fiscal foresight" is when there is no uncertainty about whether and when a future fiscal change will occur. Speculation about a future fiscal change may occur prior to the signing of the legislation into law, introducing the possibility of uncertain anticipation about whether and when the change will occur. We label impact of this latter phenomenon as "imperfect fiscal foresight."

i: An index for state $i$.

Implementation Interval. Interval between signing and qualifying months when $\mathrm{t}_{\mathrm{i}}^{\text {Signing }}<\mathrm{t}_{\mathrm{i}}^{\text {Qualifying }}$.

Implementation Regime. A JCTC with an implementation period.

Inventory overshooting effect. JCTC-induced response of employment that occurs on the effective date and reflects the accumulation of inventory that compensates for prior draw downs and/or reflects intertemporal substitution in the face of temporarily lower labor costs. Line segment DE in Figure 5.

$\mathrm{L}_{\mathrm{i}, \mathrm{t}}$. The level of employment. Monthly, seasonally adjusted, private non-farm employment data for the period January 1990 to September 2009. Source: Bureau of Labor Statistics.

$\mathrm{LGROWTH}_{\mathrm{i}, \mathrm{t}}$. Employment growth over some number of prior months. This variable is defined in eight different ways. See $\mathrm{LGROWTH}_{\mathrm{i}, \mathrm{t}}^{\mathrm{M}, \mathrm{N}}$ and $\mathrm{LGROWTH}_{\mathrm{i}, \mathrm{t}}^{\mathrm{M}, \mathrm{N}, \text { Bordering }}$ for $\mathrm{M}=0,3,6,12$ and $\mathrm{N}=3,6,12,24$.

LGROWTH $_{\mathrm{i}, \mathrm{t}}^{\mathrm{M}, \mathrm{N}}$. Employment growth defined by a pair of the $\mathrm{M}$ and $\mathrm{N}$ parameters; that is, $\mathrm{M}=0,3,6,12$ and $\mathrm{N}=3,6,12,24$ forming the four pairs, $(0,3),(3,6),(6,12)$, and $(12,24)$ : $=\left(\mathrm{L}_{\mathrm{i}, \mathrm{t}-\mathrm{M}}-\mathrm{L}_{\mathrm{i}, \mathrm{t}-\mathrm{N}}\right) / \mathrm{L}_{\mathrm{i}, \mathrm{t}-\mathrm{N}}$. 
LGROWTH $\mathrm{i}_{\mathrm{i}, \mathrm{t}}^{\mathrm{N}, \text { Bordering }}$. Employment growth in the states bordering state $\mathrm{i}$ defined by a pair of the $M$ and $N$ parameters: that is, $M=0,3,6,12$ and $N=3,6,12,24$, forming the four pairs $(0,3),(3,6),(6,12)$, and $(12,24)$ :

$=\left(\mathrm{L}_{\mathrm{i}, \mathrm{t}-\mathrm{M}}^{\text {Bordering }}-\mathrm{L}_{\mathrm{i}, \mathrm{t}-\mathrm{N}}^{\text {Bordering }}\right) / \mathrm{L}_{\mathrm{i}, \mathrm{t}-\mathrm{N}}^{\text {Bordering }}$,

$\mathrm{L}_{\mathrm{i}, \mathrm{t}}^{\text {Bordering }}=\sum_{\mathrm{j}=1}^{48} \omega_{\mathrm{j}, \mathrm{i}}^{\text {Bordering }} \mathrm{L}_{\mathrm{j}, \mathrm{t}}$

$\omega_{\mathrm{j}, \mathrm{i}}^{\text {Bordering }}=1$ if state $\mathrm{j}$ borders state $\mathrm{i}, \omega_{\mathrm{j}, \mathrm{i}}^{\text {Bordering }}=0$ otherwise

REPUBLICAN $_{i, t}$. An indicator variable taking the value of 1 if both the governorship and the legislature are Republican controlled, a value of $1 / 2$ if only one of these elected bodies is Republican controlled, and 0 if neither of these elected bodies are Republican controlled. Source: Statistical Abstract of the United States (U.S. Census Bureau (Various Years)).

$\mathrm{t}_{\mathrm{i}}^{\text {Qualifying }}$ (or $\mathrm{t}_{\mathrm{i}}^{\mathrm{Q}}$ ). Qualifying month for the JCTC; the earliest month a new hire may qualify for a JCTC. Source: Authors' compilation.

$\mathrm{t}_{\mathrm{i}}^{\text {Signing }}$ (or $\mathrm{t}_{\mathrm{i}}^{\mathrm{S}}$ ). Signing month for the JCTC; the month during which the governor in state i officially signs or enacts JCTC legislation into law. Source: Authors' compilation.

$\tau_{\mathrm{i}, \mathrm{t}}$. The legislated rate of a Job Creation Tax Credit. Source: see discussion in Section III.A. and Appendix B.

$\mathrm{UCC}_{\mathrm{i}, \mathrm{t}}$. The user cost of capital that measures the nominal incentive effects due to business capital taxes.

$\mathrm{W}_{\mathrm{i}, \mathrm{t}}$. The nominal wage rate. 


\section{APPENDIX B: THE JCTC DATASET}

JCTCs are credits against a state's business income taxes, which are generally corporate income taxes (assessed on "C-corporations") and individual income taxes, such as those assessed on S-corporations, limited liability partnerships, and other pass-through entities for which business income is passed through to owners as individual income. Texas has a franchise tax accessed on both types of business enterprises. This appendix describes the unique state-level JCTC data that we have collected and contains details about the identification, valuation, and design of JCTCs.

\section{Identifying And Dating}

We focus on broad-based JCTCs and identify states with these tax credits in three steps. First, we use Rogers (1998) to identify state JCTCs in place as of 1997. Only Maine and Nebraska had tax credits that were enacted prior to 1990. Second, Site Selection's website (www.siteselection.com) contains tables documenting various state tax incentives from 1997 onward. Third, we supplement these sources with, for each state, a general web search for "tax credits" and a more targeted search in the legal database WestLaw. We believe that we have identified all broad-based JCTCs for which both the signing and effective dates are prior to December 2007, the start of the Great Recession. Such credits have a high potential of being enacted as countercyclical fiscal policy tools and hence of being endogenous with respect to contemporaneous employment growth.

Having identified all 19 states that adopted a broad-based, permanent JCTC between January 1990 and December 2007, we then use WestLaw to obtain the state statute code for the legislation associated with the JCTC. ${ }^{38}$ The state statute code identifies the session law that includes the bill signed into law, officially authorizing the credit. States session laws and bills are found either in WestLaw or on the state's house/assembly website. These bills contain all of

\footnotetext{
${ }^{38}$ These 19 JCTCs were passed with the intent that they would be permanent. In the vast majority of cases, there was no expiration date in the legislation. In three cases, the legislation included an expiration date far into the future. By contrast, Idaho and Rhode Island enacted tax credits that were explicitly temporary, set to expire within one year and three years, respectively; we exclude these JCTCs from our sample.
} 
the relevant JCTC information needed for this paper. ${ }^{39}$ In particular, the bills indicate the signing and qualifying dates for the JCTC. ${ }^{40}$

\section{Valuation Of The Legislated Tax Credit}

The legislated tax credit rates for the state JCTCs in our sample are computed in one of three ways, depending on the details of the enabling legislation,

$$
\tau_{\mathrm{i}, \mathrm{t}}=\left\{\tau_{\mathrm{i}, \mathrm{t}}^{\mathrm{WAGES}}, \tau_{\mathrm{i}, \mathrm{t}}^{\mathrm{WITHHOLD}}, \tau_{\mathrm{i}, \mathrm{t}}^{\text {DOLLAR }}\right\} .
$$

In most JCTC states, the legislation explicitly provides a tax credit rate as a fraction of the new hire's annual wages $\left(\tau_{i, t}^{\text {WAGES }}\right)$. This rate is taken directly from the legislation. In other JCTC states, the legislation specifies a rate based on the new hire's income tax withholdings $\left(\tau_{i, t}^{\text {WITHHOLD }}\right)$. We estimate this tax credit rate as the product of the rate in the legislation and average income tax withholding in a state-year, the latter calculated as the product of average annual manufacturing wage and the statutory personal income tax rate (for the income bracket corresponding to that annual wage) in that state-year. The wage data are obtained from the Annual Survey of Manufacturers Geographic Area Statistics. In a third set of JCTC states, as well as the federal JCTC in President Obama's proposed (but not adopted) American Jobs Act of 2011, the legislation specifies an annual dollar tax credit per new employee. We compute the

associated tax credit rate $\left(\tau_{i, t}^{\text {DOLLAR }}\right)$ as the dollar tax credit in the legislation divided by average annual wages in a state-year. For five of the 19 credits in our sample, the tax credit value is determined by a state agency or committee on an employer-by-employer basis. Unfortunately, these states do not routinely report both the tax expenditures and the incremental jobs or wages claimed by companies that used the credits, which would be needed to compute an average credit value. We must thus exclude these states from our estimation using the pecuniary JCTC in

\footnotetext{
${ }^{39}$ These bills are available from the authors upon request.

${ }^{40}$ For six of the 13 immediate JCTC states, the JCTC is retroactive in the sense that the qualifying date precedes the signing date by more than 15 days. For each retroactive JCTC state in our sample, the qualifying date is January 1 of the year in which the credit was signed into law. In these cases, only net employment increases made after January 1 can qualify for a credit. We treat these retroactive states equivalently to other immediate-JCTC states in the empirical analysis.
} 
Table 5. (The number of JCTCs used in Table 4 (indicator JCTC) and Table 5 (pecuniary JCTC) differs by these five states.)

For some of the state JCTCs, firms can take the credit for multiple years as long as the new hire (or more accurately, the incremental addition to the firm's level of employment) is retained. In those cases, we compute the present discounted value of this stream of yearly credit amounts based on the number of years for which the firm gets the credit.

\section{The General Design ${ }^{41}$}

As mentioned above, we focus on broad-based JCTCs with little or no restrictions on eligible industries and few or no restrictions on eligible geographic areas within the state. ${ }^{42}$ Focusing on a broad-based tax credit allows us to avoid the distorting effects of a "stigma" that accompanies targeted tax credits, as employers may use the availability of a targeted credit as a signal of unobservable labor productivity (Bartik, 2001, Chapter 8 and Katz (1998)). In addition, our primary empirical objective is to assess the extent to which JCTCs impact aggregate employment; narrowly targeted credits are much less likely to have an economically meaningful impact on aggregate employment. The details of these tax credits vary widely, but their basic designs are quite similar.

These tax credits are intended to subsidize net job creation by businesses. That is, only new jobs that expand a business' total payroll employment level qualify for the tax credit. With many state JCTCs, a firm can only claim the credit if the number of jobs and/or wages associated with new jobs are above specified thresholds and meet certain other requirements, such as providing health insurance. These credits are refundable in a little under half of JCTC states, meaning that firms can receive the credit even if they do not have positive taxable income. Other states allow the credit to be either carried back or carried forward or both, meaning firms can use the credit to offset past tax payments (equivalent to a current refund) or future tax liabilities.

In order to target net job creation instead of gross job creation, the base level of employment is defined on a "rolling basis." That is, in any given period (e.g., month), the value of the credit is based on the number of employees (or total payroll) at the end of the period

\footnotetext{
${ }^{41}$ This description is based largely on the information provided in Wilson and Notzon (2009).

${ }^{42}$ Georgia is an exception because only jobs in manufacturing are eligible for the credit. California and New Jersey have extremely narrowly targeted JCTCs, and they are excluded from our dataset.
} 
relative to the number of employees at the end of the prior period or, in some cases, averaged over a number prior periods (e.g., 12 months). This new level of employment or payroll then becomes the base level for defining "new" employment in the next period. For example, Georgia's JCTC legislation defines the level of employment eligible for the credit as follows: "The number of new full-time jobs to which this Code section shall be applicable shall be determined each month by comparing the number of full-time employees subject to Georgia income tax withholding as of the last payroll period of such month or as the payroll period during each month used for the purpose of reports to the Department of Labor with the number of such employees for the previous month."

Lastly, some states offer multiple tax credit rates that increase with the number of, or wages associated with, the added jobs. 


\section{APPENDIX C. Additional Empirical Results}

Table 1: Effects of JCTCs on Employment Growth by Regime and Interval Alternative After Lengths

ATE-IPW Estimator JCTC Measured By Indicator Variable

Pre-signing Length $=2$ months

Drop observations beyond $2007 \mathrm{~m} 12$

\begin{tabular}{|c|c|c|c|c|c|c|}
\hline & \multicolumn{2}{|c|}{ After $=12 \mathrm{~m}$} & \multicolumn{2}{|c|}{ After $=24 \mathrm{~m}$} & \multicolumn{2}{|c|}{ After $=36 \mathrm{~m}$} \\
\hline & Delayed & Immediate & Delayed & Immediate & Delayed & Immediate \\
\hline \multirow[t]{3}{*}{ Pre-signing } & -0.069 & 0.034 & -0.065 & 0.033 & -0.064 & 0.037 \\
\hline & $(0.039)$ & $(0.041)$ & $(0.039)$ & $(0.041)$ & $(0.039)$ & $(0.042)$ \\
\hline & {$[0.080]$} & {$[0.410]$} & {$[0.096]$} & {$[0.411]$} & {$[0.096]$} & {$[0.376]$} \\
\hline \multirow[t]{3}{*}{ Before } & -0.039 & 0.000 & -0.034 & 0.000 & -0.034 & 0.000 \\
\hline & $(0.021)$ & $(0.000)$ & $(0.021)$ & $(0.000)$ & $(0.021)$ & $(0.000)$ \\
\hline & {$[0.062]$} & {$[0.000]$} & {$[0.096]$} & {$[0.000]$} & {$[0.117]$} & {$[0.000]$} \\
\hline \multirow[t]{3}{*}{ At } & 0.148 & 0.063 & 0.152 & 0.063 & 0.153 & 0.067 \\
\hline & $(0.043)$ & $(0.038)$ & $(0.044)$ & $(0.039)$ & $(0.044)$ & $(0.040)$ \\
\hline & {$[0.001]$} & {$[0.098]$} & {$[0.001]$} & {$[0.102]$} & {$[0.000]$} & {$[0.093]$} \\
\hline \multirow[t]{3}{*}{ After } & -0.031 & 0.014 & 0.018 & 0.005 & 0.019 & 0.020 \\
\hline & $(0.034)$ & $(0.016)$ & $(0.015)$ & $(0.016)$ & $(0.015)$ & $(0.014)$ \\
\hline & {$[0.354]$} & {$[0.393]$} & {$[0.224]$} & {$[0.747]$} & {$[0.218]$} & {$[0.159]$} \\
\hline \multirow[t]{3}{*}{ Cumulative Effect (CUM) } & -0.545 & 0.292 & 0.291 & 0.253 & 0.525 & 0.863 \\
\hline & $(0.451)$ & $(0.252)$ & $(0.386)$ & $(0.417)$ & $(0.592)$ & $(0.579)$ \\
\hline & {$[0.227]$} & {$[0.245]$} & {$[0.451]$} & {$[0.544]$} & {$[0.375]$} & {$[0.136]$} \\
\hline Number of JCTCs & 6 & 11 & 6 & 11 & 5 & 11 \\
\hline
\end{tabular}

Notes: Cells show coefficient, standard error (in parentheses), and p-value [in brackets]. The cell entries for the Pre-signing, Before, At, and After intervals measure the effects on employment growth per month. The Cumulative Effect sums the product of each interval's coefficient and the number of months in that interval for either the delayed or immediate regime. Each model includes Two-Way Fixed Effects And Controls. 
Table 2: Effects of JCTCs on Employment Growth by Regime and Interval Alternative After Lengths

ATE-IPW Estimator

JCTC Measured By Indicator Variable

Pre-signing Length $=2$ months

Control for Investment and R\&D tax credits

\begin{tabular}{|c|c|c|c|c|c|c|}
\hline & \multicolumn{2}{|c|}{ After $=12 \mathrm{~m}$} & \multicolumn{2}{|c|}{ After $=24 \mathrm{~m}$} & \multicolumn{2}{|c|}{ After $=36 \mathrm{~m}$} \\
\hline & Delayed & Immediate & Delayed & Immediate & Delayed & Immediate \\
\hline \multirow[t]{3}{*}{ Pre-signing } & -0.074 & 0.047 & -0.069 & 0.047 & -0.068 & 0.049 \\
\hline & $(0.041)$ & $(0.036)$ & $(0.042)$ & $(0.036)$ & $(0.042)$ & $(0.037)$ \\
\hline & {$[0.075]$} & {$[0.194]$} & {$[0.099]$} & {$[0.186]$} & {$[0.104]$} & {$[0.176]$} \\
\hline \multirow[t]{3}{*}{ Before } & -0.041 & 0.000 & -0.036 & 0.000 & -0.035 & 0.000 \\
\hline & $(0.021)$ & $(0.000)$ & $(0.020)$ & $(0.000)$ & $(0.021)$ & $(0.000)$ \\
\hline & {$[0.046]$} & {$[0.000]$} & {$[0.076]$} & {$[0.000]$} & {$[0.085]$} & {$[0.000]$} \\
\hline \multirow[t]{3}{*}{ At } & 0.141 & 0.043 & 0.146 & 0.044 & 0.147 & 0.046 \\
\hline & $(0.049)$ & $(0.032)$ & $(0.049)$ & $(0.032)$ & $(0.049)$ & $(0.033)$ \\
\hline & {$[0.004]$} & {$[0.179]$} & {$[0.003]$} & {$[0.174]$} & {$[0.003]$} & {$[0.165]$} \\
\hline \multirow[t]{3}{*}{ After } & -0.024 & 0.019 & 0.031 & 0.013 & 0.029 & 0.019 \\
\hline & $(0.032)$ & $(0.015)$ & $(0.021)$ & $(0.014)$ & $(0.017)$ & $(0.012)$ \\
\hline & {$[0.454]$} & {$[0.210]$} & {$[0.139]$} & {$[0.353]$} & {$[0.085]$} & {$[0.116]$} \\
\hline \multirow[t]{3}{*}{ Cumulative Effect (CUM) } & -0.477 & 0.362 & 0.584 & 0.445 & 0.908 & 0.813 \\
\hline & $(0.427)$ & $(0.234)$ & $(0.532)$ & $(0.358)$ & $(0.651)$ & $(0.480)$ \\
\hline & {$[0.264]$} & {$[0.122]$} & {$[0.272]$} & {$[0.214]$} & {$[0.163]$} & {$[0.090]$} \\
\hline Number of JCTCs & 6 & 13 & 6 & 13 & 6 & 13 \\
\hline
\end{tabular}

Notes: See Table 4 notes. 


\section{APPENDIX D: COMPUTING THE JCTC FISCAL MULTIPLIER}

This appendix derives expressions for computing the substitution and income effects associated with a JCTC. In a standard diagram of an isoquant with labor and some other productive factor on the axes, the adoption of a JCTC rotates the line segment representing the relative price of labor, forcing the optimizing firm to substitute along the isoquant and then shifting to a higher isoquant. Since the JCTC fiscal multiplier involves only the latter effect, we derive an expression that isolates the substitution effect and compute the income effect as a residual.

We assume that a neoclassical firm produces output constrained by a constant-returns-toscale CES production function that depends on labor and one or more additional factors of production, faces competitive input and output markets, and chooses labor and other inputs to maximize profits. The first order condition for labor is as follows,

$$
\mathrm{L}=\xi^{\sigma}\left(\mathrm{W}^{\mathrm{e}}\right)^{-\sigma} \mathrm{QU},
$$

where $\mathrm{L}$ is labor input, $\xi$ is the CES distribution parameter, $\sigma$ is the substitution elasticity between labor and any other productive factor, $\mathrm{W}^{\mathrm{e}}$ is the effective wage rate, $\mathrm{Q}$ is output, and $\mathrm{U}$ is a shock (usually thought of as a productivity shock but indistinguishable from a demand shock). Taking logs and differentiating with respect to a fall in $\mathrm{W}^{\mathrm{e}}$, we obtain the following equation,

$$
\% \Delta \mathrm{L}=-\sigma * \% \Delta \mathrm{W}^{\mathrm{e}}+\% \Delta \mathrm{Q} . \quad \% \Delta \mathrm{W}^{\mathrm{e}}<0
$$

As we move along an isoquant, $\% \Delta \mathrm{Q}=0$, and equation (D-2) can be written as follows,

$$
\% \Delta \mathrm{L}=-\sigma * \% \Delta \mathrm{W}^{\mathrm{e}} . \quad \% \Delta \mathrm{W}^{\mathrm{e}}<0
$$

In order to derive a quantitatively useful expression, we need to relate $\% \Delta \mathrm{W}^{\mathrm{e}}$ to the legislated rate for the JCTC. We assume that, in the "initial" period, there is no JCTC and, in the “stimulus" period, $\mathrm{W}^{\mathrm{e}}$ equals its steady-state value (equation (10b)). A general expression for $\mathrm{W}^{\mathrm{e}}$ is as follows,

$$
\begin{aligned}
\mathrm{W}^{\mathrm{e}}= & \mathrm{W} * \mathrm{~F}[\mathrm{JCTC}] . \\
& \mathrm{F}[\mathrm{JCTC}] \equiv\left(1-\mathrm{JCTC}^{*}(\rho /(1-\rho))\right)
\end{aligned}
$$


where JCTC is the statutory job creation tax credit, F[JCTC] captures the effects of the JCTC on the effective wage rate, $\mathrm{W}$ is the market wage rate (assumed to be invariant with respect to changes in the JCTC), and $\rho$ is a real discount rate. The percentage change in $\mathrm{W}^{\mathrm{e}}$ with respect to the JCTC is written as follows,

$$
\% \Delta \mathrm{W}^{\mathrm{e}}=\frac{\mathrm{W}^{*} \mathrm{~F}[\mathrm{JCTC}>0]-\mathrm{W}^{*} \mathrm{~F}[\mathrm{JCTC}=0]}{\mathrm{W}^{*} \mathrm{~F}[\mathrm{JCTC}=0]}=\mathrm{F}[\mathrm{JCTC}>0]-1,
$$

where $\mathrm{F}[\mathrm{JCTC}=0]=1$. We assume that $\rho$ equals 0.07 , and hence equation (D-5) can be written as follows,

$$
\% \Delta \mathrm{W}^{\mathrm{e}}=\mathrm{F}[\mathrm{JCTC}]-1=-0.065 * \mathrm{JCTC} .
$$

Equation (D-6) can be used to quantify the impact of JCTC's on the effective wage rate, though the impacts will differ across regimes because the mean values of the JCTC's differ across regimes. The mean values are taken from Table 2, panel C, column 1. In turn, these computations are used to quantify the substitution effect via equation (D-3),

\section{Delayed Regime}

$$
\% \Delta \mathrm{L}=-\sigma * \% \Delta \mathrm{W}^{\mathrm{e}}=\sigma * 0.065 * 0.04828=\sigma * 0.0031382,
$$

\section{Immediate Regime}

$$
\% \Delta \mathrm{L}=-\sigma * \% \Delta \mathrm{W}^{\mathrm{e}}=\sigma * 0.065 * 0.11596=\sigma * 0.0075374,
$$

The overall $\% \Delta \mathrm{L}$ 's for the baseline results in Table 4 are approximately 0.083 for both regimes. For a given change in the JCTC, we need to separate the overall change in employment into a substitution effects (equations (D-7)) and the output effect (the residual given the overall \% $\Delta \mathrm{L}$ ). The results are presented in the following table,

\begin{tabular}{|c|c|c|c|c|c|c|}
\hline & \multicolumn{2}{|c|}{ Delayed Regime } & \multicolumn{2}{c|}{ Immediate Regime } & \multicolumn{2}{c|}{ Weighted (6/19, 13/19) } \\
\hline & Substitution & Income & Substitution & Income & Substitution & Income \\
\hline$\sigma=0.5$ & $19 \%$ & $81 \%$ & $45 \%$ & $55 \%$ & $37 \%$ & $63 \%$ \\
\hline$\sigma=1.0$ & $38 \%$ & $62 \%$ & $91 \%$ & $9 \%$ & $74 \%$ & $26 \%$ \\
\hline$\sigma=1.5$ & $57 \%$ & $43 \%$ & $136 \%$ & $-36 \%$ & $111 \%$ & $-11 \%$ \\
\hline
\end{tabular}


Columns 5 and 6 are weighted averages of the substitution and income effects for delayed and immediate regimes with weights of $6 / 19$ and $13 / 19$, respectively, corresponding to the proportions of delayed and immediate JCTC states.

We use the figures in column 6 to multiply the gross employment increase due to the JCTC to derive the employment representing an income shift. ${ }^{43}$ In turn, this figure is multiplied by $0.111(\mathrm{dQ} / \mathrm{dL})$ to estimate the JCTC spending multiplier in equation (28).

\footnotetext{
${ }^{43}$ Note that when the elasticity of substitution between capital and labor is very large, a value of 1.5 , the estimated income effect becomes negative. In other words, with such a large elasticity of substitution, the implied substitution effect on employment from the decline in the effective wage rate is larger than our empirical estimate of the total employment effect. This negative income effect occurs for any elasticity of substitution above 1.350.
} 
Figure 1: Diffusion of JCTCs

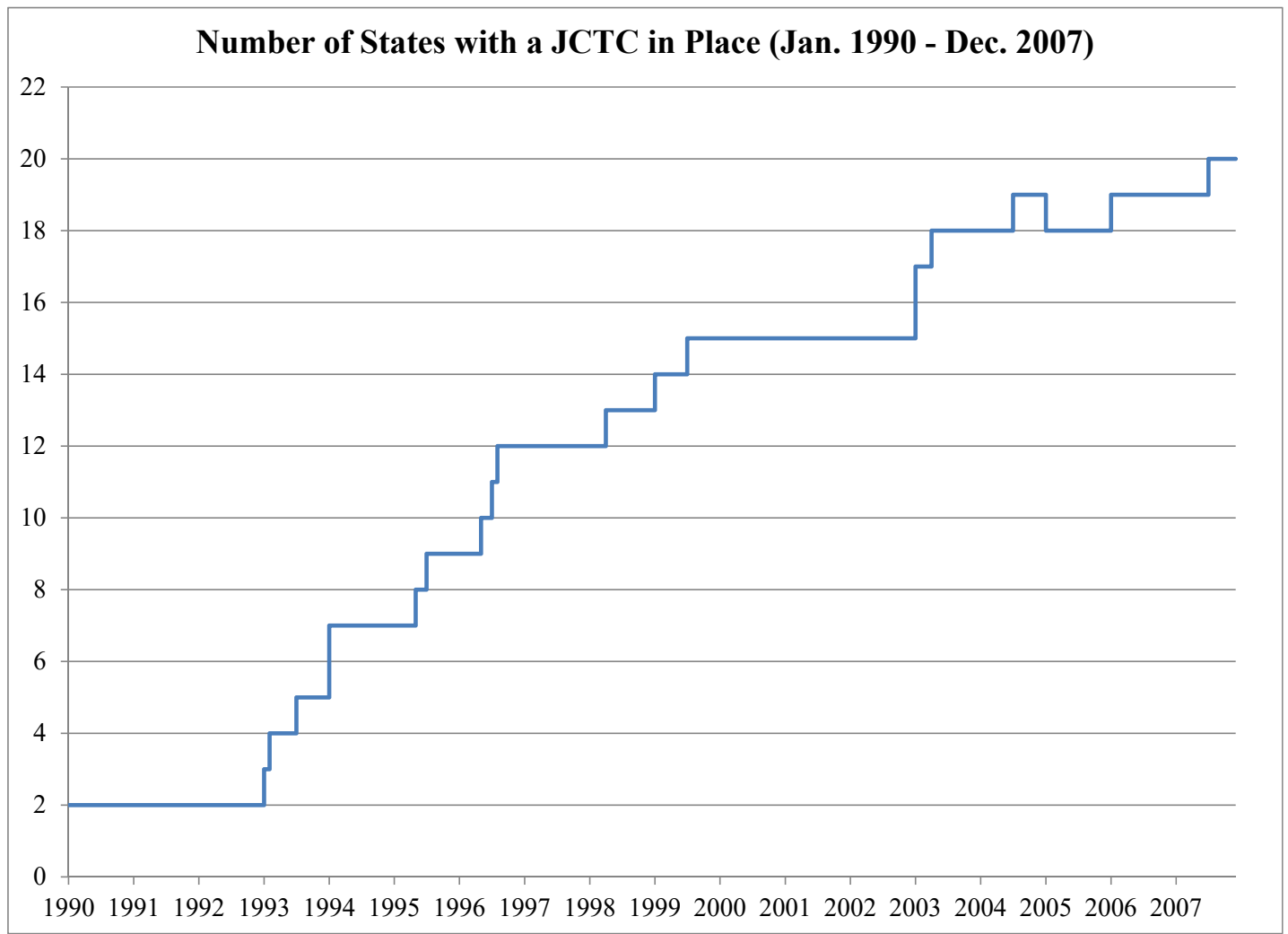

Figure 2: Geographical Distribution of JCTCs

States Enacting Permanent JCTCs During Sample Period (January 1990 - December 2007)

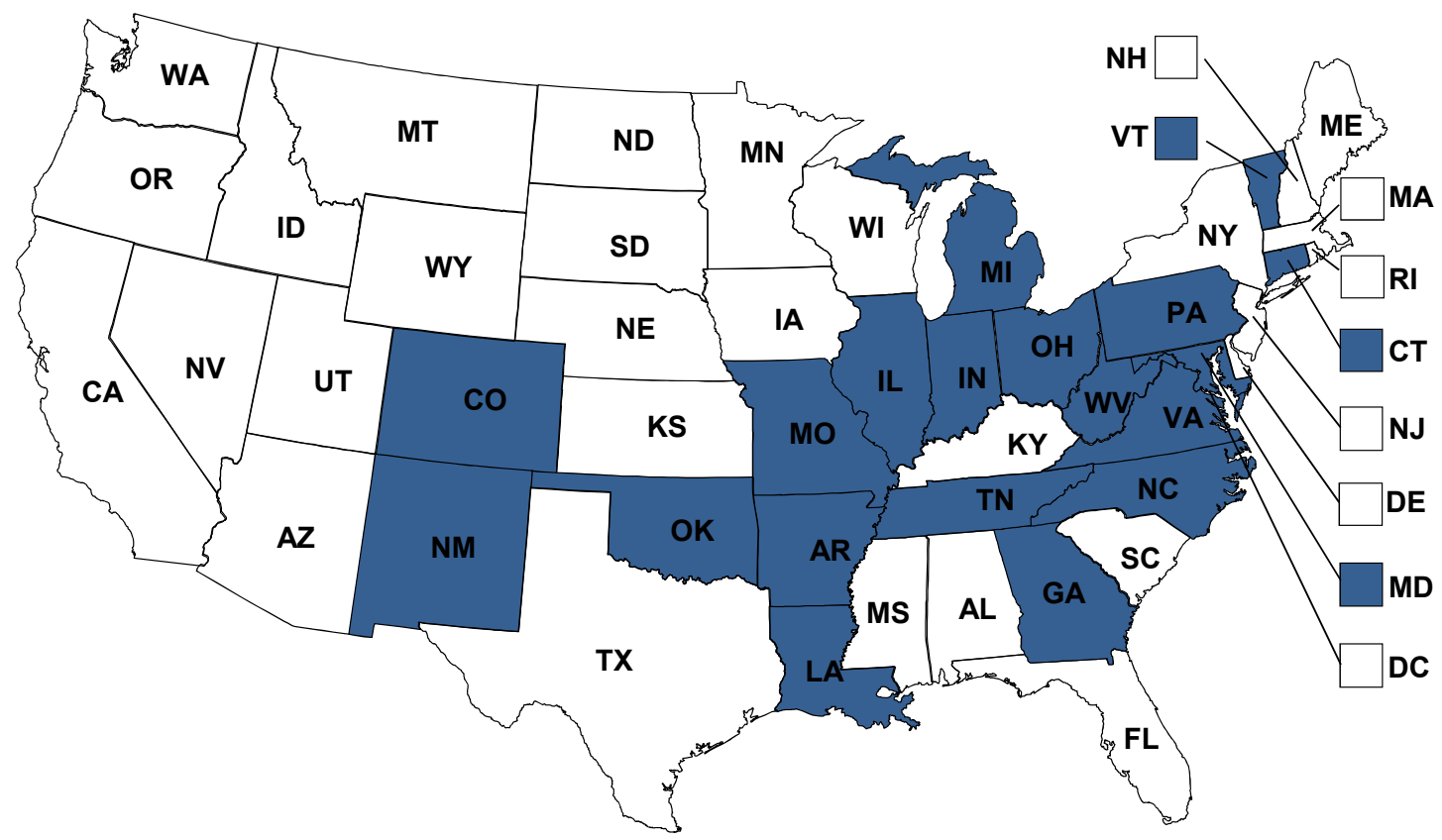




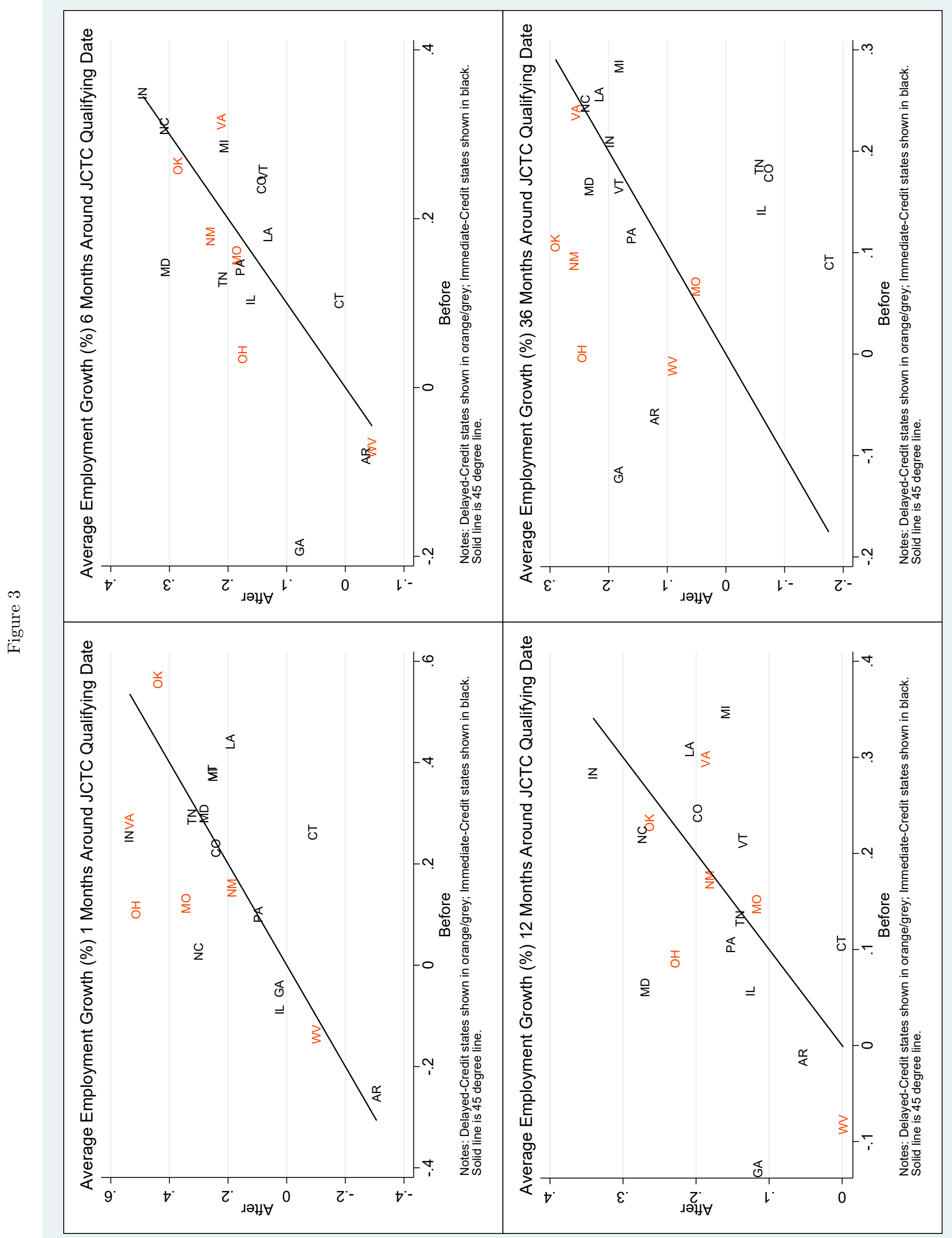


Figure 4: Theoretical Predictions of the Path of Employment around a JCTC "event"

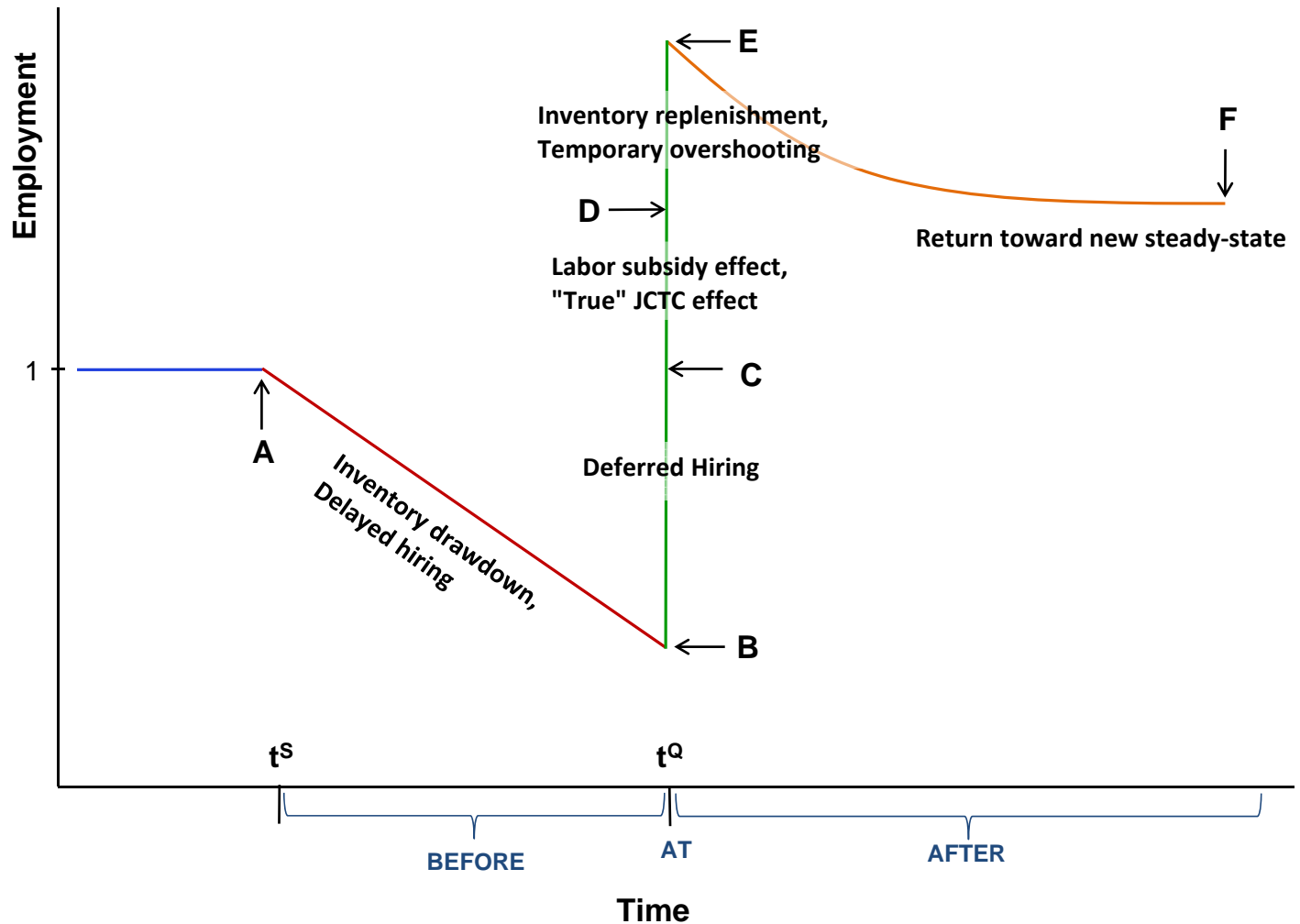

Figure 5

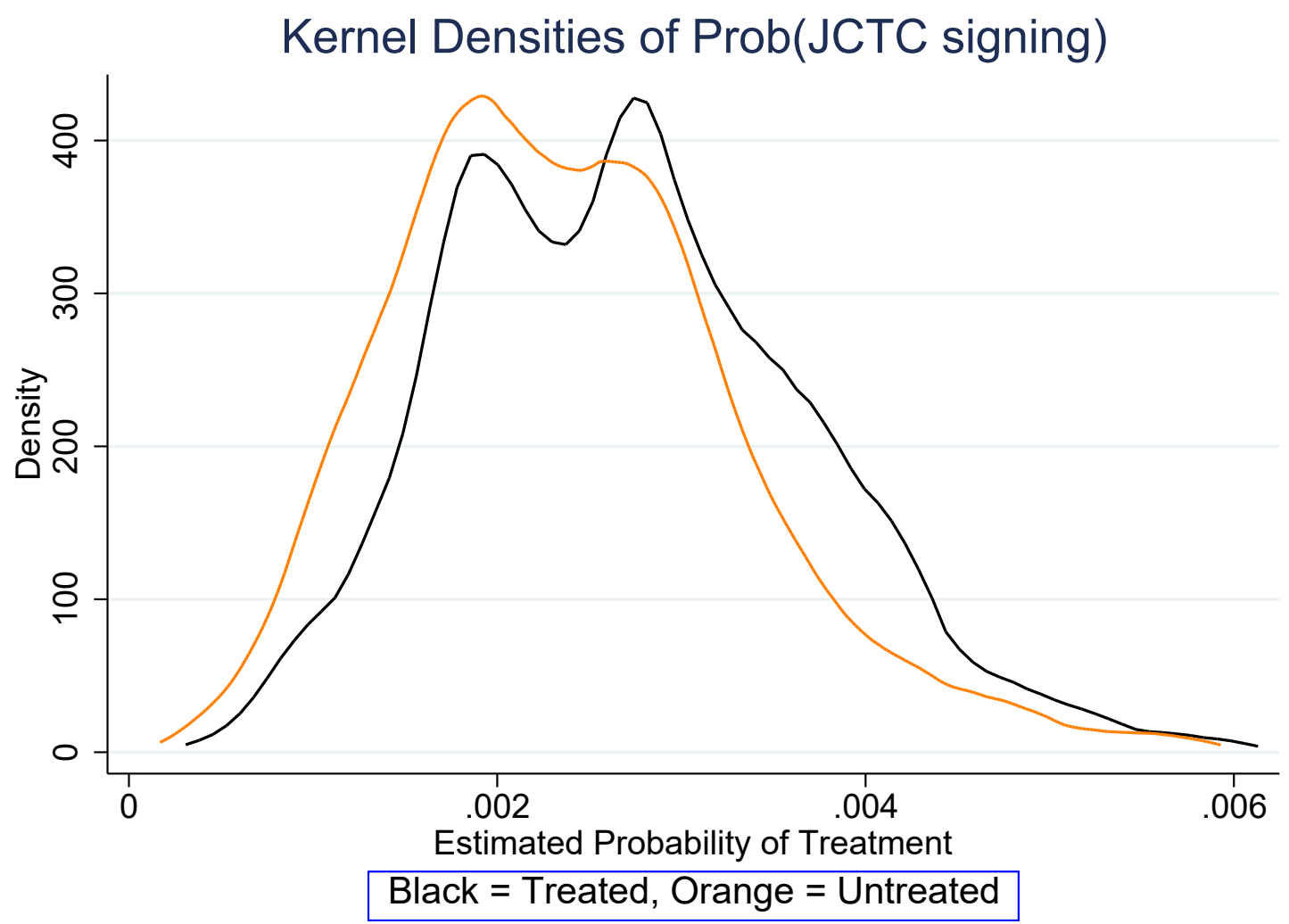

Notes: "Treated" are state-month observations in which a JCTC has been signed and has not been repealed or expired. "Untreated" are all other observations. 


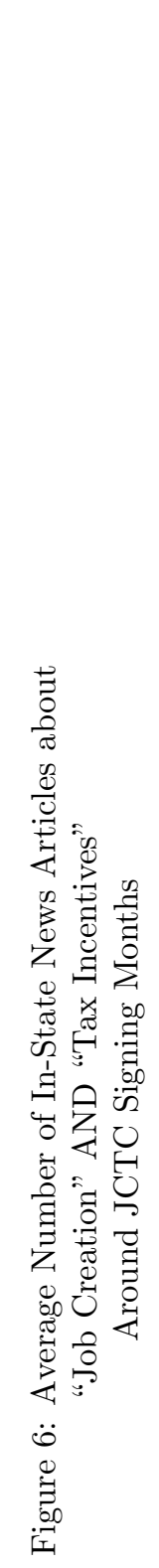

兒:

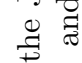

过

ธี

ฮั

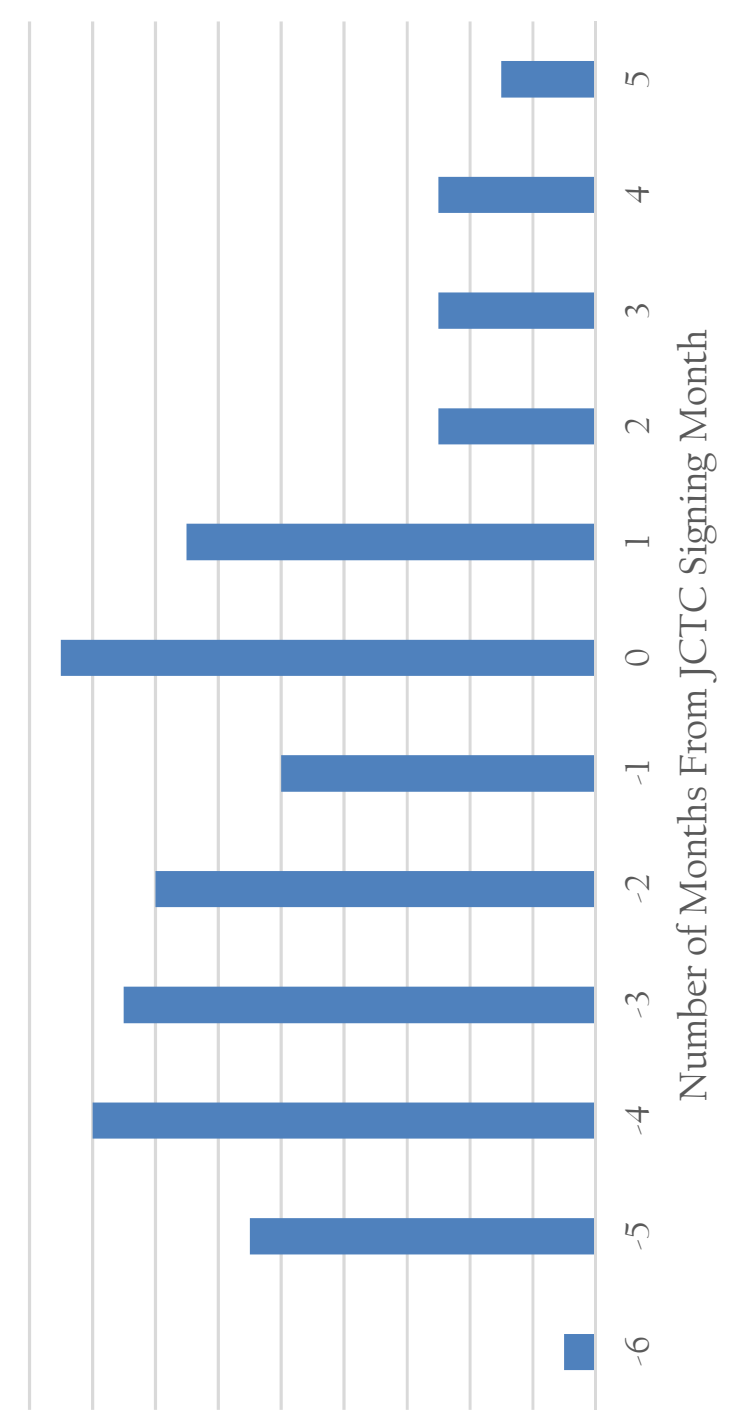

붕 월

善.

졸

근

을

$\infty$

苛

넘

娄

要

$\exists . \stackrel{\mathscr{C}}{0}$

항

省

है.

월

范荡

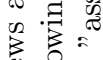

苛

幽

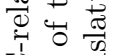

讨 궁

पे

焉

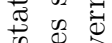

0 .

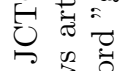

요릴

엉

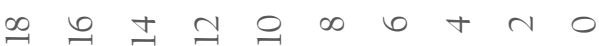

过

$0 \%$

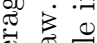

蛋

进

is

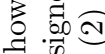

क क :

50

可.

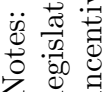


Table 1: Expected Impacts Of JCTCs On Employment Growth By Regime, By Interval Theoretical Predictions

\begin{tabular}{|l|c|c|c|c|}
\hline Regimes & \multicolumn{4}{|c|}{ Intervals } \\
& $\begin{array}{c}\text { Before } \\
(1)\end{array}$ & $\begin{array}{c}\text { At } \\
(2)\end{array}$ & $\begin{array}{c}\text { After } \\
(3)\end{array}$ & $\begin{array}{c}\text { Total } \\
(4)\end{array}$ \\
\hline Delayed & - & ++ & + or - & + \\
& {$[\mathbf{A D}]$} & {$[\mathbf{C R}]$} & & {$[\mathbf{C U M}]$} \\
\hline Immediate & N/A & + & + or - & + \\
& & {$[\mathbf{C R}]$} & & {$[\mathbf{C U M}]$} \\
\hline
\end{tabular}

Table 2: Summary Statistics

Employment Level, Employment Growth, and Legislated JCTCs By State JCTC Status (Delayed, Immediate, No-JCTC)

\begin{tabular}{|c|c|c|c|c|}
\hline State JCTC Status & Mean & Median & Std. Dev. & N \\
\hline & $(1)$ & $(2)$ & $(3)$ & $(4)$ \\
\hline $\begin{array}{c}\text { A. Employment Level } \\
\text { (Thousands) }\end{array}$ & & & & \\
\hline Delayed-JCTC & 1957.8 & 1606.7 & 1419.2 & 1,296 \\
\hline Immediate-JCTC & $2,447.8$ & $2,219.2$ & $1,371.2$ & 2,808 \\
\hline No-JCTC & $2,323.0$ & $1,346.2$ & $2,718.3$ & 5,400 \\
\hline All & $2,310.1$ & $1,562.3$ & $2,247.4$ & 9,504 \\
\hline & & & & \\
\hline $\begin{array}{c}\text { B. Employment Growth } \\
\text { (\%, monthly frequency) }\end{array}$ & & & & \\
\hline Delayed-JCTC & 0.108 & 0.112 & 0.284 & 1,296 \\
\hline Immediate-JCTC & 0.086 & 0.106 & 0.338 & 2,808 \\
\hline No-JCTC & 0.137 & 0.149 & 0.324 & 5,400 \\
\hline All & 0.119 & 0.130 & 0.324 & 9,504 \\
\hline & & & & \\
\hline $\begin{array}{c}\text { C. Legislated JCTCs } \\
\text { (\% of average state wage) }\end{array}$ & & & & \\
\hline Delayed-JCTC & 4.828 & 3.392 & 2.934 & 1,080 \\
\hline Immediate-JCTC & 11.596 & 5.000 & 19.633 & 1,944 \\
\hline No-JCTC & 0 & 0 & 0 & 5,400 \\
\hline All & 3.295 & 0 & 10.639 & 8,424 \\
\hline
\end{tabular}

Notes: Data for the baseline regression sample, covering the period January 1990 to December 2010. The data in Panel C exclude the 5 of 19 JCTC states for which the credit rate is unknown. Employment Level is in thousands. Employment Growth and JCTC values are in percentage points. 
Table 3: JCTC Adoption Decision

Logit Estimator

\begin{tabular}{|c|c|c|c|c|c|}
\hline & $(1)$ & $(2)$ & $(3)$ & $(4)$ & $(5)$ \\
\hline \multirow[t]{3}{*}{ Employment growth from t- 3 to $t$} & 0.164 & 0.242 & & 0.143 & \\
\hline & $(0.461)$ & $(0.518)$ & & $(0.526)$ & \\
\hline & {$[0.722]$} & {$[0.640]$} & & {$[0.785]$} & \\
\hline \multirow[t]{3}{*}{ Employment growth from t- 6 to t- 3} & 0.197 & 0.282 & & 0.141 & \\
\hline & $(0.489)$ & $(0.495)$ & & $(0.510)$ & \\
\hline & {$[0.688]$} & {$[0.569]$} & & {$[0.782]$} & \\
\hline \multirow[t]{3}{*}{ Employment growth from t- 12 to t- 6} & 0.072 & 0.222 & & 0.136 & \\
\hline & $(0.258)$ & $(0.306)$ & & $(0.371)$ & \\
\hline & {$[0.781]$} & {$[0.467]$} & & {$[0.714]$} & \\
\hline \multirow[t]{3}{*}{ Employment Growth from t- 24 to t- 12} & & & & 0.063 & \\
\hline & & & & $(0.152)$ & \\
\hline & & & & {$[0.679]$} & \\
\hline \multirow[t]{3}{*}{ Relative employment growth from t- 3 to $t$} & & & 0.242 & & 0.142 \\
\hline & & & $(0.520)$ & & $(0.529)$ \\
\hline & & & {$[0.642]$} & & {$[0.789]$} \\
\hline \multirow{3}{*}{ Relative employment growth from t- 6 to $t-3$} & & & 0.281 & & 0.139 \\
\hline & & & $(0.497)$ & & $(0.513)$ \\
\hline & & & {$[0.571]$} & & {$[0.786]$} \\
\hline \multirow[t]{3}{*}{ Relative employment growth from t- 12 to $\mathrm{t}-6$} & & & 0.226 & & 0.141 \\
\hline & & & $(0.308)$ & & $(0.373)$ \\
\hline & & & {$[0.462]$} & & {$[0.706]$} \\
\hline \multirow[t]{3}{*}{ Relative Employment Growth from t- 24 to t- 12} & & & & & 0.063 \\
\hline & & & & & $(0.153)$ \\
\hline & 0.009 & 0.094 & 0.094 & 0.091 & $\begin{array}{c}{[0.682]} \\
0.091\end{array}$ \\
\hline \multirow{2}{*}{ COMPETITION } & $(0.008)$ & $(0.036)$ & $(0.036)$ & $(0.038)$ & $(0.038)$ \\
\hline & {$[0.298]$} & {$[0.008]$} & {$[0.008]$} & {$[0.015]$} & {$[0.015]$} \\
\hline \multirow[t]{3}{*}{ CORPORATE INCOME TAX RATE (CITR) } & 0.072 & -1.100 & -1.100 & -1.044 & -1.044 \\
\hline & $(0.086)$ & $(0.756)$ & $(0.756)$ & $(0.766)$ & $(0.766)$ \\
\hline & {$[0.403]$} & {$[0.145]$} & {$[0.145]$} & {$[0.173]$} & {$[0.173]$} \\
\hline \multirow[t]{3}{*}{ REPUBLICAN } & -0.446 & 2.070 & 2.071 & 2.224 & 2.225 \\
\hline & $(0.642)$ & $(1.378)$ & $(1.377)$ & $(1.407)$ & $(1.407)$ \\
\hline & {$[0.487]$} & {$[0.133]$} & {$[0.133]$} & {$[0.114]$} & {$[0.114]$} \\
\hline Joint Significance of emp growth lags (p-value) & 0.695 & 0.510 & 0.510 & 0.884 & 0.883 \\
\hline Observations & 7963 & 1963 & 1963 & 1735 & 1735 \\
\hline
\end{tabular}

Notes: Cells show coefficient, std. error (in parentheses), and p-value [in brackets]. State fixed effects are excluded from the model in Column (1) but included in the models in Columns (2)-(5). 
Table 4: Effects of JCTCs on Employment Growth by Regime and Interval Alternative After Lengths

ATE-IPW Estimator

JCTC Measured By Indicator Variable

Pre-signing Length $=2$ months

\begin{tabular}{|c|c|c|c|c|c|c|}
\hline & \multicolumn{2}{|c|}{ After $=12 \mathrm{~m}$} & \multicolumn{2}{|c|}{ After $=24 \mathrm{~m}$} & \multicolumn{2}{|c|}{ After $=36 \mathrm{~m}$} \\
\hline & Delayed & Immediate & Delayed & Immediate & Delayed & Immediate \\
\hline \multirow[t]{3}{*}{ Pre-signing } & -0.072 & 0.045 & -0.068 & 0.046 & -0.067 & 0.047 \\
\hline & $(0.040)$ & $(0.035)$ & $(0.040)$ & $(0.034)$ & $(0.040)$ & $(0.035)$ \\
\hline & {$[0.068]$} & {$[0.193]$} & {$[0.090]$} & {$[0.184]$} & {$[0.094]$} & {$[0.173]$} \\
\hline \multirow[t]{3}{*}{ Before } & -0.039 & 0.000 & -0.034 & 0.000 & -0.033 & 0.000 \\
\hline & $(0.022)$ & $(0.000)$ & $(0.022)$ & $(0.000)$ & $(0.022)$ & $(0.000)$ \\
\hline & {$[0.071]$} & {$[0.000]$} & {$[0.112]$} & {$[0.000]$} & {$[0.124]$} & {$[0.000]$} \\
\hline \multirow[t]{3}{*}{ At } & 0.141 & 0.043 & 0.146 & 0.043 & 0.147 & 0.045 \\
\hline & $(0.050)$ & $(0.032)$ & $(0.050)$ & $(0.032)$ & $(0.050)$ & $(0.033)$ \\
\hline & {$[0.005]$} & {$[0.178]$} & {$[0.003]$} & {$[0.174]$} & {$[0.004]$} & {$[0.167]$} \\
\hline \multirow[t]{3}{*}{ After } & -0.025 & 0.020 & 0.029 & 0.014 & 0.027 & 0.019 \\
\hline & $(0.030)$ & $(0.014)$ & $(0.020)$ & $(0.014)$ & $(0.016)$ & $(0.010)$ \\
\hline & {$[0.420]$} & {$[0.156]$} & {$[0.148]$} & {$[0.311]$} & {$[0.092]$} & {$[0.065]$} \\
\hline \multirow[t]{3}{*}{ Cumulative Effect (CUM) } & -0.474 & 0.367 & 0.542 & 0.466 & 0.821 & 0.836 \\
\hline & $(0.411)$ & $(0.212)$ & $(0.505)$ & $(0.347)$ & $(0.610)$ & $(0.421)$ \\
\hline & {$[0.249]$} & {$[0.084]$} & {$[0.284]$} & {$[0.179]$} & {$[0.178]$} & {$[0.047]$} \\
\hline Number of JCTCs & 6 & 13 & 6 & 13 & 6 & 13 \\
\hline
\end{tabular}

Notes: See equation (23). Cells show coefficient, standard error (in parentheses), and p-value [in brackets]. The cell entries for the Pre-signing, Before, At, and After intervals measure the effects on employment growth per month. The Cumulative Effect sums the product of each interval's coefficient and the number of months in that interval for either the delayed or immediate regime. Each model includes Two-Way Fixed Effects And Controls. 
Table 5: Effects of JCTCs on Employment Growth by Regime and Interval Alternative After Lengths

ATE-IPW Estimator

JCTC Measured by Pecuniary Credit Rate Variable

Pre-signing Length $=2$ months

\begin{tabular}{|c|c|c|c|c|c|c|}
\hline & \multicolumn{2}{|c|}{ After $=12 \mathrm{~m}$} & \multicolumn{2}{|c|}{ After $=24 \mathrm{~m}$} & \multicolumn{2}{|c|}{ After $=36 \mathrm{~m}$} \\
\hline & Delayed & Immediate & Delayed & Immediate & Delayed & Immediate \\
\hline \multirow[t]{3}{*}{ Pre-signing } & -0.636 & 0.000 & -0.520 & 0.000 & -0.543 & 0.000 \\
\hline & $(0.566)$ & $(0.000)$ & $(0.550)$ & $(0.000)$ & $(0.548)$ & $(0.000)$ \\
\hline & {$[0.261]$} & {$[0.000]$} & {$[0.344]$} & {$[0.000]$} & {$[0.321]$} & {$[0.000]$} \\
\hline \multirow[t]{3}{*}{ Before } & -1.098 & 0.000 & -0.991 & 0.000 & -1.013 & 0.000 \\
\hline & $(0.265)$ & $(0.000)$ & $(0.260)$ & $(0.000)$ & $(0.252)$ & $(0.000)$ \\
\hline & {$[0.000]$} & {$[0.000]$} & {$[0.000]$} & {$[0.000]$} & {$[0.000]$} & {$[0.000]$} \\
\hline \multirow[t]{3}{*}{ At } & 0.986 & 0.560 & 1.081 & 0.696 & 1.060 & 0.682 \\
\hline & $(1.515)$ & $(0.720)$ & $(1.513)$ & $(0.710)$ & $(1.523)$ & $(0.726)$ \\
\hline & {$[0.515]$} & {$[0.436]$} & {$[0.475]$} & {$[0.327]$} & {$[0.487]$} & {$[0.347]$} \\
\hline \multirow[t]{3}{*}{ After } & -0.694 & -0.844 & 0.613 & 0.407 & 0.285 & 0.210 \\
\hline & $(0.439)$ & $(0.346)$ & $(0.258)$ & $(0.304)$ & $(0.163)$ & $(0.314)$ \\
\hline & {$[0.114]$} & {$[0.015]$} & {$[0.017]$} & {$[0.180]$} & {$[0.081]$} & {$[0.503]$} \\
\hline \multirow[t]{3}{*}{ Cumulative Effect (CUM) } & -13.887 & -9.568 & 9.987 & 10.470 & 5.380 & 8.247 \\
\hline & $(5.468)$ & $(4.443)$ & $(5.890)$ & $(7.366)$ & $(5.506)$ & $(11.521)$ \\
\hline & {$[0.011]$} & {$[0.031]$} & {$[0.090]$} & {$[0.155]$} & [0.329] & {$[0.474]$} \\
\hline Number of JCTCs & 5 & 9 & 5 & 9 & 5 & 9 \\
\hline
\end{tabular}

Notes: See Table 4 notes. $\gamma_{D e l}^{\text {Before }}$ is multiplied by -1 to maintain comparability with Table 4 (see text for details). 
Table 6: Effects of JCTCs on Employment Growth by Regime and Interval Pre-Signing Interval of Alternative Lengths

ATE-IPW Estimator

JCTC Measured By Indicator Variable

After Length $=36$ months

\begin{tabular}{|c|c|c|c|c|c|c|c|c|}
\hline & \multicolumn{2}{|c|}{ Pre-signing $=1 \mathrm{~m}$} & \multicolumn{2}{|c|}{ Pre-signing $=2 \mathrm{~m}$} & \multicolumn{2}{|c|}{ Pre-signing $=4 \mathrm{~m}$} & \multicolumn{2}{|c|}{ Pre-signing $=6 \mathrm{~m}$} \\
\hline & Delayed & Immediate & Delayed & Immediate & Delayed & Immediate & Delayed & Immediate \\
\hline \multirow[t]{3}{*}{ Pre-signing } & -0.070 & 0.045 & -0.067 & 0.047 & -0.005 & 0.020 & 0.008 & 0.009 \\
\hline & $(0.023)$ & $(0.039)$ & $(0.040)$ & $(0.035)$ & $(0.030)$ & $(0.019)$ & $(0.040)$ & $(0.023)$ \\
\hline & {$[0.002]$} & {$[0.246]$} & {$[0.094]$} & {$[0.173]$} & {$[0.873]$} & {$[0.302]$} & {$[0.835]$} & {$[0.705]$} \\
\hline \multirow[t]{3}{*}{ Before } & -0.033 & 0.000 & -0.033 & 0.000 & -0.033 & 0.000 & -0.032 & 0.000 \\
\hline & $(0.022)$ & $(0.000)$ & $(0.022)$ & $(0.000)$ & $(0.022)$ & $(0.000)$ & $(0.021)$ & $(0.000)$ \\
\hline & {$[0.133]$} & {$[0.000]$} & {$[0.124]$} & {$[0.000]$} & {$[0.131]$} & {$[0.000]$} & {$[0.132]$} & {$[0.000]$} \\
\hline \multirow[t]{3}{*}{ At } & 0.147 & 0.045 & 0.147 & 0.045 & 0.147 & 0.045 & 0.148 & 0.045 \\
\hline & $(0.051)$ & $(0.033)$ & $(0.050)$ & $(0.033)$ & $(0.050)$ & $(0.033)$ & $(0.050)$ & $(0.033)$ \\
\hline & {$[0.004]$} & {$[0.171]$} & {$[0.004]$} & {$[0.167]$} & {$[0.003]$} & {$[0.171]$} & {$[0.003]$} & {$[0.175]$} \\
\hline \multirow[t]{3}{*}{ After } & 0.027 & 0.019 & 0.027 & 0.019 & 0.027 & 0.019 & 0.028 & 0.019 \\
\hline & $(0.016)$ & $(0.010)$ & $(0.016)$ & $(0.010)$ & $(0.016)$ & $(0.011)$ & $(0.016)$ & $(0.011)$ \\
\hline & {$[0.085]$} & {$[0.068]$} & {$[0.092]$} & {$[0.065]$} & {$[0.082]$} & {$[0.068]$} & {$[0.086]$} & {$[0.075]$} \\
\hline \multirow[t]{3}{*}{ Cumulative Effect (CUM) } & 0.899 & 0.775 & 0.821 & 0.836 & 0.963 & 0.816 & 1.048 & 0.782 \\
\hline & $(0.582)$ & $(0.409)$ & $(0.610)$ & $(0.421)$ & $(0.583)$ & $(0.440)$ & $(0.700)$ & $(0.487)$ \\
\hline & {$[0.123]$} & {$[0.058]$} & {$[0.178]$} & {$[0.047]$} & {$[0.098]$} & {$[0.064]$} & {$[0.134]$} & {$[0.108]$} \\
\hline Number of JCTCs & 6 & 13 & 6 & 13 & 6 & 13 & 6 & 13 \\
\hline
\end{tabular}

Notes: See Table 4 notes. Cell entries for Pre-signing interval measure the effects on employment growth per month within the interval. 
Table 7: Effects of JCTCs on Employment Growth by Regime and Interval ATE-IPW Estimator

After Length $=36$ Months

JCTC Measured By Indicator Variable

Pre-signing Length $=2$ months

\begin{tabular}{|c|c|c|c|c|c|c|c|c|}
\hline & \multicolumn{2}{|c|}{ Baseline } & \multicolumn{2}{|c|}{ No Controls } & \multicolumn{2}{|c|}{$\begin{array}{c}\text { No Controls or State } \\
\text { FEs }\end{array}$} & \multicolumn{2}{|c|}{$\begin{array}{c}\text { No Controls or Time } \\
\text { FEs }\end{array}$} \\
\hline & Delayed & Immediate & Delayed & Immediate & Delayed & Immediate & Delayed & Immediate \\
\hline \multirow[t]{3}{*}{ Pre-signing } & -0.067 & 0.047 & -0.070 & 0.049 & -0.082 & 0.011 & -0.012 & 0.089 \\
\hline & $(0.040)$ & $(0.035)$ & $(0.039)$ & $(0.037)$ & $(0.041)$ & $(0.037)$ & $(0.044)$ & $(0.051)$ \\
\hline & {$[0.094]$} & {$[0.173]$} & {$[0.073]$} & {$[0.191]$} & {$[0.044]$} & {$[0.768]$} & {$[0.785]$} & {$[0.079]$} \\
\hline \multirow[t]{3}{*}{ Before } & -0.033 & 0.000 & -0.034 & 0.000 & -0.043 & 0.000 & 0.093 & 0.000 \\
\hline & $(0.022)$ & $(0.000)$ & $(0.022)$ & $(0.000)$ & $(0.028)$ & $(0.000)$ & $(0.088)$ & $(0.000)$ \\
\hline & {$[0.124]$} & {$[0.000]$} & {$[0.126]$} & {$[0.000]$} & {$[0.127]$} & {$[0.000]$} & {$[0.289]$} & {$[0.000]$} \\
\hline \multirow[t]{3}{*}{ At } & 0.147 & 0.045 & 0.143 & 0.051 & 0.126 & 0.013 & 0.282 & 0.045 \\
\hline & $(0.050)$ & $(0.033)$ & $(0.049)$ & $(0.032)$ & $(0.043)$ & $(0.030)$ & $(0.090)$ & $(0.064)$ \\
\hline & {$[0.004]$} & {$[0.167]$} & {$[0.003]$} & {$[0.119]$} & {$[0.003]$} & {$[0.671]$} & {$[0.002]$} & {$[0.486]$} \\
\hline \multirow[t]{3}{*}{ After $(36 \mathrm{~m})$} & 0.027 & 0.019 & 0.020 & 0.020 & 0.002 & -0.015 & 0.113 & 0.034 \\
\hline & $(0.016)$ & $(0.010)$ & $(0.013)$ & $(0.012)$ & $(0.022)$ & $(0.013)$ & $(0.042)$ & $(0.038)$ \\
\hline & {$[0.092]$} & {$[0.065]$} & {$[0.122]$} & {$[0.094]$} & {$[0.925]$} & {$[0.259]$} & {$[0.007]$} & {$[0.371]$} \\
\hline \multirow[t]{3}{*}{ Cumulative Effect (CUM) } & 0.821 & 0.836 & 0.581 & 0.869 & -0.156 & -0.499 & 4.749 & 1.456 \\
\hline & $(0.610)$ & $(0.421)$ & $(0.500)$ & $(0.486)$ & $(0.898)$ & $(0.517)$ & $(1.861)$ & $(1.444)$ \\
\hline & {$[0.178]$} & {$[0.047]$} & {$[0.245]$} & {$[0.074]$} & {$[0.862]$} & {$[0.335]$} & {$[0.011]$} & {$[0.313]$} \\
\hline Number of JCTCs & 6 & 13 & 6 & 13 & 6 & 13 & 6 & 13 \\
\hline
\end{tabular}

Notes: See Table 4 notes. 
Table 8: Effects of JCTCs on Employment Growth in Other States by Regime and Interval

ATE-IPW Estimator

JCTC Measured By Indicator Variable

After Length $=36$ months

Pre-signing length $=2$ months

\begin{tabular}{|c|c|c|c|c|c|c|}
\hline & \multicolumn{2}{|c|}{$\begin{array}{c}\text { Bordering States, } \\
\text { Equal Weighted }\end{array}$} & \multicolumn{2}{|c|}{$\begin{array}{c}\text { All Other States, } \\
\text { Supplier-Trade } \\
\text { Weighted }\end{array}$} & \multicolumn{2}{|c|}{$\begin{array}{c}5 \text { Closest States, } \\
\text { Inverse-Distance } \\
\text { Weighted }\end{array}$} \\
\hline & Delayed & Immediate & Delayed & Immediate & Delayed & Immediate \\
\hline \multirow[t]{3}{*}{ Pre-signing } & 0.042 & 0.075 & 0.000 & 0.018 & 0.008 & 0.077 \\
\hline & $(0.033)$ & $(0.025)$ & $(0.011)$ & $(0.007)$ & $(0.023)$ & $(0.024)$ \\
\hline & {$[0.202]$} & {$[0.002]$} & {$[0.973]$} & {$[0.008]$} & {$[0.734]$} & {$[0.001]$} \\
\hline \multirow[t]{3}{*}{ Before } & -0.013 & 0.000 & -0.000 & 0.000 & -0.023 & 0.000 \\
\hline & $(0.009)$ & $(0.000)$ & $(0.006)$ & $(0.000)$ & $(0.011)$ & $(0.000)$ \\
\hline & {$[0.146]$} & {$[0.000]$} & [0.979] & {$[0.000]$} & {$[0.035]$} & {$[0.000]$} \\
\hline \multirow[t]{3}{*}{ At } & 0.039 & 0.002 & 0.009 & -0.000 & -0.004 & 0.008 \\
\hline & $(0.041)$ & $(0.043)$ & $(0.023)$ & $(0.012)$ & $(0.048)$ & $(0.047)$ \\
\hline & {$[0.343]$} & {$[0.971]$} & {$[0.712]$} & {$[0.986]$} & {$[0.941]$} & {$[0.870]$} \\
\hline \multirow[t]{3}{*}{ After $(36 \mathrm{~m})$} & 0.007 & 0.015 & -0.003 & 0.005 & 0.013 & 0.012 \\
\hline & $(0.011)$ & $(0.013)$ & $(0.008)$ & $(0.005)$ & $(0.013)$ & $(0.014)$ \\
\hline & {$[0.521]$} & {$[0.234]$} & {$[0.707]$} & {$[0.275]$} & {$[0.315]$} & {$[0.363]$} \\
\hline \multirow[t]{3}{*}{ Cumulative Effect (CUM) } & 0.304 & 0.689 & -0.093 & 0.213 & 0.375 & 0.609 \\
\hline & $(0.363)$ & $(0.483)$ & $(0.275)$ & $(0.174)$ & $(0.536)$ & $(0.546)$ \\
\hline & {$[0.401]$} & {$[0.154]$} & {$[0.735]$} & {$[0.221]$} & {$[0.485]$} & {$[0.265]$} \\
\hline Number of JCTCs & 7 & 13 & 7 & 13 & 7 & 13 \\
\hline
\end{tabular}

Notes: Employment Growth in "Other" states defined by a weighted average of employment growth in other states. For "Bordering States," the weights are either $1 / N_{i}$, where $N_{i}$ is the number of states bordering state $i$, for each bordering state and 0 otherwise. For "All Other States, Supplier-Trade Weighted," the weights are $p_{i j} / \sum_{j}^{50} p_{i j}$, where $p_{i j}$ is the value of commodity shipments from state $j$ to state $i$. For " 5 Closest States, Inverse-Distance Weighted," the weights are $\left(1 / D_{i j}\right) / \sum_{j}^{50}\left(1 / D_{i j}\right)$, where $D_{i j}$ is the distance between the population centroids of states $i$ and $j$. See Table 4 notes and text for other details. 
Table 9: Estimated JCTC Cost Per Job Created (CPJC)

\begin{tabular}{|c|c|c|c|}
\hline & $\begin{array}{c}\text { Delayed } \\
\text { States }\end{array}$ & $\begin{array}{c}\text { Immediate } \\
\text { States }\end{array}$ & $\begin{array}{c}\text { All JCTC } \\
\text { States }\end{array}$ \\
\hline & $(1)$ & $(2)$ & $(3)$ \\
\hline Cost Per Job Created & $\$ 14,511$ & $\$ 19,479$ & $\$ 17,884$ \\
\hline Marginal Subsidy & $\$ 2,491$ & $\$ 4,141$ & $\$ 3,552$ \\
& $(17 \%)$ & $(21 \%)$ & $(20 \%)$ \\
\hline Inframarginal Subsidy & $\$ 12,020$ & $\$ 15,338$ & $\$ 14,332$ \\
& $(83 \%)$ & $(79 \%)$ & $(80 \%)$ \\
\hline
\end{tabular}

Notes: The dollar values in each column are based on equation (27) in the text and use average values for that group of states (Delayed-JCTC states, Immediate-JCTC states, and All JCTC states) for each component in the equation. 
Ministry of Economy and Finance

Department of the Treasury

Directorate I: Economic and Financial Analysis

Address:

Via XX Settembre, 97

00187 - Rome

Websites:

WWW.mef.gov.it

www.dt.mef.gov.it/it/

e-mail:

dt.segreteria.direzione1@tesoro.it

Telephone:

$+390647614202$

$+390647614197$

Fax:

$+390647821886$
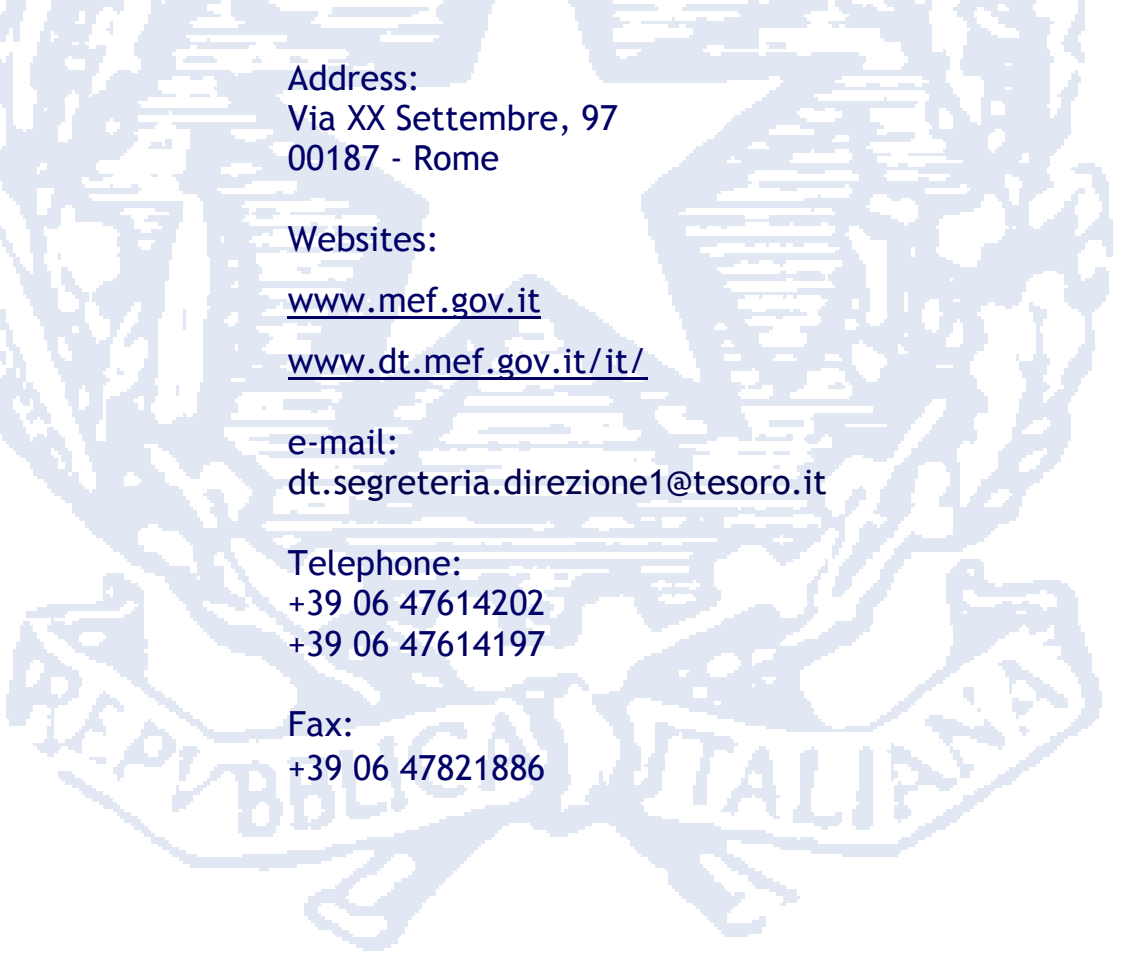